Florida International University FIU Digital Commons

3-18-2013

\title{
Constructing Threat: How Americans Identify Economic Competitors
}

Shelley D. Wick

Florida International University, shelleywik@yahoo.com

DOI: $10.25148 /$ etd.FI13042328

Follow this and additional works at: https://digitalcommons.fiu.edu/etd

Part of the International Relations Commons

\section{Recommended Citation}

Wick, Shelley D., "Constructing Threat: How Americans Identify Economic Competitors" (2013). FIU Electronic Theses and Dissertations. 860.

https://digitalcommons.fiu.edu/etd/860

This work is brought to you for free and open access by the University Graduate School at FIU Digital Commons. It has been accepted for inclusion in FIU Electronic Theses and Dissertations by an authorized administrator of FIU Digital Commons. For more information, please contact dcc@fiu.edu. 


\title{
FLORIDA INTERNATIONAL UNIVERSITY
}

Miami, Florida

CONSTRUCTING THREAT:

HOW AMERICANS IDENTIFY ECONOMIC COMPETITORS

\author{
A dissertation submitted in partial fulfillment of \\ the requirements for the degree of \\ DOCTOR OF PHILOSOPHY \\ in \\ INTERNATIONAL RELATIONS
}

by

Shelley D. Wick 
To: Dean Kenneth G. Furton

College of Arts and Sciences

This dissertation, written by Shelley D. Wick, and entitled Constructing Threat: How Americans Identify Economic Competitors, having been approved in respect to style and intellectual content, is referred to you for judgment.

We have read this dissertation and recommend that it be approved.

Thomas Breslin

Steven Heine

Paul Kowert, Major Professor

Date of Defense: March 18, 2013

The dissertation of Shelley D. Wick is approved.

Dean Kenneth G. Furton

College of Arts and Sciences

Dean Lakshmi N. Reddi

University Graduate School

Florida International University, 2013 


\section{DEDICATION}

This Dissertation is dedicated to Ed Montesano. His constant love, patience, encouragement and support made this achievement possible. 


\section{ACKNOWLEDGMENTS}

I would like to acknowledge Florida International University for providing me with financial support first through a Teaching Assistantship (2005-2012), and then through a Dissertation Year Fellowship (2012-2013). I would also like to thank the numerous experts who willingly provided me with guidance and assistance. My committee members Dr. Julie Zeng, Dr. Thomas Breslin, and Dr. Steven Heine each gave me wonderful suggestions and advice throughout the process. Dr. Asia Eaton was helpful in the design of my social scientific experiment. Dr. Paulette Johnson provided a great deal of help as I learned to use Statistical Product and Service Solutions (SPSS) Software. Dr. Harry Gould was always available to answer my questions and frequently provided much needed encouragement and support. Lastly, I would like to give a special thank you to the chair of my committee Dr. Paul Kowert, who remained constantly patient with my numerous questions, and whose clear and detailed feedback at every stage of the process was invaluable. 


\title{
ABSTRACT OF THE DISSERTATION \\ CONSTRUCTING THREAT: \\ HOW AMERICANS IDENTIFY ECONOMIC COMPETITORS \\ by
}

\author{
Shelley D. Wick \\ Florida International University, 2013 \\ Miami, Florida \\ Professor Paul Kowert, Major Professor
}

China's emergence as an economic powerhouse has often been portrayed as threatening to America's economic strength and to its very identity as "the global hegemon." The media's alarmist response to an economic competitor is familiar to those who remember U.S.-Japanese relations in the 1980s. In order to better understand the basis of American threat perception, this study explores the independent and interactive impact of three variables (perceptions of the Other's capabilities, perceptions of the Other as a threat versus as an opportunity, and perceptions of the Other's political culture) on attitudes toward two different economic competitors (Japan 1977-1995 and China 19852011). Utilizing four methods (historical process tracing, public polling data analysis, social scientific experimentation, and content analysis), this study demonstrates that increases in the Other's economic capabilities have a much smaller impact on attitudes than is commonly believed. It further shows that while perceptions of threat/opportunity played a significant role in shaping attitudinal response toward Japan, perceptions of political culture are the most important factor driving attitudes toward China today. This study contributes to a better understanding of how states react to threats and construct 
negative images of their economic rivals. It also helps to explain the current SinoAmerican relationship and enables better predictions as to its potential future course.

Finally, these findings contribute to cultural explanations of the democratic peace phenomenon and provide a boundary condition (political culture) for the liberal proposition that opportunity ameliorates conflict in the economic realm. 


\section{TABLE OF CONTENTS}

CHAPTER

PAGE

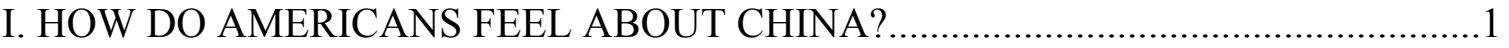

Is China a Threat? - the Theoretical Debate …………...........................................

Is China a Threat? - the Empirical Debate.............................................................13

(Mis)Understanding China's Motives ………………......................................18

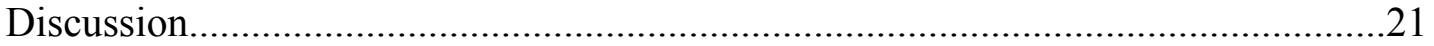

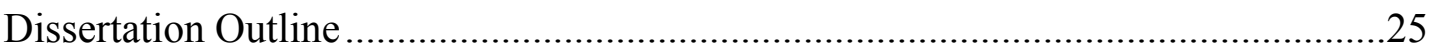

II. WHY STUDY AMERICAN ATTITUDES TOWARD CHINA?.................................

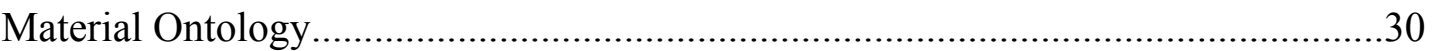

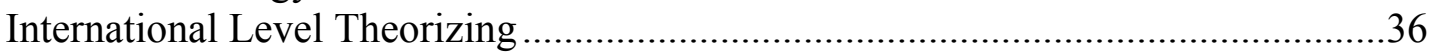

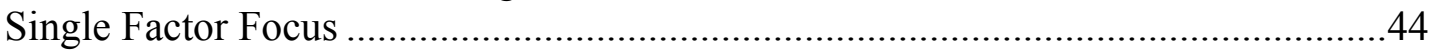

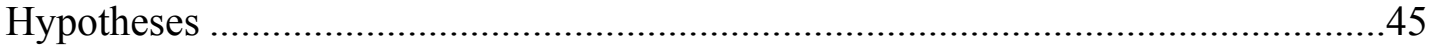

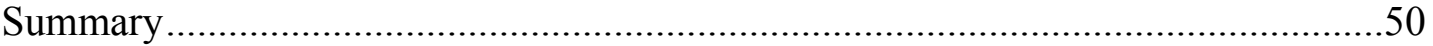

III. HOW DO AMERICANS RESPOND TO THE RISING ECONOMIC

CAPABILITITES OF DIFFERENT ECONOMIC COMPETITORS?..............................53

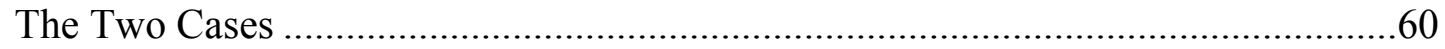

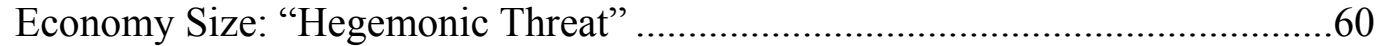

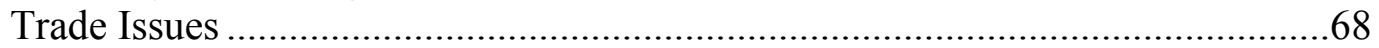

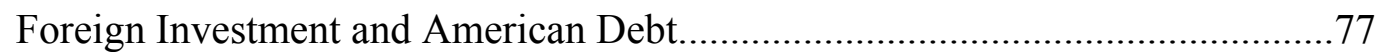

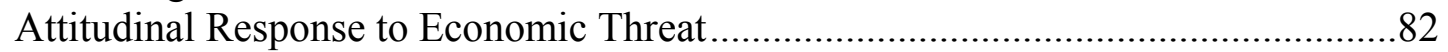

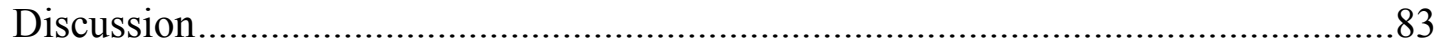

IV. WHAT OTHER FACTORS EXPLAIN AMERICAN ATTITUDES TOWARD

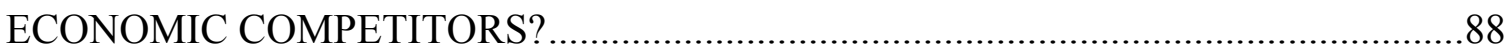

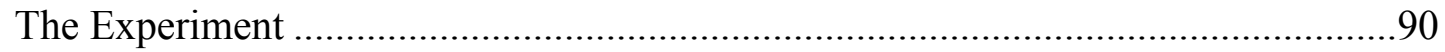

Part I the Impact of Threat, Opportunity, and Political Culture on Attitudes .............93

Part II the Impact of Political Culture and Relationship on Concerns about

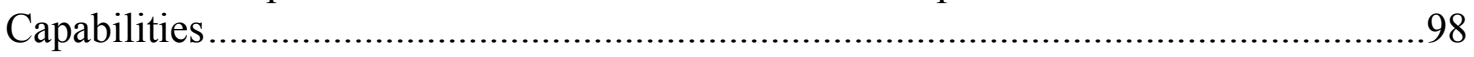

Part III Attitudes toward Specific Countries …………….....................................101

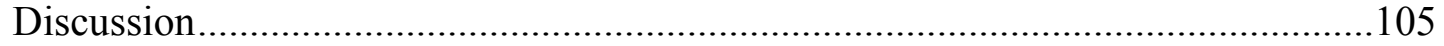

\section{HOW HAVE AMERICAN REPRESENTATIONS OF CHINA'S POLITICAL}

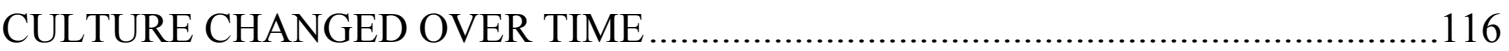

Apparent Correlation between Media Representation and Public Opinion..............119

Representations of China's Political Culture over Time ...........................................123

Trends in American Discourse on China..............................................................130

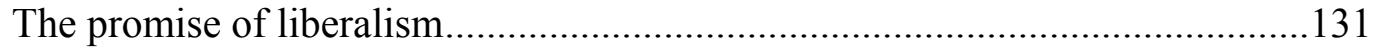

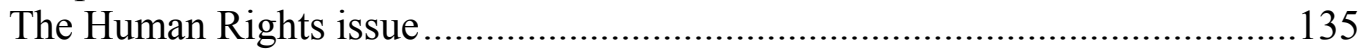

Power, interdependence, and the need for cooperation ......................................142 
Discussion.

VI. WHAT DO THESE FINDINGS MEAN FOR UNDERSTANDING AND PREDICTING THE SINO-AMERICAN RELATIONSHIP?

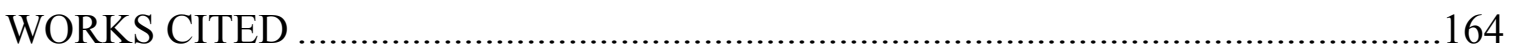

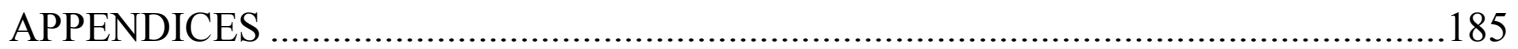

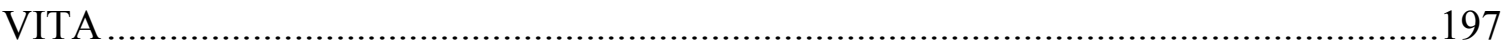




\section{LIST OF FIGURES}

FIGURE

PAGE

Figure 1 GDP Growth Rates for United States and Japan 1970-2000...........................63

Figure 2 GDP Growth Rates for the United States and China 1970-2017 .....................65

Figure 3 United States —World Trade Balance from 1970-2011 _................................68

Figure 4 United States-Japan Trade Balance 1980-2000 .......................................... 71

Figure 5 United States-China Trade Balance 1985-2011* ...........................................74

Figure 6 Foreign Holdings of US Long Term Securities 1974-2010 ..............................77

Figure 7 Japanese Direct Investments in the United States 1980-1995 ...........................79

Figure 8 China's Holdings of US Treasury Securities as a Percent of Total Foreign

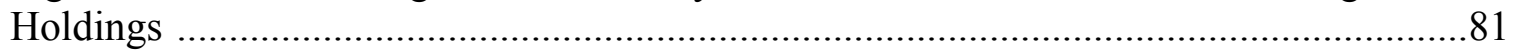

Figure 9 American Attitudes toward Japan 1977-2011 _...........................................83

Figure 10 American Attitudes toward China 1977-2011 ..............................................83

Figure 11 the Impact of Political Culture and Security Relationship on Attitudes ..........96

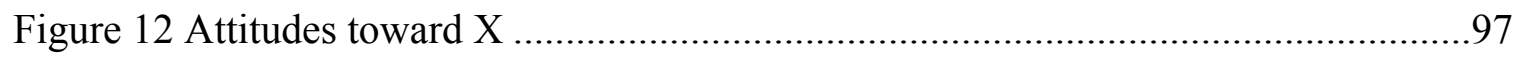

Figure 13 the Impact of Political Culture and Economic Relationship on Attitudes.........98

Figure 14 Mean Level of Concern about Rising Capabilities.......................................99

Figure 15 Concerns about Rising Capabilities as a Function of Political Culture...........101

Figure 16 American Attitudes toward Other Countries ..............................................102

Figure 17 Comparison of American Attitudes with Media Representationsl of China...122

Figure 18 Percentage of Articles That Use the Terms "Communist" or "Communism".126

Figure 19 Percentage of Articles That Use the Term "Authoritarian"...........................127

Figure 20 Percentage of Articles That Use the Term "Repression" or "Repressive" ......128 
Figure 21 Percentage of Articles That Use the Term "Human Rights".

Figure 22 Percentage of Articles That Refer to the June $4^{\text {th }}$ Incident in Tiananmen

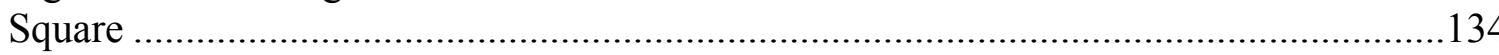




\section{HOW DO AMERICANS FEEL ABOUT CHINA? ${ }^{1}$}

"I remain convinced that a successful China can make our country more prosperous, not less. As trade and investment bind us together, we have a stake in each other's success. On issues from global security to global economic growth, we share common challenges and responsibilities -- and we have incentives to work together...We often focus on Chinese exports to America, but last year American companies exported more than $\$ 100$ billion worth of goods and services to China, supporting hundreds of thousands of jobs here. In fact, our exports to China have been growing much faster than our exports to the rest of the world"

"China is a case in point. Having embraced free enterprise to some degree, the Chinese Government and Chinese companies have quickly divined the benefits of ignoring the rules followed by others. China seeks advantage through systematic exploitation of other economies. It misappropriates intellectual property by coercing "technology transfers" as a condition of market access; enables theft of intellectual property, including patents, designs and know-how; hacks into foreign commercial and government computers; favors and subsidizes domestic producers over foreign competitors; and manipulates its currency to artificially reduce the price of its goods and services abroad."

These quotes represent a dichotomy in American perspectives on China's current and future role as a global economic super-power. Over the last three decades, the tension between these two perspectives has become ever more striking as Chinese economic power has increased. As a source of cheap manufactured products and as a large consumer of primary products China has come to play a crucial role in the trade of many of the world's economies. As the world's second largest economy, it has become a vital source of both aid and investment for developing countries in Africa, Latin America

\footnotetext{
${ }^{1}$ Excerpts of this dissertation appear in a forthcoming article titled "Capabilities, Cooperation, and Conflict: Mapping American Ambivalence toward China," by Shelley Wick, which will be published in Foreign Policy Analysis.

${ }^{2}$ Vice President Joseph Biden Jr., in an Op-Ed piece appearing in the New York Times on September $8^{\text {th }}$ 2011

${ }^{3}$ Presidential Candidate Mitt Romney, in and Op-Ed piece appearing in the Washington Post on October $14^{\text {th }} 2011$
} 
and South East Asia. In addition, while China's military capabilities are still far behind those of the United States and other powerful states they are rapidly expanding and modernizing, which suggests that China's military power could eventually approach the level of its economic power. Growth in Chinese power in both the security and economic milieus has serious implications for the balance of power in Asia, as well as the future potential for international cooperation and global economic health.

The importance of the Sino-American relationship to the continued prosperity and peace of the United States is difficult to overstate. Not only does China's rising status potentially threaten American hegemony but it also plays a vital role in the American domestic economy. Americans' penchant for deficit spending and their voracious appetite for inexpensive Chinese products have led China to become the United States' second largest trading partner as well as its largest creditor. China watchers have both warned about the potential for a "new Cold War," if the current Sino-American economic competition evolves into confrontation and conflict, and celebrated the potential for sustained peace, cooperation and economic growth if we see "a deepening U.S.-China entente" (Friedberg 2005, 8). It has been said that the "The American military contest with China in the Pacific will define the twenty-first century" (Kaplan 2005). While statements about the significance of this relationship have often tended toward hyperbole, it is undeniable that the interdependence and relative power of the two countries will ensure that shifts in the Sino-American relationship will have far reaching domestic and international consequences.

Despite the importance of this relationship, however, there is a general lack of agreement in the United States about how Americans should view this rising power. 
Should Americans see China as an enemy or as a friend, as a threat or as an opportunity, as a competitor or as a partner? How Americans answer questions about their relationship with China has a profound impact on how they perceive Chinese motivations, how they understand Chinese behavior, and ultimately on the direction this relationship is likely to take. Yet there is no easy answer. Polls suggest ambivalence; headlines go to hyperbolic extremes and pundits stand on opposite sides of the table. Many China threat theorists have mentioned the possibility of a Cold War with China (Ferguson 2009; Kissenger 2011), yet there is nothing resembling the almost universal animosity Americans felt toward the Soviet Union during the Cold War. On the other hand, despite major gains from trade and a prevailing optimism that engagement with China will lead the People's Republic of China (PRC) down the path toward democracy and openness; Americans are far from viewing China with the trust and acceptance of a friend.

This contestation is both cause and consequence of a general ambivalence towards China that pervades every corner of American society. A quick survey of available polling data shows that the American public is fairly evenly divided between those who feel warmly toward China and those who do not. ${ }^{4}$ In a February 2010, Gallup Poll $42 \%$ of respondents reported having very favorable or mostly favorable opinions of China, with $53 \%$ of respondents having mostly unfavorable or very unfavorable opinions. The apparent anti-China majority is reversed in a Pew Global Attitudes Project Poll conducted just two months later. In this case $49 \%$ of respondents felt favorably toward

\footnotetext{
${ }^{4}$ The survey results reported here were obtained from searches of the iPOLL Databank and other resources provided by the Roper Center for Public Opinion Research, University of Connecticut.
} 
China while only $36 \%$ had negative feelings. The Transatlantic Trends Survey conducted in June of the same year showed a more or less even split with $48 \%$ reporting positive feelings toward China and 51\% reporting negative feelings.

The evidence suggests that as a people Americans are undecided in their feelings toward China. Approximately half feel negatively toward China while the other half feels positively. In fact, in all three of the above-mentioned polls, only a small minority had strong feelings either way. Across the three polls only $12 \%-17 \%$ had very unfavorable feelings and 5\%-10\% had very favorable feelings. The majority of respondents reported feelings that were either "somewhat favorable" or "somewhat unfavorable." It is clear that Americans see China as neither a "friend" nor as an "enemy" but rather as something in between.

American political elites are also divided as to how they feel about China. Over the last several decades we have seen differences in attitudes toward China from administration to administration as decision makers have struggled with defining the important relationship. In 1997, then President Bill Clinton rattled the cages of many China threat theorists when he referred to China as a "strategic partner." Despite frequent mentions of human rights issues the Clinton administration's attitude toward China was generally positive and characterized by a deep belief in the power of economic engagement to move China toward becoming an active stakeholder and supportive member of the status quo. This attitude contrasts with that of the George W. Bush administration, which made it clear early on that it saw China as a threat, as a revisionist

\footnotetext{
${ }^{5}$ The term "strategic partnership," was first used in a joint US-China statement released by the White House on October 29, 1997(United States White House). This communiqué was a result of the first American visit by a Chinese President in eight years. The term was repeated by Secretary of State Madeleine Albright, when visiting China on April 30, 1998 (Gellman 1998).
} 
state, and most specifically as a competitor, NOT as a partner. George W. Bush explicitly made this latter point several times, both as a candidate and as the President (Lippman, 1999). In a 2000 article appearing in Foreign Affairs, Condoleezza Rice (Rice $2000,56)$ put this second point of view in print, arguing that "China resents the role of the United States in the Asia-Pacific region. This means that China is not a 'status quo' power but one that would like to alter Asia's balance of power in its own favor. That alone makes it a strategic competitor, not the 'strategic partner' the Clinton administration once called it." While the confrontational rhetoric of the Bush administration softened somewhat after 9-11, it never came close to embracing the positive attitudes of its predecessors.

The Obama administration has been walking a sort of middle ground between the previous two approaches. Less quick to label China, the administration has fully embraced neither the engagement rhetoric of the Clinton administration, nor the containment rhetoric of the Bush administration. As a candidate, Barack Obama described the Sino-American relationship as "mature," and "wide-ranging." Acknowledging the existence of both mutual interest and mutual distrust, he advocated "candid" dialogue between the two countries (Obama 2008, 2). In September 2009, the Obama administration introduced the so-called policy of "mutual reassurance" in U.S. dealings with China. The administration has subsequently been able to take advantage of the inherent vagueness in this policy name to fluctuate, according to audience, in their emphasis upon which side should be reassuring the other and how they should go about it (Panda 2009; Currie 2009). Most recently, President Obama has been referring to the Sino- American relationship as one of "friendly competition" ("China in the Mind" 2011; 
Nakamura 2011). This phrase has the benefit of softening the implications of a term like "competitor," while at the same time eschewing the positive connotations of a term like "partner." Such an approach serves to exemplify a middle of the road rhetorical strategy made possible by American ambivalence. While American foreign policy toward China has changed very little in the last thirty years, these carefully crafted terms represent the important divisions that have existed between, and within, each administration as to the extent to which a rising China constitutes a threat to the United States.

This variation in attitude toward China among American elites is reflective of a general division in American society between those who view China with cautious optimism and those who lean toward wary skepticism. In no administration however, has the rhetoric moved toward the extremes of hostility or amicability with which some other countries have been discussed. It is difficult, for example, to conceive of a president referring to China as a member of "the axis of evil." Nor could we currently imagine China being discussed in the warm terms of friendship that are often applied to so-called allies like Britain and Canada. What exists rather, is a sort of middle ground in which we see frequent yet mild shifts between pessimism and optimism about the implications of China's rise.

The scholarly discourse about China both reflects and contributes to American's ambivalence toward China. Despite a generally prolific research agenda, experts have failed to reach any sort of consensus as to how the United States should view or respond to a rising China. Most western discussions of Sino-American relations focus on determining whether or not China is a threat to the United States, to East Asia, or to the international order. Politicians, pundits and analysts typically look for answers by 
attempting to measure China's capabilities, by attempting to understand China's cultural personality, or by attempting to understand whether China's motivations are driven by status quo or revisionist impulses (Carpenter and Dorn 2000; Lardy 2003; Goldstein 2005; Al-Rodhan 2007). The implication of this discourse is that the better we understand China, the more accurately we will be able to predict the course of this important bi-lateral relationship and the more prepared the United States will be to respond appropriately to the challenges that lay ahead. There is an undeniable logic to such attempts to understand the competition. Nevertheless, despite more than two decades of fervent research, this approach has yielded little more than a cacophony of disparate voices giving contradictory opinions about whether Americans should fear China and what should be done about it.

\section{Is China a Threat?- the Theoretical Debate}

International Relations theory has done little to clarify American perceptions of China. With different theoretical paradigms focusing on particular aspects of the relationship, each comes up with a contradictory conclusion as to its future course. Realists tend to see inevitable conflict between China and the United States as a consequence of increases in Chinese capabilities. Neo liberals suggest that the significant opportunities afforded by a peaceful relationship will cause both states to avoid rocking the boat. And many Democratic Peace (DP) posit that Sino-American relations will remain uneasy as long as China remains an authoritarian state.

The realists' conclusion that the Sino-American relationship is destined to move toward enmity is built on the assumption that as one state gains proximity in capability with another conflict becomes more likely, especially among great powers. The 
reasoning behind this realist tenet has evolved over time. Traditional realists argued that man's nature is self interested and war-like and therefore successful states will always seek to exploit others for their own gain if they believe they have sufficient capabilities to succeed (Carr 1939; Morgenthau 1973). In 1979 Kenneth Waltz significantly altered the realist perspective by suggesting that it is actually the anarchic nature of the system that is responsible for compelling states to act in an aggressive manner. While a general consensus as to the validity of Waltz' "structural" perspective has emerged, further disagreements have arisen among realists, concerning the actual motive for conflictual behavior at the unit (state) level (Brooks 1997; Snyder 2002; Montgomery 2006). So called "defensive realists," such as Waltz himself, have argued that states are not always seeking power for its own sake, rather they often seek only security. According to this argument, since no state can be sure of another's motivations, increases in the capabilities of one state will cause others to react defensively. Since it is often impossible to distinguish, with certainty, between defensive and offensive motives, and since capabilities created with defensive motives may later be used for offensive aims, the rising capabilities of one state often lead others to feel insecure, motivating them to increase their own capabilities (Jervis 1976, 1978; Waltz 1979). The cycle continues until it ultimately ends up in conflict leading to what has been called the "security dilemma" (Jervis 1978; Glaser 1997). On the other hand, offensive realists argue that states seek power as their primary objective and will always strive to revise the status quo until they are at the top in terms of regional, if not global dominance (Grieco 1988; Mearsheimer 2001, 2010). According to this argument, the only thing that will keep a state from acting in a revisionist manner is a fear that they cannot win. Therefore, an 
increase in a state's capabilities will eventually compel them to take on powerful rivals in a battle for hegemony. In this case the anarchic system is still to blame as it creates certain incentives that compel states to seek power for its own sake.

While variation in the underlying motivation suggests differing policy decisions to achieve state objectives, both defensive and offensive realists tend to predict conflict between a rising China and a hegemonic United States. Defensive realists often point to signs that a security dilemma is already occurring between the two nations. Offensive realists assert that China, (like any other rising superpower) is necessarily revisionist and will attempt to make changes to an international order that it did not have a stake in creating. Those making this argument often point to history as evidence that rising superpowers are usually destabilizing and conflictual (Kristof 1993; Rice 2000; Kagan 2005; Kaplan 2005; Layne 2008). ${ }^{6}$

An alternative perspective suggests that it is the nature of the bilateral relationship, rather than shifts in relative capabilities, that will determine the future of China's relationship with the United States. There are two different theoretical perspectives that support this argument. The first is the neoliberal economic argument, which suggests that economic interdependence lessens the likelihood of conflict between states because such conflict would cause a loss of the potential benefits that would be gained by sustaining the current economic relationship (Keohane and Nye 1977,

\footnotetext{
${ }^{6}$ There are those who have used the historical record to argue that powerful states may rise without conflict. Fareed Zakaria (1996) has referred to the historical record, specifically the rise of Britain and the United States and the Post World War II rise of Germany and Japan as evidence that powers may rise without undue conflict. Henry Kissinger (2011) has pointed to the rise of the United States in the $20^{\text {th }}$ century to suggest that "[c]onflict is not inherent in a nation's rise," and further argued that "thoughtless and provocative policies" can cause relations between a hegemon and a rising powers to become conflictual. David C. Kang (2003) posits that when one looks at the historical record of East Asian relations one actually finds that regional peace is more likely the more powerful that China becomes.
} 
Copeland 1996; Papayoanou 1997). The emphasis here is on the complex

interdependence which links China and the United States. The Chinese save their money, much of which is subsequently lent to the United States to fund American debt. The Americans spend their money, much of which is spent on products made in China. This relationship has substantial benefits for both sides. China gains through rapid economic growth, and employment for its large labor pool. The United States gains through the financing of American debt and access to inexpensive consumer products, both of which serve to keep inflation at bay. In 2008, Niall Ferguson, noting the symbiotic relationship between the two countries, suggested that the two had formed a single economy, which he termed "Chimerica" (245-251). Many observers argue that neither side can afford any action which would disrupt this mutually beneficial relationship.

Neoliberals assume that states are "rational actors" and as such, are likely to employ a cost benefit analysis, which, in the case of China and the United States, will likely prevent conflict for the foreseeable future, and perhaps even promote a deepening friendship between the two states. Some neoliberals have argued that the presence of opportunity leads to the construction and maintenance of international institutions which in turn promote cooperation (Keohane 1984; Keohane and Martin 1995). Other relevant links that have been explored include that between economic regime types and cooperation (Gartzke 2007). Neoliberal China watchers argue that the benefits that China gains from its current relationship with the United States determine that China will continue to see maintenance of the status quo as in its national interest (Lardy 2003; Lampton 2007). 
While the assertions that international institutions and interdependence promote peace result in optimistic predictions about the future of Sino-American relations, these predictions become more ambivalent when one looks at the third leg of the so called "liberal triad"- democracy. Democratic Peace (DP) theorists, emphasize the "law like" nature of the observed phenomenon that democracies do not go to war with each other (Rummel 1983; Levy1988; Russett 1993; Ray 1997). While there are many disagreements as to whether this phenomenon can be explained by institutional, normative, or cultural aspects of political culture, for those working within this research program political culture is seen as the most important causal variable in explaining international relationships.

This research agenda has mixed results when it comes to predicting SinoAmerican relations. There are those who argue that Sino-American interdependence fostered through an American policy of "engagement," is leading China slowly but surely down the path toward Democracy (Rowen 2007). Those who support engagement with China assume that a Democratic China is in the best interest of the United States due in part to the fact that such a change in China's political culture would eliminate many points of contention between the two countries.

On the other hand, there is substantial evidence suggesting that this gradual shift in political culture is not happening, nor is it likely to happen in the near future. Richard Bernstein and Ross Munro (1997, 26-27) point out that China has never demonstrated any affinity toward "limited government," or any cultural appreciation of liberal human rights, at any point throughout its history. They argue that "China has always been ruled by a self-selected and self-perpetuating clique that operates in secret and treats opposition 
as treason" (emphasis added). They further posit that the PRC equates political reform with chaos and is thus highly unlikely to rock the boat by allowing any movement in a liberal direction.

Whether or not an authoritarian China must necessarily conflict with a democratic United States is also cause for disagreement. For many DP theorists the authoritarian nature of the PRC does not necessarily indicate that the U.S. and China will come into conflict just because the peace causing effects of bi-lateral democratic relations are missing. On the other hand, some DP researchers have demonstrated that an authoritarian-democratic relationship is by its very nature conflictual. Realist DP theorists, argue that, since Democracy just inhibits the natural inclination for states to fight, if these constraints are removed from one side of the equation, conflict is, once again, inevitable. Barbara Farnham $(2003,396)$ suggests that a "presumption of enmity" is one of the "central tenets" of the Democratic Peace Theory. Others argue that the same mechanisms that constrain democracies from fighting other democracies, compel these states toward conflict with authoritarian others. John Owen (1994), for example, has argued that while democratic institutional constraints prevent democracies from warring with each other, knowledge of these constraints cause authoritarian leadership to have an exploitable edge over democracies. Therefore, he suggests that it is rational for democracies to preemptively attack authoritarian states to avoid exploitation. Some analysts also predict conflict from the opposite direction. Robert Kagan (2005) posits that it is natural for authoritarian governments to feel threatened by democratic superpowers. For these analysts therefore, the conclusion is obvious: If China were to become a democracy it would ameliorate conflict but this isn't likely in the short term. Since the 
relationship between an authoritarian state like China and the United States is necessarily conflictual than we should expect continued and increasing conflict between the two states as China becomes powerful enough to challenge the U.S..

\section{Is China a Threat?- the Empirical Debate}

Considering the limits of this theoretical debate, many analysts attempting to determine whether or not China is a threat, focus on the second level of analysis, examining the particulars of the dyadic relationship in order to determine the extent to which a rising China does or does not constitute a threat. Again there is a great deal of disagreement. On one side of the China Threat debate there are the pessimists who find that China has both the capability and the will to challenge the status quo, to hinder the ability of the United States to achieve its national objectives, and to disrupt global peace.

On the other side are the optimists who argue that China either doesn't have the capability or doesn't have the will to challenge the United States or to endanger the current international system. The most optimistic analysts argue that China's rise is, on balance, a positive event.

Many pessimists, arguing China's potential to challenge U.S. national interests, emphasize its growing economic strength. China's rise from a developing state in the late 1970s to a world power today has been dramatic and unprecedented, particularly in the economic milieu. China has seen rapid economic growth since Deng Xiaoping first initiated reforms in 1978. Since then China's gross national product has more than quadrupled. The Chinese passed Japan in 2010 to become the second largest economy in the world. Although the American economy is still three times bigger than China's, the latter is growing much more quickly. In fact it seems likely that China will soon match 
and then surpass the United States in economic strength (O'Neil and Supnytska 2009, 4; Fogel 2010).

Many argue that an economically powerful China is a threat to American national interests. Some fear that cheap labor and poor labor standards enable the Chinese to "steal" American jobs. According to Robert E. Scott, a pro-labor advocate at the liberal Economic Policy Institute, trade with China cost 450,000 American jobs in just three years (2008-2010) (Quoted in Hamburger et al., 2012). China is further charged with giving unfair support to domestic industries, unfairly manipulating its currency to give them an exporting advantage, and "refusing" to enforce intellectual protection rights, all actions that lead to loss of American jobs (Barboza, 2009).

Optimists, on the other hand, have asserted that the economic threat argument is not only hyperbolic but misses several important economic points. Considering fears about job loss they note that manufacturing jobs had already left the United States by the time China became a serious competitor and would not return even if Sino-American trade was reduced through RMB appreciation or American protectionism (Lardy 2003; Elwell, Labonte and Morrison 2007). In addition, as David Lampton $(2007,121)$ points out, when an item is "made in China" it means only that China is the last link in the production chain. Thus he argues that restricting trade with China would hurt the economic interests of America and its allies who are responsible for other links in the chain that often have higher value added components.

In fact, rather than a threat, some optimists believe that an economically strong China constitutes an opportunity for the United States. While most economists acknowledge some trade-related losses to certain sectors, firms and jobs, many suggest 
that, on balance, the benefits of the Sino-American economic relationship far outweigh the costs. They point to the benefits of cheap imported products including lower cost and greater choice for American consumers, cheaper inputs for American firms, and reduced inflation for the American economy. They also point to the benefit of China's welcoming environment for American Foreign Direct Investment (FDI), which gives American firms access to cheap Chinese labor as well as China's huge and growing market (Lardy 2003; Elwell, Labonte and Morrison 2007).

Another aspect of the China threat debate asks whether China is a security threat. There is, of course, some overlap between the economic milieu and the security milieu. Of particular interest here is China's role as America's banker. The United States currently owes China $\$ 3.4$ trillion in foreign currency assets (U.S. Department of Treasury 2011, 15). It has been suggested that these immense Chinese holdings of American debt give China a great deal of power over the United States. Even though China is not the only U.S. creditor, critics point to the close relationship between the PRC and China's banking sector as cause for particular concern because, they argue, it gives the Chinese state direct influence on American interests through its ability to invest in firms or sectors (in the United States) with particular strategic or political value, or most importantly through its ability to undermine the stability or worth of American currency (Thompson 2007; Chin and Helleiner 2008, 90-91).

Another concern is the degree to which China can translate its wealth into political influence over other states. Robert Kaplan (2005) asserts that China's economic strength gives it "soft" power, which the Chinese are using to become "masters of indirect influence." This sentiment has been underscored by recent books and articles 
tracing the influence that Chinese investment and aid has purchased in Latin America, the Caribbean and Africa (Michel and Beuret 2009; Chin and Helleiner 2008; Halper 2010; Archibold 2012).

Despite the general agreement that China's growing economic clout makes it resistant to pressure from the United States or elsewhere (Chin and Helleiner 2008; Drezner 2009), optimists argue that China has neither the power nor the will to use its wealth to challenge the United States. This side posits that any attempt to do so would have a prohibitively negative impact on China's economy (Elwell, Labonte and Morrison 2007). For example, as of June 30, 2011, dollar denominated assets made up $\$ 1.73$ trillion of China's international reserves (Clark and Davis 2012). If the dollar decreases in value so will the value of these reserves. Yet if the Chinese stop buying dollars, they risk causing their own currency to appreciate thus threatening jobs in their manufacturing sector. The Chinese, it is argued, can not afford to make any moves that will cause the dollar to decline in value.

While China's impressive economic growth dominates the headlines, it is certainly not the only, or even the biggest cause for concern in terms of relative capabilities. China has recently increased its military expenditures and has made strides toward modernizing its military (United States Department of Defense 2010). While it is generally acknowledged that the United States is far superior to China in terms of military strength, there is general disagreement as to how long this will last. Some see nothing to worry about in terms of China's near term military potential. They point to the great gap that exists between American and Chinese military capabilities and argue that socioeconomic problems, a weak tax base, and an inability to either produce or obtain 
everything that is needed for a modern military are likely to inhibit Chinese progress in closing that gap (Al-Rodhan 2007, 44). Others however, suggest that China may already have the capabilities to challenge the U.S..

The Pentagon releases numerous reports annually regarding some new technological leap achieved by the Chinese military. It is often implied if not downright stated that these advances signal Chinese abilities to challenge the United States as well as a desire to do so. In 2005 Robert Kaplan reported that recent Chinese investments in submarines provided "a clear signal" that they are attempting to gain projectable power. In 2008 the Director of National Intelligence, Michael McConnell, testified in front of the senate that China's continual development of conventional theater range ballistic and cruise missile capabilities "put U.S. forces and regional bases throughout the Western Pacific and Asia at greater risk" (Quoted in U.S. Congress 2011a). In 2011 American military officials told the New York Times that "there is a growing danger of a confrontation between American and Chinese forces in the Pacific Ocean, where Chinese ships have begun to challenge the United States Navy" (Bumiller 2011).

Another cause of fear is the purported independence of the Chinese military, its secrecy, and a perceived hostility toward American forces. The 2010 Quadrennial Defense Review Report raised concerns about China's military, stating that the "lack of transparency and the nature of China's military development and decision-making processes raise legitimate questions about its future conduct and intentions within Asia and beyond" (U.S. Department of Defense, 60). In January of 2011 suspicions about both the independence and intentions of the PLA were aroused when reportedly they staged a test of a new stealth fighter jet during a meeting with Defense Secretary Robert 
Gates apparently without the knowledge of Chinese president Hu Jintao (Wines and Bumiller 2011).

\section{(Mis)Understanding China's Motives}

The previous analysis shows that the best attempts of our greatest China watchers has resulted in a vast array of contradictory information that when taken in its entirety offers very little in way of answering the question: Is China a threat? While there is some disagreement as to whether or not China has the capability to challenge the United States, the bulk of the China threat debate focuses on whether or not China has the inclination to act in such a way as to significantly undermine the United States' ability to achieve its national interests. In fact attempts to understand China's motivations form an integral part of the China threat debate. The question in this case: Is China a revisionist or a status quo power? Does China seek to challenge American hegemony and change the existing global order or does China seek to work with the United States and make an increasingly larger contribution to the status quo. Again there is a great deal of disagreement as to the answer.

Many have warned that China is indeed a revisionist state. In 1997 Richard Bernstein and Ross Monro for example, predicted that China would directly challenge U.S. global hegemony. Bill Gertz (2000) has taken this further, arguing that China is "the most serious national security threat the United States faces at present and will remain so into the foreseeable future." He adds that the rise of China "puts at risk the very national existence of the United States." Steven Mosher (2002) warns that the quest for global hegemony is a fundamental part of China's very identity. 
Most pessimists, however, suggest that China is currently interested in regional, rather than global, hegemony. John Mearsheimer $(2001,2010)$ has argued that global hegemony is impossible in practice and that it is regional hegemony that gives states a relative power advantage over others in the system. He further suggests that China as a rising power will necessarily pursue the rational objective of relative power gains through regional hegemony.

There are those who feel that China can achieve regional hegemony without seriously disrupting the status quo. Robert S. Ross (2005) for example, has acknowledged the loss of American influence in East Asia, yet argues that this is something that the United States will willingly hand over as East Asian hegemony no longer figures in American conceptions of national interest. The majority of pessimists, however, see China as a revisionist power whose bid for regional hegemony will challenge American interests and necessarily lead to conflict (Christenson 2001; Howle 2001; Mearsheimer 2010).

Optimists, on the other hand, argue that China is not a revisionist state and is actually supportive of the status quo (Ikenberry 2011). After examining numerous claims about China's revisionist intent Ian Alistair Johnston (2003) found that there is little in the way of clear supporting evidence. Gregory Chin and Ramesh Thakur $(2010,120)$ present evidence that the opposite is actually true, pointing out that "the predominant pattern to date is China's socialization into global norms, rules, practices, and standards as a 'status quo' power helping mainly to maintain the post-1945 institutional arrangements" They suggest that Chinese internalization of the norms of status quo institutions like the WTO in addition to its stewardship of institutions like the Shanghai 
Cooperation Organization (SCO), which more closely reflect specific Chinese concerns, contribute to "a greater sense of global obligation and increased stewardship." Avery Goldstein, $(2005,30-31)$ argues that the Chinese government, wary of suffering the same fate as the former Soviet Union, has been careful to eschew revisionism within their "grand strategy." realm, China has been an "ardent supporter" of the existing order. He even suggests that, at times, the Chinese have been better supporters of the status quo than has been the United States.

Both sides show a great deal of concern about the potential negative effects of erroneous perception on the course of Sino-American relations. The pessimists warn that the United States is misperceiving China as a harmless status quo power when in actuality the PRC harbors serious revisionist intentions. The result, they suggest could be that we are actually inviting unnecessary conflict. Thomas Christensen (2001) asserts that a failure to treat China as a revisionist state could be misinterpreted as a lack of either the capability or the will to stand up to her. Such misperception, he claims, has often led weaker states to challenge stronger states in the past. Roy C Howle (2001) argues that "imponderables" such as self-delusion, and miscalculation are the "biggest threat to [the U.S.] interests in Asia today," and suggests that reducing the ambiguity of American policy towards the Chinese military, through a clear containment policy, would reduce the likelihood of misunderstandings.

\footnotetext{
${ }^{7}$ While Goldstein acknowledges that it is difficult to predict how China's "grand strategy," will evolve if and when it becomes secure in its status as a world power, he further argues that the current strategy is likely to last for several more decades because it has proven "politically sustainable," among a broad consortium of China's elites despite serious challenges, and it has remained viable despite a dramatic evolution in China's international circumstances (177-203)
} 
On the other hand, many optimists are concerned, that American misgivings about China are causing an overstatement of Chinese capabilities and a misperception of China's intentions that might lead to a self fulfilling prophesy in which we create that which we fear (Kissinger 2011; Glaser 2011). As David Lampton $(2007,115)$ puts it, "if U.S. policymakers continue to view China's power in substantially coercive terms when it is actually growing most rapidly in the economic and intellectual domains, they will be playing the wrong game, on the wrong field, with the wrong team."

\section{Discussion}

While the stakes are high enough to warrant the continued pursuit of accurate information about Chinese intentions, there is a great deal of theoretical and empirical evidence to suggest that it is unlikely if not impossible that we can ever achieve that goal. Even if decision makers had unlimited access to information about China we would not be able to simply "discover" the "truth" of Chinese motivations. Contrary to the assumptions implicit in much of the China threat literature, motives are dynamic and China's position as a revisionist or status quo state is not simply a static given waiting to be understood. The role that a powerful China will play in international politics is far from decided and is rather a point of contestation within Chinese national discourse. In addition, what role China ultimately chooses to play will not be decided by China alone but will be shaped in part by how others perceive and react to China as it transforms from a minor to a major power on the world stage.

Various sections of the Chinese populace imagine and articulate national identity in competing ways and advocate different roles for an increasingly powerful China. Much attention in the West has been paid to the popular nationalist images of China that 
call for China to resume its rightful place as the center of the universe, but this is just one of the national images that are popular in China today. Many Chinese see their country as a stakeholder in the current system and assume that they are seeing the dawning of an era of multi-polarity with China as one power among many equals. Others see China's identity as intrinsically tied to its relationship with other East Asian countries. Still others continue to see China as a developing state and suggest that China's role has been, and should continue to be, the champion of the Global South (Van Ness 1993;

Shambaugh 2011). Which of these national identities becomes dominant has yet to be decided and will not be determined by China alone.

Most China threat theorists emphasize the role that China will play in future conflict. The implication being that it is up to China whether or not such a conflict arises. Some even say this explicitly. Robert Kagan (2005) for example, has stated that "we need to understand that the nature of China's rise will be determined largely by the Chinese and not by us. The Chinese leadership may already believe the United States is its enemy, for instance, and there is nothing we can do to change that." Andrew Small, (U.S. Congress $2011 \mathrm{~b}, 80$ ) asserts that the question in need of answering is "whether the Chinese leadership is willing, or even fully able, to go through a deeper process of revisiting its strategy, adding that, if they are not, the result will be increasing degrees of “competition" and "confrontation" between China and the United States. The American Deputy Secretary of State, Jim Steinberg, told the Economist in 2010 That China's choice of role is "the great question of our time. The peace and prosperity of the world depends on which path it takes" ("Brushwood and Gall," 4). This widely held view erroneously assumes that the possibility of conflict with China is solely dependent on Chinese 
behavior. In fact, "the peace and prosperity of the world" is also partly dependent on how others perceive China's behavior. An equally important question therefore is: What role are we likely to assign China?

Both pessimists and optimists tend to share the conviction that China has an intrinsic character that may be discovered and understood by American analysts. Constructivists argue, on the other hand, for a more supple approach to state differences or identities. Constructivists suggest that relations among states are the result of interactions in which each state constructs and enacts its own (national) identity in direct reference to what it perceives to be the identities of the others in the system. While much of the China threat literature assumes that China's motives are static and formulated in isolation from international interaction, constructivists argue that state's identities and interests are dynamic and are constantly being shaped through interaction with others (Campbell 1992; Neumann 1999; Hopf 2002; Copeland 2006; Odysseos 2007). As Peter Hays Gries and Thomas J. Christensen $(2001,157)$ notes "metaphorically putting China 'on the couch,' safely debating from afar whether China is strong or weak, benign or malign, dangerously dismisses the role that other nations play in shaping Chinese behavior." If we acknowledge that the Chinese role in international relations is not just chosen by China but is also partly chosen by the states that interact with China, then we must acknowledge that the "truth" of Chinese intentions is not an objective condition to be discovered. These intentions are, rather, evolving through interactions with other players in the system. Even as the United States is constructing policy, based in part on its interpretations of China's role as a revisionist or status quo power, China's inclination 
toward one role or the other is being shaped in part by its interpretation of the motives behind American foreign policy.

The current American ambivalence toward China has serious implications for the future of Sino-American relations. American attitudes toward China shape American perceptions of Chinese motives and actions. These perceptions, in-turn, shape American policy towards China. American ambivalence, whether it is expressed as cautious optimism or wary skepticism, colors the current environment in which Sino-American relations take place. These attitudes toward China create current conditions of possibility which shape the kinds of policy responses that are possible and prohibit those which are inconceivable. While the current attitudinal environment allows the United States to vacillate between reacting to China as a "strategic partner," or as a "competitor," it is currently difficult for decision makers to react to China as an "enemy" or as a "friend."

This situation is of course mutable. It is reasonable to assume that as with many other important bi-lateral relationships (i.e., the U.S. and the Soviet Union, the U.S. and Britain, The U.S. and Japan) American attitudes will ultimately move in one direction or the other. ${ }^{8}$ There are many who suggest that this movement is most likely to be toward hostility yet there is no reason to assume this automatically. We need only look to the examples of Germany and Japan after WWII to see how quickly and thoroughly states can come to be perceived as part of America's in-group rather than her out-group (Schonberg 2009). Whether American attitudes turn toward amity or enmity will have

\footnotetext{
${ }^{8}$ This point is made by Karl Schonberg $(2009,35)$, who points to the changing identity relationships between the United States and Japan and Germany after World War II, and between the United States and the Soviet Union after 1989 to demonstrate that just as national identity can change over time, so can international identity relationships. For a good discussion of the importance of mutability in identity relationships to constructivism see (Copeland 2006).
} 
serious consequences in terms of the global potential for economic growth, stability and peace.

It is the purpose of the current study to explore the basis of American attitudes toward other states in order to help determine why, when, and how American attitudes toward China are likely to move in either direction. To answer this question the study employs a multi-method approach meant to enhance both the validity and generalizability of the results. The rest of this chapter briefly mentions the hypotheses and states why they are relevant, discusses the methodology that is employed to test these hypotheses and lays out the organization of the dissertation

\section{Dissertation Outline}

In chapter two I explore the theoretical justification for my study with particular emphasis on image theory and constructivism. This study is designed to address three weaknesses with traditional mainstream approaches to understanding the current SinoAmerican relationship — each of which contribute to misleading predictions about the future: The first is the traditional materialist ontology, which ignores the importance of ideational factors, such as identity, in the shaping of bilateral relationships. The second is the degree to which the international level of analysis informs traditional theoretical and empirical conclusions. And the third is a tendency for traditional approaches to focus on single-factor explanations for complex bilateral relationships. I then present the research question -What is the underlying basis for American attitudes toward economic competitors in general and toward China in particular?

To answer this question, I first seek to understand how American attitudes toward economic competitors are impacted by various independent variables. Drawing on 
International Relations (IR) theory, I therefore come up with three testable hypotheses:

The first hypothesis, based on a realist understanding of the current relationship, suggests that American attitudes toward competitors should become more hostile as each competitor's capabilities increase relative to the U.S. The second hypothesis, based on a neoliberal understanding of the current relationship, suggests that American responses to competitors should be determined by the degree to which each competitor is seen as a threat or as an opportunity. The third hypothesis, informed by a liberal discussion of the Democratic Peace, suggests that American responses to competitors should reflect perceptions of its political culture. Chapters three, four, and five test these hypotheses.

In chapter three I test the hypothesis that changes in relative power drive attitudes toward economic competitors like China by comparing American attitudes toward Japan from 1975-1995, with attitudes toward China from 1990-2010. Through analyzing shifts in American attitudes towards two different powerful states, as each demonstrates a rapid rise in economic capabilities that threaten U.S. hegemony, I am able to test the degree to which this assumption holds true under varying circumstances. To this end, I first trace changes in each countries' relative economic capabilities along three important dimensions: economy size, trade balance (with the U.S.), and East Asian investment in the U.S. I then analyze a large set of relevant polling data in order to determine if there are correlations between the rise of the economic capabilities of each country, relative to the United States, and a growing American hostility toward it. ${ }^{9}$ While Japan emerges as an economic threat to the United States in the mid to late 1970s, American attitudes

\footnotetext{
${ }^{9}$ My study utilizes data from 93 different polls or surveys, conducted by 19 different organizations and agencies. All polling data was collected from the ipoll Databank and other resources provided by the Roper Center for Public Opinion Research, University of Connecticut.
} 
toward Japan remain consistently positive until 1986, at which point they trend downward until 1992 when they once again begin to rise. Despite the fact that economic threat has been increasing from China, particularly since 2001, when it joined the WTO American attitudes toward China trended positively for much of the decade and have remained consistently ambivalent (vacillating between slightly positive and slightly negative), since 2006. Even though attitudes in the Japan case do seem to be reacting to economic threat after 1986, both cases demonstrate a stability of attitudes in the face of dramatic changes in relative economic power, suggesting that American attitudes toward Others might be primarily driven by other factors. Not only does this finding raise the question of what other factors are more likely to cause attitudinal changes, but also what accounts for difference in feelings toward the two powerful countries. This finding therefore suggests alternative hypotheses about what drives American attitudes toward powerful Others. These are explored and tested in chapters four and five.

In chapter four I utilize experimental methods to test three questions raised in chapter three. First, what accounts for the stability in American attitudes toward economic competitors over such an extended period of time - particularly in the case of China? Second, what accounts for difference in feelings toward the two powerful countries? Third, assuming that American attitudes are changeable, what factors are likely to precipitate that change? To this end I test both the independent and interactive effects of each of three dimensions of IR on attitudes toward hypothetical states. The independent variables are: perceptions of the other state's capabilities relative to the U.S., perceptions of the threat or the opportunity that the other state offers to the U.S., and perceptions of the other state's political culture. The impacts of these variables on 
American attitudes are explored through analyzing the results of a social psychological experiment. ${ }^{10}$ Results further confirm the findings in chapter three that changes in economic capabilities have a minimal impact on attitudes toward Others. Analysis shows that while perceptions of a hypothetical competitor's rising economic capabilities have little impact on attitudes, perceptions of the competitor's political culture drive subject attitudes, both in general and toward China in particular. In addition to the direct impact of political culture on American attitudes toward Others, the experiment illuminates two indirect impacts: First, political culture determines the extent to which the Other's military capabilities are seen as threatening and thus likely to elicit hostility and second, political culture determines the degree to which perceptions of economic threat or economic opportunity moderate attitudes.

In chapter five I seek, through content analysis, to better understand American perceptions of China's political culture and how these have evolved over time. To this end I analyze content from three different sources (the New York Times, the Wall Street Journal, and the Federal News Service Database) to explore the myriad ways that China has been represented in American discourse from 1985-2011. First I demonstrate a strong correlation between the general tone in media representations of China and the evolution in American attitudes toward China over the same period of time. Then I use key word in context (KWIC) searches to show the correlation between media preoccupation with the negative aspects of China's political culture in the years from

\footnotetext{
${ }^{10} 123$ subjects were asked to read two scenarios: one describing economic relations and one describing security relations, between the Unites States and a hypothetical country. Within each scenario, relations were described as either positive or negative and the hypothetical country was described as either democratic or authoritarian. Subjects were then asked to rate their feelings toward each state as well as their level of concern about its potential growth in economic or military power. Lastly, subjects were asked a series of questions about their feelings toward, and perceptions of, several countries (including China).
} 
1989-1999 and negative attitudes toward China at that time. By demonstrating the link between negative attitudes and negative representations of Chinese political culture, this Content Analysis further proves the importance of perceptions of China's political culture in shaping American attitudes. Lastly, I use constructivist discourse analysis to discover and then explore the dominant themes in China discourse over the entire twenty-six year period.

This analysis uncovers three dominant themes that are prevalent throughout the American China discourse. These are (1) enthusiasm for Chinese economic reforms and debates about what they mean for Chinese political reforms, (2) Concern about the human rights issue in China and debates about the American role in promoting liberal Chinese political reforms, and (3) Awareness of China's growing power and the subsequent dependence that the United States has on Chinese cooperation to achieve its strategic goals. The importance which Americans place on China's domestic political culture is obvious within the first two themes and is further demonstrated through textual analysis. The implications of evolving perceptions of China's political culture on the tone of representation is also discussed

Chapter six discusses the potential impact that national attitudes have on foreign policy and thus the implications that this study has for predicting the course of SinoAmerican relations. It further acknowledges the limitations of this study and suggests avenues for future research. 


\section{WHY STUDY AMERICAN ATTITUDES TOWARD CHINA?}

Prediction is notoriously difficult and widely thought to be impossible (Friedberg 2005). Yet this does not keep us from trying. Predictions about the future course of Sino-American relations are frequently passing the lips of pundits, analysts, and policy makers. What is striking about these predictions is not the audacity of prognostication but the level of conviction with which contradictory predictions are espoused. This forecasting has particular significance for American Foreign policy, as predictions about the future have normative implications for current actions. With few exceptions (Bueno De Mesquita 2002, 2010), IR scholars avoid attempts at predicting the future.

Nevertheless, IR scholarship informs the debate about the future both theoretically and empirically. My study aims to add to this contribution by addressing three weaknesses with traditional mainstream approaches to understanding the current Sino-American relationship - each of which contribute to misleading predictions about the future. The first is the traditional materialist ontology, which ignores the importance of ideational factors, such as identity, in the shaping of bilateral relationships. The second is the degree to which the international level of analysis informs traditional theoretical and empirical conclusions. And the third is a tendency for traditional approaches to focus on single-factor explanations for complex bilateral relationships.

\section{Material Ontology}

Traditional scholarship tends to assume that the United States has a given national interest which dictates how it will respond to a future powerful China. One of the foundations of this popular perspective is Kenneth Waltz' (1979) “Theory of International Politics," which argues that, anarchy, assumed to be a systemic, a priori, 
static, fact, constrains states' ability to maximize their interests. Beginning, with assumptions about the existence of self-evident material realities that limit and shape state actions, Waltz and his fellow realists take national interests as exogenously given and uniform, built on conceptions of "threat" as material facts to which states are forced to respond in a limited number of ways.

Neoliberal institutionalists pose a challenge to realism by suggesting that ideas play a role in international relations through regimes, defined as principles, norms, rules, and decision-making procedures (Krasner 1983, 1). Yet, most neoliberals have come to accept many of the assumptions of the realists, particularly those of rationality and "functional similarity," causing many to lump both camps together under the term "rationalists" (Katzenstein, Keohane and Krasner 1998). In order to understand and predict the Sino-American relationship, rationalists assume that, we need only accurately assess tangible realities such as Chinese capabilities or Chinese motivations. American responses to these realities are then often assumed to be necessary, predetermined and predictable.

This perspective misses the fact that American attitudes toward China shape perceptions of Chinese capabilities and motivations to such an extent that an "accurate" assessment is impossible. Social Identity Theory demonstrates that individuals, as "social perceivers," frequently make mistakes when choosing whether to attribute an Other's behavior to dispositional qualities or to situational factors. These mistakes are so common that they have come to be known as the fundamental attribution error (FAE) (Fiske and Taylor 1984, 73). When exploring the causes of FAE among social groups (such as states), social psychologists found that group A's perceptions of group B's 
motivations are often dependent upon how group A feels about group B. While intergroup relations are not necessarily hostile (Brewer 1999, Larson and Shevchenko 2010), when relations break down to conceptions of "us" against "them," perceptions of the Other's intentions can become skewed in predictable and dangerous ways. If the effects of the Other's actions are negative, for example, then one assumes that the actions were because of the Other's flawed disposition (i.e., carelessness or malicious intent). On the other hand, if one perceives an actor to be a member of one's in-group then one is more likely to perceive negative outcomes to be caused by situations beyond the control of the actor (Hewstone 1990). ${ }^{11}$ As Chengxin Pan $(2004,306)$ puts it,

"U.S. conceptions of China as a threatening other are always intrinsically linked to how U.S. policymakers/mainstream China specialists see themselves (as representatives of the indispensable, security-conscious nation, for example). As such, they are not value-free, objective descriptions of an independent, preexisting Chinese reality out there, but are better understood as a kind of normative, meaning-giving practice that often legitimates power politics in U.S.-China relations and helps transform the "China threat" into social reality. In other words, it is selffulfilling in practice, and is always part of the "China threat" problem that it purports merely to describe."

Once one accepts the proposition that individual attitudes have an important effect on perceptions of threat, one is no longer surprised that some individuals might see China's rise as an opportunity, while others might see it as a threat. What is far more important to the understanding of the Sino-American relationship is an understanding of how each side is likely to perceive the Other's capabilities and motives - a question which may only be fully addressed by looking at identity. To this end my study draws on

\footnotetext{
${ }^{11}$ For a discussion of how attribution error has contributed to relations between China and the United States see Wang 2000, 256; Gries 2001; Gries and Peng 2002, 176-178; Gries 2005; Gries 2006, 66-70; and Moore 2010.
} 
constructivism, an approach which encourages the researcher to take non-material factors, such as identity, into account when attempting to understand international relationships.

Identity has been defined as a social category that "an individual member either takes special pride in or views as a more-or-less unchangeable and socially consequential attribute." People see themselves as belonging to a group with certain "rules of membership" and a number of characteristics such as "beliefs, desires, moral commitments, and physical attributes" (Fearon and Latin 2000,848). Scholars working with psychoanalytic theory have suggested the concept of an "extended self" whereby individuals include the nation and its symbols within their own articulations of selfidentity. These studies have shown "connections between injury to the 'group self" or nation and damage to individual self-esteem, with consequent aggressive, hate, and even rage reactions" (Kaplowitz 1990, 42). National identity, therefore, is both a part of an individual's identity and an expression of numerous individuals in aggregate. It is this latter aspect of identity that is particularly significant to IR constructivists.

Constructivism argues that relations among state are the result of interactions in which each state constructs and performs its own (national) identity in direct reference to what it perceives to be the identities of the Others in the system. These Others may be individuals (such as powerful dictators), organizations (such as the International Monetary Fund or NATO), or states (such as China).

Theorists disagree as to the extent to which this Self/Other dichotomy is inherently necessary to articulations of national identity. Louiza Odysseos (2007), for example, has argued that Western rationality has led to an arbitrary distinction between 
the Self/state (subject) and Other/state (object), which ignores the reality that the Other is always and already a part of the Self and its reality. Others suggest that this dichotomy is a result of a Western "statist" approach to understanding international relations.

According to R.B.J. Walker $(1992,175)$, it is the widely accepted rule of state sovereignty that "not only suggests how it is necessary to defend the borders but also how it is necessary to think about borders, about the delineation of political possibility in both space and time." Another theorist has suggested that it is the Westphalian state system that has institutionalized the "realm of the international" as the "realm of difference" (Neumann 1999, 29).

On the other hand, many suggest that difference is necessary to the very possibility of identity. David Campbell $(1992,17)$ makes this point when he points out that "identity — whether personal or collective — is not fixed by nature, given by God, or planned by intentional behavior. Rather, identity is constituted in relation to difference." Glenn Chafetz, Michael Spirtas and Benjamin Frankel (1998), define identity as "the state of being similar to some actors and different from others in a particular circumstance" (viii). Regardless, Constructivism holds that national identity is constructed through the logic of difference, suggesting that an understanding of the Self/state is expressed and understood through an articulation of what one believes that one is not. Collective identity is thus constituted through arbitrary distinctions between what constitutes the Self that lies inside of the "social boundary," and what constitutes the Other that lies outside.

While the significance of identity to international relations is one of the foundational tenets of the constructivist approach, constructivists disagree as to extent to 
which national identity may be understood and analyzed. Ted Hopf (1998) has suggested that constructivists are of two types, those he labels "conventional constructivists" and those he labels "critical constructivists." According to Hopf, the conventional constructivists assume the existence of identities and "seek to discover them, explore their reproduction, and use them as causal variables in explaining state actions." Critical theorists, on the other hand, object to the idea that the world is "knowable" and focus their analysis on the underlying power relations that form the dominant discourse, which then masquerades as a description of reality. In other words, the goal of the critical constructivist is to "explode the myths associated with identity formation," and the goal of the conventional constructivist is "to treat those identities as possible causes of action" (184).

The deconstruction of theory is a valuable project, which helps to prevent theoretical ossification and prevents theorists from erroneous conclusions derived from unquestioned assumptions. On the other hand, theory is a necessary tool in the search for answers to questions about how perceptions of Self and Other interact in determining national interest. Iver Neumann $(1999,208)$ has argued that a focus on "unique, contextbound instantiation of identity, fails to examine the social process of identification" and therefore limits the ability of analysts to understand how states construct politically actionable conceptions of Self." It remains both possible and necessary for IR scholars to attempt to understand how identity contributes to international relations while at the same time taking care to utilize theory that is both "contextualized and sensitive to process" (Mattern 2005, 5). 
The current study builds on the constructivist tenet that international relationships are a function of perceptions about both the national Self and of the Others out there. This assumption does not suggest that other factors such as relative capabilities, cultural distance, or the presence of opportunity or threat, aren't still significant causal variables in understanding conflict, just that relations are determined by how these factors are perceived, in the co-constitution and performance of identity, rather than any material fact of their existence.

\section{International Level Theorizing}

The second reason why mainstream theories are particularly poor at explaining specific bilateral relationships is their tendency to focus on the international level of analysis. By this I mean both that analysts are emphasizing the international over the domestic and that they are emphasizing the role of structure over agent when explaining international relations. This particular focus, when combined with a materialist ontology, causes theorists to misunderstand variations in each state's national interest. The realist focus on human self interest and the liberal focus on human rationality both suggest a similarity among individuals, or what Yosef Lapid $(2001,3)$ has described as, "a reality made up of discrete, self-identical things." When analysis is moved to the international level, states are thus anthropomorphized as self-interested rational actors, obfuscating the differences among them and the way that these differences are perceived and utilized by governments when defining their own unique national interests and when constructing foreign policy. While so-called China watchers often look at specific Chinese characteristics to determine whether or not China "is" a threat to the United States, their conclusions are most often informed by international level theories that explain how 
"functionally similar" states are likely to behave. This perspective can cause experts to misinterpret the implications of the events they are studying.

It may be argued that the materialist ontology and the international level of analysis are both necessary to acquire the "parsimony" that many rationalists seek. Nevertheless, several theorists have taken issue with the limited picture provided by such theories. According to Robert Powell $(1994,318)$, the rationalists are focusing on states preferences over strategies, while what is missing is an explanation of preferences over outcomes. In addition, some have begun to express doubt regarding the legitimacy of accepting national interest as exogenously given, suggesting that we ought to move toward the domestic level of analysis in order to determine how these interests are formed. Andrew Moravcsik (1997), for example, has championed a multi-causal approach to explaining state behavior that begins with liberal theories of domestic interest formation before moving to the international level to explain how states act to achieve their ends. Robert Keohane, $(1993,14)$ argues that "without a theory of interests, which requires analysis of domestic politics, no theory of international relations can be fully adequate." To address these concerns my study turns to existing theories of interest formation in order to explore domestic level causes for American foreign policy toward China. In particular my study draws on Image theory, which not only works at the second level of analysis but also challenges the materialist ontology that has dominated IR thinking, by suggesting that it is perception, rather than any material reality that determines how states are likely to respond to each other.

Long before the advent of the constructivist approach in IR, image theorists were theorizing and testing the causal relationship between a country's perceptions of Self and 
Others and its foreign policy. As early as 1959 Kenneth Boulding posited that "images," defined as the "total cognitive, affective and evaluative structure of the behavior unit, or its internal view of itself and its universe," play a role in shaping state responses to others. Boulding further added that, in international relations, the most important images are "those which a nation has of itself and of those other bodies in the system which constitute its international environment" (120-121). In the mid-1970s Richard Cottam $(1977,12)$ developed a theory of images derived from the assumption that humans behave in "perceptually patterned ways" that are identifiable and may be systemized for the purpose of drawing inference. It has been argued that these "perceptual patterns" or "clusters of knowledge" about other actors in the international arena reflect strategic judgments about that actor's relative capability, about that actor's culture, and about the threat or opportunity which that other actor represents. These judgments give rise to ideal typical images that act like stereotypes (Hermann and Fischerkeller 1995, Hermann, et al. 1997). Once a decision maker has perceived a particular state through an image, whether this image is accurate or not, his or her expectations about that state's behavior are impacted and subsequently so are his or her assessments of threat or opportunity afforded by that state as well as the choice of goals and the choice of tactics to be used in their achievement" (M. Cottam 1992; Schafer and Young 1998, 79). Image theory does not dismiss the realist observation that relative power capabilities limit state options, but rather it addresses the way that images of Self and Other guide individuals in the choices they make, be it the choice to fight, to bandwagon, or to balance, or whether to engage, confront or contain a perceived threat, as well as how states choose to pursue these 
objectives (M. Cottam 1992; Herrmann and Fischerkeller 1995; Schafer and Young 1998, $80)$.

Many empirical studies have provided evidence in support of the claim that images of the national self and images of other states impact foreign policy. Ole Holsti (1970) demonstrated how one decision maker's (John Foster Dulles) views of the Soviet Union affected his foreign policy positions. Martha Cottam (1992) discussed how the images held by different perceptual groups within the United States impacted American foreign policy toward Nicaragua in the late 1970s. Other theorists have used experiments to show the impact of the enemy image on the processing and interpretation of new information (Herrmann, et al. 1997), the impact of the national self image on recall (Hirshberg 1993a), and the impact of perceived cultural differences and perceived historical relationships on foreign policy recommendations (Schafer 1997).

Since individual images of China are likely to vary, Image Theory helps account for the vast disparity of opinions as to whether China constitutes a threat or an opportunity, as well as the variety of perspectives on what should be done about it. However, Image Theory is less successful at explaining American foreign policy toward China over an extended period of time. Since decision-makers' images of China are likely to be equally varied, we should expect that American foreign policy toward China would vacillate far more than it does. Despite huge swings in attitude toward China from administration to administration American foreign policy toward China has remained fairly stable for thirty years. This is a puzzle which Image Theory is unable to sufficiently address. 
In fact, despite the success of image theory in explaining the current and past policy decisions of specific decision makers, and thus an important aspect of relations between two states at a particular point in time, it fails to tell us much about how states are likely to react to others in general or how those reactions are likely to change over time. As Mark Schafer and Michael D. Young (1998) have pointed out, the focus of Image theorists on individual (elite) cognition, which is necessarily idiosyncratic, has produced research that is unsatisfactory in terms of generalizability and replicability. Noel Kaplowitz $(1990,44)$ has added that, "the predictive power of this level of analysis concerning state behavior and its potential for theory-building, regarding international relations is limited," suggesting that what is needed are "psychologically informed theories" that focus on "the ways in which conflict strategies and outcomes are determined by perceptions, beliefs, and attitudes held by parties and groups within nations, and which characterize broad schools of thought regarding foreign policy that transcend individual leaders."

This weakness of image theory is shared by most theorists working at the domestic level of inquiry. As Jarrod Hayes $(2009,981)$ has noted, most of the constructivists who have moved beyond theory in order to explore how identity impacts specific relationships tend to focus on the individual decision maker. He points out that "a critical gap in the literature lies at the junction of the domestic and the international" and suggests that "the argument should be extended to the public in democracies because their perception of threat is an important factor in democratic security policy."

The causal relationship between public opinion and foreign policy is widely debated. While this debate is explored more fully in chapter six, my study assumes that 
public opinion plays some role in shaping and constraining elite decisions. The current study therefore asks whether a generally unified image of China might exist, within the national consciousness, which shapes public opinion and constrains elite responses to events on the ground. Focusing mostly on national (self) identity, constructivism explains how such an image might be constructed at the national level.

If, as constructivism contends, national identity is always insecure and must be constantly produced and reproduced, through differentiation, then we must ask how this is accomplished and by whom. If national identity is understood as an aggregate of individually held beliefs, then, as Freidrich Kratochwil $(2006,27)$ has pointed out, this begs the question of where these beliefs came from and why they are held in aggregate. There is an element of power necessary for the construction of identity, and constructivism holds that this power is demonstrated through certain articulations that serve as representations of reality. Some articulations will be more effective than others in producing stable sources of "shared knowledge" (Mattern, 2005, 94). Drawing on Louis Althusser, Himadeep Muppidi $(1999,124)$, suggests that identity construction is accomplished through two processes that organize meaning — "articulation" and "interpellation." Those who attempt to articulate national identity make suggestions regarding which conceptions of self are legitimate and which are not. The production of national identity requires "political work" which causes certain conceptions to become fixed in the minds of the nation. Yet this "work" is not so easily accomplished that powerful speakers may cause dramatic changes in national identity any time they wish. Muppidi points out that any particular articulation may be rejected by the receivers. In other words, attempts to create "mutually shared meanings" through the discourse of 
national identity may fail if individuals do not recognize themselves within that discourse (124-125).

Internally, the logics of identity and difference are constructed and maintained through the discourse of numerous competing voices. The state plays its role through socialization, i.e. educating youth on the myths of the formation of the nation-state, through policies such as immigration, and through the rhetoric of foreign policy, which often emphasizes the distinction between the good Self and the "others out there." Other sources attempt to tap into existing conceptions of "who we are" to achieve a variety of goals. Advertisers and politicians utilize the narratives of national identity to promote themselves or their product. News media emphasize these narratives both through choosing what events to report and through the ways that they choose to report them. These practices rearticulate these narratives and reaffirm these conceptions (Laffy 1999, 238).

The constructivist approach explains how a unified national (Self) identity is constructed through discourse. Since the Self and the Other are co-constituted through interaction this approach simultaneously explains how images of the Other are constructed via the same pathways. There is a burgeoning literature that explores bilateral relationships to investigate how this process occurs empirically (Doty 1993; Weldes 1999; Hopf 2002; Laffey and Weldes 2008). The majority of these studies look at Cold War relationships due in part to their relatively clear cut dichotomous nature. ${ }^{12}$ In fact, much of the constructivist literature emphasizes the negative end of the spectrum

\footnotetext{
12 These dichotomies include the east west division in which states across the iron curtain from each other were clearly defined as enemies (Weldes 1999; Hopf 2002; Laffey and Weldes 2008) and the power division which clearly separated the colonial powers from the weak former colonies (Doty 1993).
} 
when discussing the process of Other construction. Particular emphasis is put on the process of "Othering," whereby, in times of crises, difference is transformed to otherness to secure identity against direct challenges (Campbell 1992; Weldes 1999). This negative emphasis is also found in Image Theory, which is dominated by studies that test the impact of the "enemy image," on the construction of foreign policy.

The focus on dichotomy aids in testing the theoretical concepts, yet it leaves less easily definable relationships, like that between China and the United States underexplored. ${ }^{13}$ While few would call China a friend, most Americans would hesitate to consider China an enemy. In fact, the lack of a media consensus about how the United States should react to China is reflected in a public ambivalence about how Americans should feel toward China. Unfortunately, if we are unable to fit American images of China into the archetypical categories explicated by Image theorists than we find ourselves without the predictive power that these categories supply.

A more fruitful approach lies in exploring national attitudes toward China in order to determine, what constructivists call "conditions of possibility." It has been argued that, by focusing on the constitution of subjects and objects in International Relations, constructivism seeks to answer "how possible" questions rather than "why" questions (Kratochwil 2006; Doty 1993). The argument here is that interests are linked to constructed identities (of both the Self and the Other) which in turn make certain policies desirable and other policies inconceivable. Theorists working in this vein have typically analyzed discourse in order to explain how a certain event or response was made possible. Pinar Bilgin and Kivanc Cos (2010), for example, explore discursive moves

\footnotetext{
${ }^{13}$ For an interesting exception see Gregory J Moore "Not Very Material but Hardly Immaterial: China's Bombed Embassy and Sino-American Relations.” Foreign Policy Analysis, 2010: 23-41.
} 
that allowed Turkey to represent the USSR as a friend and respond to it accordingly, despite changes in material capabilities and Soviet actions that might have been perceived as threatening under different conditions.

By taking a similar approach to understanding American representations of China, my study seeks to explain the conditions that shape American foreign policy toward China. However, rather than attempting to answer "how possible" questions about something that has already happened, my study seeks to better understand how an image of China is shaped through national discourse in order to understand what the current conditions of possibility are and how these conditions might shape current and future policy responses to events on the ground. It additionally seeks to better understand the components of American attitudes toward China in order to better understand how, when, and why conditions of possibility might change in the future thus enabling that policy toward China which is currently desirable to become inconceivable or vice versa.

\section{Single Factor Focus}

A third weakness with mainstream theories has been a tendency to focus on one aspect of bilateral relations at the expense of others that may be equally or even more important, thus causing theorists to de-emphasize, or miss altogether, important causes of state behavior. Peter Katzenstein and Nobuo Okawara (2001-2002) have lamented what they call the "clash of paradigms," a situation in which theorists are too busy defending the supremacy of a particular theoretical approach to consider the benefits of causal variables which may come from alternative theories. They argue that this situation causes theorists to fail to grasp real world complexities and have called for "analytical eclecticism," an approach which looks at "a combination of forces and factors," to 
explain international relations. The third goal of my study is to employ such an approach in order to analyze the research questions from different perspectives. To this end it draws on these perspectives in order to test the independent and interactive effects of three independent variables that might help to explain American attitudes toward China. These are: perceptions of China as a threat or as an opportunity, perceptions of China's political culture and perceptions of China's capabilities.

\section{Hypotheses}

My study is designed to test three hypotheses, each predicting the effect of three independent variables on American attitudes toward China. Since chapters three, four, and five each utilize different methods, these independent variables are operationalized differently according to the dictates of each method. The thinking behind these decisions will be discussed in those chapters. However, it might be useful here to discuss how each variable is generally conceptualized for the purpose of my study. The following discussion first describes three hypotheses, each suggesting that a different independent variable has a dominant impact on American attitudes toward economic competitors, then explains how each of the three variables was chosen and operationalized

Hypothesis \#1 predicts that subject attitudes will be driven primarily by the rising capabilities of powerful Others. Of the three variables, "relative capabilities" is the easiest to define and operationalize for two reasons. First, it is relatively easy to quantify and measure. Second, it is one of the most common independent variables in IR as it is often used to test realist theoretical expectations. Nevertheless, there are some complexities with this variable that must be acknowledged. For example, soft power may be conceived of as a capability that is much more difficult to measure than are military and 
economic capabilities. Also, the understanding of what constitutes military power is changing through advances in technology, increases in the importance of transnational actors, and increases in non-traditional security threats. Since my study attempts to measure the impact of perceptions of China's capabilities relative to the United States, rather than to accurately assess those capabilities these complexities don't offer too much difficulty.

Hypothesis \#2 predicts that subject attitudes toward Others will be shaped primarily by perceptions of the U.S.-Other relationship. In particular, it predicts that subjects will feel negatively toward states that are perceived as threatening and positively toward states that are perceived as providing an opportunity. Since conceptions of "threat" and "opportunity" differ depending on whether one is referring to either the economic or the security milieus, this variable was operationalized for each milieu and its effects were tested separately.

The explanatory power of economic threat and opportunity is implicit in various strains of neoliberal thinking that analyze the relationship between this variable and the potential for cooperation among states. Consequently, conceptions of economic threat and opportunity are well defined in the literature. My study draws on this work and conveys economic threat through reference to the loss of American independence, the loss of American jobs, and the weakening of the American economy. Economic opportunity is conveyed through reference to an increase of product choices and a decrease in product prices. ${ }^{14}$

\footnotetext{
${ }^{14}$ In order to make the study as reflective of the real world environment as possible, operationalization decisions were based, in part, on content analysis of 2009-2010 New York Times articles about the SinoAmerican relationship.
} 
To operationalize the concept of security related threat or opportunity, my study utilized the question posed by Richard K. Herrmann, James F. Voss, Tonya Y.E. Schooler, and Joseph Ciarrochi, when attempting to define this same variable: "Do the other actor's intentions threaten to reduce my country's current achievement of valued objectives or does the other actor present an opportunity for me to advance and expand my country's interests?" $(1997,408)$. Using this question as a guide "security threat" and "security opportunity" were operationalized along the lines of conflict, or cooperation, in long term security goals. For the sake of brevity and clarity, the presence of threat or conflict in the economic milieu or the presence of cooperation or conflict in the security milieu is sometimes referred to as the economic or the security relationship.

Hypothesis \#3 predicts that subject attitudes will be shaped primarily by perceptions of the Other's political culture. Culture, as a causal variable explaining state behavior, has been most frequently examined by political psychologists. The key concept here is "cultural distance," derived from the premise that the more one sees an Other as dissimilar from oneself the more likely one is to have hostile feelings toward that other (Geva and Hanson 1999, 806). Yet a problem lies in the many disparate definitions of the term. Image theorists typically define culture in terms of relative cultural sophistication (R. Cottam 1977; Herrmann et al. 1997). Others have defined the term along political, religious, or even ethnic lines (Schafer 1997, 813-829). As Lisa Wedeen $(2002,714)$ has pointed out "“culture' is an abstract theoretical category, a lens that focuses on meaning, rather than on, say prices or votes."

In IR the most common approach to operationalizing culture tends to be along political lines. The reasons for this go deeper than just the predisposition of the discipline 
towards politics. First, studies have shown that regime type has a large impact on individual perceptions of cultural distance (Mintz and Geva 1993; Hermann and Kegley 1995; Geva and Hanson 1999). Second, the significance of democracy as a causal variable predicting peace in IR theory makes it a particularly desirable concept to test. ${ }^{15}$ My study therefore focuses on the political dimension of culture. The variable is operationalized along authoritarian/democratic lines with particular emphasis placed on the presence or absence of democratic values - particularly human rights.

The goal then becomes to understand how perceptions of other states, along the three dimensions discussed above, interact in shaping national attitudes toward those states. Of course, one must acknowledge that these three dimensions are not the only potential independent variables. Nevertheless, IR theory has demonstrated that these variables are the ones that matter the most. Image Theorists, for example, assert that these variables are the key components of images (R. Cottam 1977; Herrmann et al. 1997). In addition, each of these variables plays a prominent role in one or more branches of IR theory. Lastly, the significance of these three dimensions of international relations, on national attitudes is illustrated by looking at the questions on any public opinion poll of foreign policy, as the majority of the questions asked are designed to measure attitudes along these lines.

\footnotetext{
${ }^{15}$ While this study does not test the validity of one strand of the democratic peace theory, which suggests that institutional characteristics explain the prevalence of peace between democracies, it does in some ways test an alternative strand that suggests the power of a common commitment to liberal ideals in generating close relations between states. Constructivists, focusing on identity issues have made great strides in explaining how perceptions of cultural similarity lead to peaceful relations among democracies. (Kahl 1998, 94-144; Hayes, 2009, 2012)
} 
At this point an additional question must be addressed — why is this polling data not sufficient to explain current attitudes? Polling provides useful data that may be analyzed to help answer the types of questions I am asking here. Benjamin I. Page and Tao Xie (2010), for example, have analyzed American public opinion polls in order to demonstrate that Americans are far less reactionary toward China than has been previously suggested. In chapter three, I use polling data to test the hypothesis that American attitudes toward economic competitors evolve in relation to changes in relative capabilities. Yet polling data alone, does not tell us everything we need to know in order to better explain and predict bilateral relationships.

There are several reasons why further study is necessary. First, while these polls may be a good measure of public attitudes toward a particular state at a particular point in time, they tell us very little about how these attitudes are likely to impact varying levels of support for current policy choices and even less about how and why national attitudes (and thus support) is likely to change over time. ${ }^{16}$ Without understanding the independent and interactive effects of these dimensions on attitudes, it is difficult to: (1) determine, how the public will respond to a policy that is perceived to have a positive impact on one dimension and a negative impact on another (2) determine whether the public is likely to support similar policies toward states that are similar in all but one

\footnotetext{
${ }^{16}$ This is not to say that attitudes toward a particular policy cannot be measured by simply asking how respondents feel about that policy. The point here is that polling data showing that the majority of the country feels negatively toward a particular country will not explain much without a basic understanding of why these people feel the way that they do.
} 
dimension and (3) determine, with any reliability, the attitudinal impact of a perceived change in any one dimension.

Second, a better understanding of the national attitudes toward each dimension will also help to explain why people have the attitudes that they do towards other states. Polls may attempt to address this question, yet they mostly fail as a consequence of the intervening effect of individually held images. In other words, when asked why one might feel a certain way about China's military capability, for example, a respondent will conflate attitudes toward China with attitudes about military strength in general. It is impossible to determine whether the respondent is "somewhat concerned" about China's military capability because China is also an economic power, because China is an authoritarian state, or because China has proven an unlikely ally of the United States. Further questions spring to mind. Would the respondent be more (or less) concerned if China had a weaker economy or was a less significant trade partner of the United States. What would the impact be if China suddenly became more or less cooperative in international issues of strategic importance? Are changes in China's domestic politics likely to impact concerns? If so, in what way do these changes affect attitudes? These questions may not be too important if the analyst wants only to understand the current national attitude toward China, but the problem becomes clear when the analyst attempts to make predictions about the direction of future relations or even the potential for change in the current relationship.

\section{Summary}

To summarize, my study assumes that the relations between two states is a function of each state's perception both itself and of the Other. An accurate 
understanding of relations between the two states is therefore dependent on not only how different perceptions lead to different actions but also what those perceptions are and why. My study further assumes that national attitude is the best measurement of "state perception" and is therefore a good indicator of how that state is likely to act and react over time. The reasoning here is that, even though events might cause short term fluctuations in national attitudes, in general, these attitudes follow similar logic as do individual images, in that they are resistant to change and serve as filters for reality. Lastly my study assumes that these attitudes are largely a function of three significant dimensions of international relations-perceptions of threat versus opportunity, perceptions of political culture, and perceptions of capabilities. While each of these dimensions is important in and of itself, a better understanding of how these factors interact in determining attitudes towards others, will lead not only to a better understanding of current relations but also to a more accurate prediction of when, how, and why attitudes are likely to change.

The remainder of my study is focused on answering the following research questions: What is the underlying basis for American attitudes toward Economic competitors in general and toward China in particular? The first task, which is begun in the following chapter, is to test hypothesis \#1. Specifically, chapter three tests the proposition that American attitudes are likely to become more hostile as Chinese economic capabilities increase. This is accomplished in two ways. First, by examining American attitudinal responses to recent changes in Chinese capabilities, we will see the extent to which changes in specific indicators have driven attitudes in the recent past. Second, by comparing how Americans responded to economic threat emanating from 
Japan in the 1980s and 1990s with how they are responding to very similar forms of economic threat emanating from China today, we will explore the extent to which Americans are responding to economic threat in general as opposed to other characteristics of the Sino-American relationship. In other words, the findings from these tests will illuminate both the extent to which changes in economic capabilities generally effect threat perception, as well as why, when and how it is likely to do so. 


\section{HOW DO AMERICANS RESPOND TO THE RISING ECONOMIC CAPABILITIES OF DIFFERENT ECONOMIC COMPETITORS?}

"Despite the increase in foreign investment and growing public concern over its consequences, U.S. policy makers and business leaders have been loath to confront the issue...This refusal by U.S. politicians to act stems partly from a fear of antagonizing the very [foreign] investors on whom we have come to depend for the financing of our federal government deficit." 17

"Trade deficits of this magnitude and duration are simply unacceptable",18

"Its becoming a mismatch... We, the great believer in free enterprise, are having our pants removed, an inch at a time, by a centrally-orchestrated, totally committed, and economic aggressor. Why can't we grasp the truth of it and get mad and fight back? We'd better develop a healthy fear, for the price of economic subordination (is) colonization. We're staring at it." $"$ p

One might be surprised to learn that these are not the words of modern day

pundits responding to an economically powerful China. They are, rather, the

proclamations of fearful observers reacting to a rising Japan 1977-1993. It is not

surprising that the rhetorical responses to Japan at that time are similar to the rhetorical

responses to China today, as the parallels in response are a direct reflection of the

numerous similarities in the perceived economic threat posed by each country at a

specific point in American history. In both cases Americans are dealing with large trade

deficits, burgeoning debt, and fears about their own declining position in the global

economy. And in both cases Americans have chosen a scapegoat that has a large trade

\footnotetext{
${ }^{17}$ Frantz, Douglas and Catherine Collins. Selling Out: How We Are Letting Japan Buy Our Land, Our Industries, Our Financial Institutions, and Our Future. Chicago: Contemporary Books, 1989; 3

${ }^{18}$ Secretary of Commerce Juanita Krepps quoted in the Miami News, September 1977, warning Japanese businessmen in Tokyo that they must do something to change the US-Japan trade balance ("Widening").

${ }^{19}$ Chrysler Motors chairmen Ben Bidwell in a speech given January 1989, quoted in the New Straits Times March 1990 ("New Bout").
} 
surplus with the U.S., is financing a large percentage of America's debt and is rapidly rising to the status of economic super-power.

The similarities between the Japan-American Economic relationship of the late 1970s-early 1990s and the Sino-American economic relationship of today are obvious and have been oft referred to (Chin and Helleiner 2008; Okimoto 2009). There are those who have used the example provided by the United States' previous economic relationships with Japan to suggest that Americans need not be too concerned about China as an economic threat. Allen Greenspan, for example, has argued that Americans need not worry excessively about China's potential to stop buying American dollars, pointing to the fact that Japan's cessation of intervention in the foreign exchange market in 2003 did not negatively impact treasury yields (Quoted in Setser 2008). Craig Elwell, Marc K, Labonte, and Wayne M Morrison $(2007,105)$ attempt to lessen concerns about the purported threat caused by China's movement up the production ladder by first comparing it with the threat posed by high-tech Japanese manufacturers in the 1980s, and then pointing to the sad fate of the Japanese economy in the late $1990 \mathrm{~s}^{20}$

Others have attempted to illuminate the threat posed by China by highlighting the differences between the two cases. Some of the more disconcerting differences lie in the nature of the creditor debtor relationship. Particularly, the fact that so much of Chinese credit comes in the form of sovereign wealth funds controlled by the Chinese government, rather than the private sources (i.e., private banks, private investors, and private companies) of Japanese funds (Thompson 2007; Setser 2008). ${ }^{21}$ My study does

\footnotetext{
${ }^{20}$ Elwell et al $(2007,105)$, further point to China's "extensive challenges" and suggest that its ability to pose a threat to American advantages in high knowledge high technology goods is "questionable."
} 
not seek to address the question as to which of these competitors has actually been more threatening to American interests. What is important here is rather how Americans respond to these threats. The similarities between the two cases offer an interesting opportunity to generalize about American responses to economic threat and the differences create the potential for insight into how other pertinent factors might influence those responses.

Throughout the 1980s and into the early 1990s, many predicted that American economic insecurity and subsequent hostility toward a rising Japan would lead to increased protectionism, worsening relations between the two countries, and ultimately a trade war reminiscent of that which occurred among the economic powers during the 1930s. While at times it seemed close, this worst-case-scenario never happened. Despite the rising tone of alarm and animosity in both popular and elite American discourse throughout the 1980s and the repeated threats and resolutions made by Congress, the U.S.-Japan relationship remained generally cooperative. By the late 1990s Japan had ceased playing the role of economic boogeyman in American discourse and it soon became apparent that China had taken its place. As discussions about China as an economic threat have become ever more ubiquitous in the American media, we are hearing similar predictions about the inevitable worsening of the Sino-American relationship.

${ }^{21}$ Brad Setser (2008, 6-10) describes several other important differences between the two cases including the fact that the current deficit expansion is so much bigger than that in the 1980s, the fact that money is now flowing from poor countries to rich country, and the fact that investors today are promised relatively low returns compared to what can be gained elsewhere and what was expected in the 1980s. 
The implications of conflict are far more serious in the case of Sino-American relations. Not only would deteriorating relations between these two powers be harmful to the world economy, but considering the fact that China has more military might and security independence then did Japan, such a conflict could be destabilizing to world peace. Therefore, it is worthwhile to investigate the degree to which continuing changes in China's economic capabilities are likely to engender negative responses in the United States. To that end, this chapter asks the following questions: To what extent do relative changes in a competitor's economic capabilities lead to American hostility toward that country? All else being equal, how likely is it that the continual rise of China's economic power will cause rising tensions between the two states? What lessons can be learned from the U.S.-Japan economic competition of the late 1970s through the early 1990s?

To answer these questions, this chapter explores the effect of changing economic capabilities on American attitudes. By analyzing shifts in American attitudes toward two different competitors over a period in which their economic capabilities began to approach those of the United States, I am able to determine if and when Americans begin to perceive an economically powerful Other as a threat. This is accomplished through first tracing the three different components of changes in relative economic power between each competitor and the United States that are likely to be most threatening to Americans. These are (1) the apparent inevitability that the competitor would surpass the United States in terms of economy size, (2) the growth in the American trade deficit concurrent with an increase in imports from the competitor, and (3) the growth in U.S. debt concurrent with an increase in the competitor's purchases of American assets. Polling data is then analyzed to trace American responses to these changes. The 
juxtaposition of shifts in American attitudes with changes in particular indicators of the Other's power offers three possible outcomes, each of which suggests unique implications about the impact of economic threat on American attitudes toward Others.

Outcome \#1 American attitudes toward both states follow similar and predictable patterns. For example, we might expect that for both cases, American attitudes become generally more hostile over time as the competitor's relative economic capabilities rise. On the other hand, we might find that in both cases Americans respond more negatively to a rising trade deficit than to growing indebtedness, or vice a versa. Since these issues emerged and peaked at separate times in both cases such a variation in attitudinal responses would be clearly visible. Lastly, we might find a lag in negative attitudinal responses to economic competition that either occurs in both cases or, considering that the China case is still evolving, appears to be occurring in both cases. The implications of any of these outcomes would be two-fold. First, finding the same results with two different economic relationships would suggest that these results might be generalized to help explain American responses to other economic competitors. And second, if we find that Americans respond similarly to economic threat emanating from two different competitors then we gain a better understanding of the significance of economic indicators in shaping American attitudes toward Others, regardless of other important factors.

Outcome \#2 American attitudes toward both states follow similar but unpredictable patterns. Such findings would generate new, testable hypotheses about how Americans respond to economic threat. For example, if we find that American attitudes trend positively in the face of a powerful Other's rising economic capabilities 
then we could hypothesize that either (1) Americans feel increasingly favorable toward economically powerful Others as they become more like the United States in economic terms, or (2) American fears about the economic threat posed by rising competitors are not strong enough to outweigh positive attitudinal responses to other factors. Another possibility is that American attitudes would remain generally unchanged in the face of rising economic competition. This outcome also suggests different possible hypotheses. For example, we could hypothesize that American attitudes toward Others are fixed at some point in the distant past and are unlikely to change, regardless of changing circumstances. An alternative hypothesis would be that American attitudes toward Others are changeable, but they are generally unresponsive to economic threat. While there are different potential explanations for each of these possible results, they both share one important implication: If we find that Americans do not respond negatively to economic threat in either case then we must begin to question many of our widely held beliefs about the presence and importance of economic insecurity in the United States.

Outcome \#3 Americans respond positively in one case and negatively in the other. Despite the numerous similarities, it is the differences between these two cases that offer the most potential for valuable insight into how Americans perceive and articulate economic threat. While these differences are numerous, there are two that are most likely to contribute to less negativity toward Japan then China: (1) In the 1980s, Japan was seen as an ideological ally in the fight against Communism. In contrast, contemporary Americans remain uneasy with the communist-authoritarianism of the current Chinese state and may not wish to see such a state become more powerful. (2) In the 1980s Japan and the United States enjoyed a security alliance, which diminished, (but did not 
eliminate) fears of a rising Japan as a security threat. On the other hand, China's current military strength and nuclear capabilities could add an additional dimension to American fears of a powerful China. There are also two important factors that could potentially contribute to less negativity toward China than toward Japan during a period of heightened economic competition: (1) China has proven a superior economic partner to Japan in neoliberal economic terms. While the Japanese constructed numerous non-tariff barriers to American products and actively prevented inward foreign direct investment (FDI) from American companies, China has become an increasingly important trade partner and has been a welcoming site for American FDI. And (2) the difference in political culture between Japan and China might actually cause Americans to feel more positive toward China's rise than toward Japan's rise. At the same time that China is growing economically it is also becoming more liberal economically. The turn away from communism may be perceived as a step toward democracy and could therefore engender a positive attitudinal response. Considering these differences, if American responses to the two cases trend in opposite directions, we should be able to generate some specific hypotheses based on which direction attitudes head in each case.

The remainder of this chapter tests the hypothesis that increases in a competitor's economic capabilities lead to increases in American hostility toward that competitor. To this end I analyze the evolution in each competitor's capabilities over an extended period of time. The first purpose here is to illustrate how East Asian capabilities changed over time and how these changes affected each country's economic relationship with the United States. The second purpose is to briefly discuss how these changes were likely perceived in order to develop a timeline of events that we could 
reasonably expect to correlate with rising American hostility toward each competitor. Lastly, I juxtapose each timeline with actual trends in American attitudes toward each country in order to test the hypothesis that one or more indicators of rising economic capabilities elicit negative American attitudes toward economic competitors.

\section{The Two Cases}

There are several different indicators of economic power, each of which might have a different impact on American attitudes toward an economic competitor. The indicators that most caused Americans concern for the two cases are: economy size, trade balance, and foreign investment. While these economic factors are, of course, interrelated, the point at which the American public became concerned about each issue is different. Therefore by analyzing shifts in American attitudes in relation to each of these different indicators separately it should be possible to discover whether one factor has a bigger impact than others.

\section{Economy Size: "Hegemonic Threat"}

The United States has been the world's largest national economy since the turn of the Twentieth Century. This economic fact has bolstered the United States' hegemonic status both materially and symbolically and has been a source of power and pride for the American people. American economic hegemony has not remained uncontested, however. It has been threatened, first by Japan, and then by China, as each became the world's second largest economy and then began closing the gap towards the number one position. Both countries experienced sustained economic growth rates that were touted as "unprecedented," and "miraculous," and in both cases the economic rise of the East Asian power was concurrent with slow growth and stagnation in the United States. For 
much of the last forty years, Americans have lived with the widely held belief that an East Asian competitor would eventually take their place at the top of the global economy.

How do Americans respond to this threat? Admittedly, economy size might be less likely to resonate with Americans than trade imbalances or foreign investment. Even for people who have a poor grasp of economics, the lines between trade balances and jobs, or foreign investment and national security are fairly easy to draw. It is equally easy to make the connection between debt and deficits on the one hand and American weakness on the other. Nevertheless, while many American may not fully grasp the relevance of GDP growth or economy size to their own lives, the symbolic significance of slipping from number one to number two could be enough to elicit strong emotional reactions. We might therefore expect that Americans would begin to feel hostility if and when it became clear that the competitor might surpass the United States to become more economically powerful. We might also expect that this hostility would climb along with increases in the certainty that such an event would transpire in the near future. The following discussion outlines the emergence and evolution of hegemonic threat in both cases.

Japanese Economic Growth

Japan was the first non-western country to have a significantly large economy. In 1968, Japan passed Germany to become the second largest economy in the noncommunist world. This was due to what came to be known as "the Japanese Miracle," in which Japan not only recovered from the economic and social devastations of World War II, but also achieved more than thirty years of remarkably high growth rates in order to ultimately join the elite international club of industrialized economies. While Japan's 
fastest growth was in the 1960s (with rates averaging over 10\% annually) and in the 1970 s (with rates averaging over $5 \%$ annually), the average rate approaching $4 \%$ in the 1980s was still impressive, and certainly more so than the sluggish growth of the United States at this time. With zero growth in 1970, and negative growth rates in 1974 and 1975 , the U.S. average GDP growth rate during this decade was only $3.2 \%$ compared with Japan's 5.2\%. Both countries saw slower growth rates in the 1980s but Japan averaged 3.8\% compared to only $2.8 \%$ for the United States (International Monetary Fund 2011). By 1970 the Japanese economy was one fifth the size of the United States'. By 1980 it had jumped to two fifths and by 1990 the American economy was less than twice as big as Japan's. Concerns about Japan's encroachment on American supremacy began to emerge in the early 1970s, when trends showed Japan surpassing the United States in real per capita income by 1985, and in total output by 1998 (Krugman 1994, 75). Even after Japanese growth began to slow in the late 1980s, analysts continued to predict that Japan would soon surpass the United States due to its superior performance in a number of economic categories. These predictions continued well into the 1990s, gaining emphasis whenever Japanese growth rates outpaced those of the United States (see figure 1). 


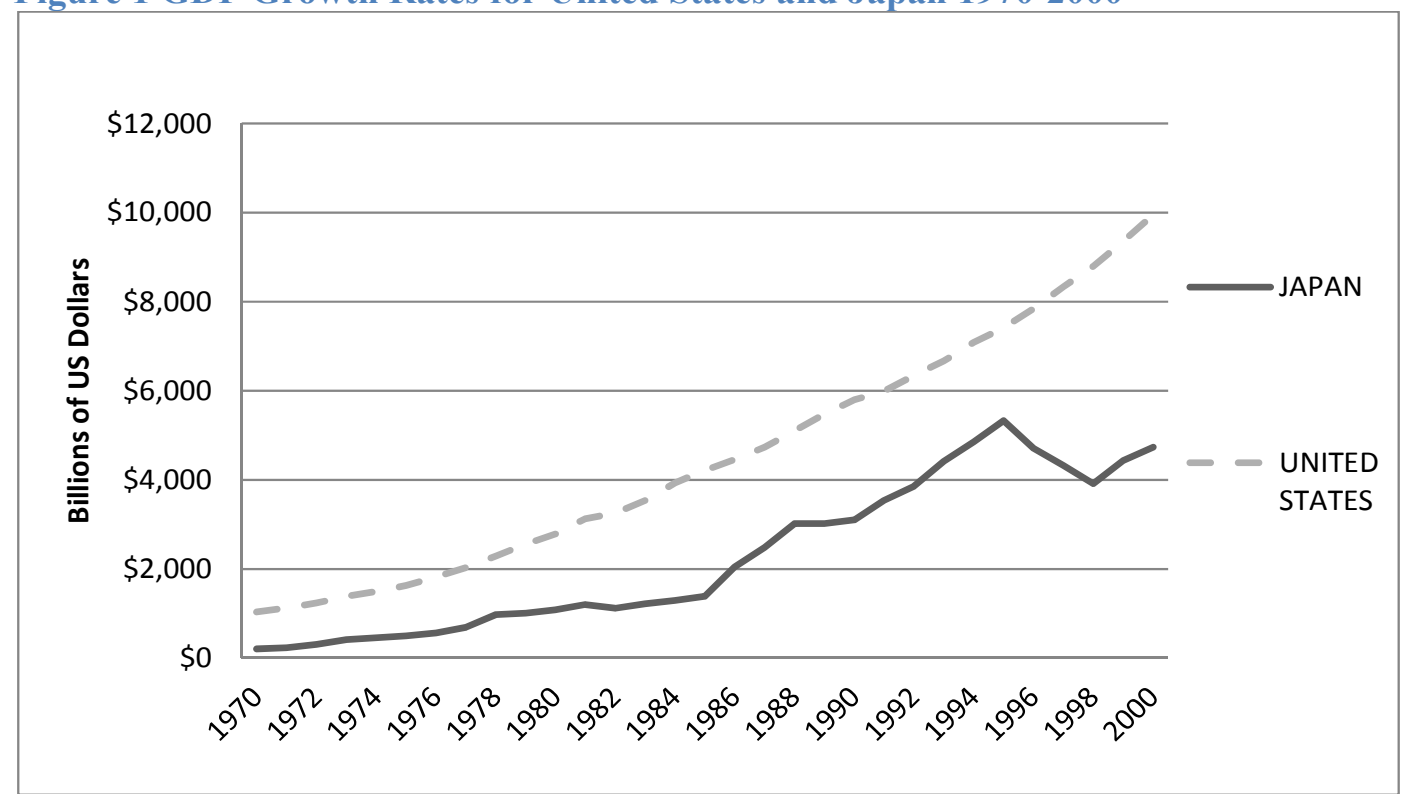

Source: IMF World Economic Outlook Database *Current Prices

The American media responded to Japanese success with a mixture of admiration and fear. Books and articles praising the apparently superior Japanese system became ubiquitous. Some warned that Americans had better change their ways or the once influential United States would fall into obscurity behind a powerful Japan (Vogel 1979; Prestowitz 1988). Others argued that this was no longer a preventable occurrence and that it was only a matter of time until the inevitable occurred. This pessimistic outlook accompanied a relatively ubiquitous discussion about the United States "obvious," decline (Kennedy 1987; Gilpin 1987; Ikenberry 1989). In the late 1980s it became popular to explore the likeliness of Japan's ascendency to global hegemony (Uchitelle 1988; Taira 1991). During this period newspapers and journals became littered with articles suggesting that maybe Americans should emulate Japan in everything from education to business practices ("New Wind” 1989; Gibbon 1989; Sumiya 1991). 
The idea that Japan either had unseated, or was on its way to unseating, the United States as the global hegemon continued well into the 1990s. Even though the Japanese began to see dramatic reductions in growth rates in 1992, and close to zero growth in 1993 and 1994, it took analysts a few years to realize that this was more than just a temporary hurdle in Japan's path toward global economic dominance. Eventually, as the Japanese recession dragged on, it became clear that Japan would not fulfill its predicted rise to the top and the conception of Japan as a hegemonic threat gradually disappeared from American discourse.

\section{Chinese Economic Growth}

Like Japan, Chinese economic growth occurred over a long period of time. China has seen growth rates averaging over $9 \%$ annually since Deng Xiaoping first initiated reforms in 1978. Since then China's gross national product has more than quadrupled. Even though China's high rates of growth over more than three decades is certainly more impressive than even the "Japanese miracle," as a poor developing country China had much further to go before Americans would begin to see it as a potential equal, let alone as a rival for economic hegemony. In fact, during the 1980s and early 1990s, even as Chinese growth rates were impressing economists everywhere, the American discourse about economic threat remained focused on Japan. Yet as the miraculous pace of Chinese growth continued and the predicted collapse of the Chinese government and the Chinese banking system showed no signs of occurring, concerns emerged that the Chinese economy could one day surpass that of the United States.

American anxiety about China's potential encroachment on the U.S. position at the top began to emerge in the late 1990s, and increased in the late 2000s as it became 
apparent that China would surpass Japan to become the world's second largest economy. Although China is still only a third of the size of the U.S. economically, disparity in current growth rates is rapidly closing that gap. Figure 2 illustrates this point by projecting current growth rates of both countries into 2017.

Figure 2 GDP Growth Rates for the United States and China 1970-2017

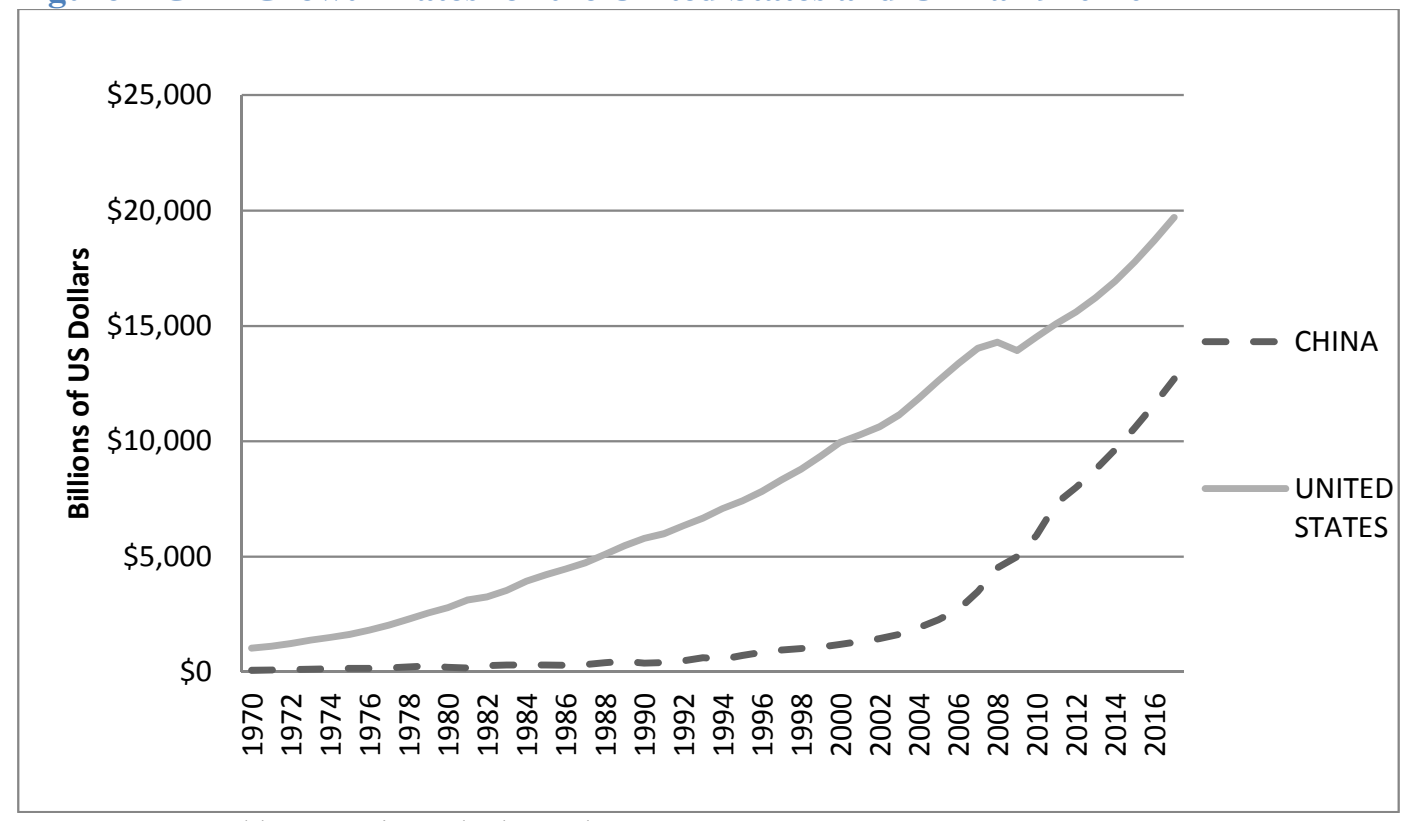

Source: IMF World Economic Outlook Database

*Current Prices

Economists are increasingly predicting that China will soon match, and then surpass, the United States in economic strength. Since the global economic crises in 2008 had a far more negative impact on American economic growth than on growth in many developing states, particularly China, this process may even be speeding up. According to a Goldman Sachs economic report released in December of 2008, projections that the Chinese economy could reach the size of the U.S. by 2027, now seemed "more, rather than less, likely" (O'Neill and Stunytska 2009). Other projections have been even more optimistic about China's future. The Nobel Prize winning economist, Robert Fogel (2010) predicted that the Chinese economy would reach $\$ 123$ 
trillion by 2040 , with China holding $40 \%$ of the world's wealth, more than double his projected shares of global GDP for the United States and the European Union combined.

The media has responded to China's rise in much the same way that it did to Japan's. In fact the familiar mix of admiration and fear is often coming from the same reporters, politicians, and academics that were raising the alarm bells in the 1980s (Porter 2005). Once again the rise of an East Asian economic power is often discussed in relation to concerns about the waning power of the United States. While the boom years of the 1990s briefly put to rest discussions of the inevitability of America's hegemonic decline, recent events have once again brought these discussions to the forefront. In 2002 Joseph Nye, for example, suggested the globalization and technological advances were undermining American influence globally (Nye 2002). In 2004 Fred Kaplan, pointed to America's growing debt, as well as its inability to translate its dominant military power into influence, as evidence of its waning international power. And In 2011, John Ikenberry announced "There is no longer any question: wealth and power are moving from the North and the West to the East and the South, and the old order dominated by the United States and Europe is giving way to one increasingly shared with non-Western rising states" (56).

Many of these discussions focus on the potential of states like China either to undermine American hegemony or to displace the United States altogether. In 2004, Jason T. Shaplen and James Laney reported in the New York Times that in East Asia "China's influence is rapidly rising and America's is rapidly declining," adding that, "the Bush administration still thinks of the United States as the sole superpower in a unipolar world, Tokyo and Seoul do not share this view." In 2008 Christopher Layne wrote "the 
era of American hegemony is drawing to a close right before our eyes. The rise of China is the biggest reason for this."

As was the case with Japan, writers of all kinds have churned out books and articles exploring the extent to which this East Asian success story should serve as a role model to other countries. Many admirers have suggested that the United States could learn a lot from China (Stern 2011; Herbold 2011). Others argue that it would be both impossible and undesirable for western democracies like the U.S. to look toward China for examples of successful practices (Chin and Thakur 2010).

These disagreements tend to focus, in part, on how the so-called "China Model," is defined. There are those who point to general East Asian cultural characteristics as the root of China's success (Mahbubani 2009). Others suggest that China is practicing a form of strong-state developmentalism similar to that successfully practiced by many states throughout history (Overholt 2011; S. Breslin 2011). Critics emphasize that it is the authoritarian/communist government enacting these policies that is the defining element. More significantly, many fear that the Chinese are willfully influencing other states to adopt a model that encourages authoritarianism or discourages free-market principles (Schoolland 2012).

The biggest concern about the spread of the "China Model," for many, is that it threatens American hegemony through undermining American influence. They argue that it will ultimately prove bad for developing countries and for the United States if a "Beijing Consensus," replaces "the Washington Consensus," as an international guide to economic success (Halper 2010). This discourse shows no sign of disappearing any time 
soon and will likely continue as long as the Chinese economy continues to appear stronger and healthier than that of the United States

\section{Trade Issues}

Both in the 1980s and today, fears about America's declining power have frequently focused on America's growing trade deficit. In the earlier case this was the first time the United States had experienced large deficits over a sustained time period. In the latter case the deficit grew so quickly and so dramatically that it soon dwarfed the earlier trade gap (see Figure 3). While a trade deficit has some symbolic significance, Americans tend to view sustained trade imbalances in mostly tangible terms, often making a direct connection between trade deficits on the one hand and job losses and debt increases on the other.

Figure 3 United States-World Trade Balance from 1970-2011

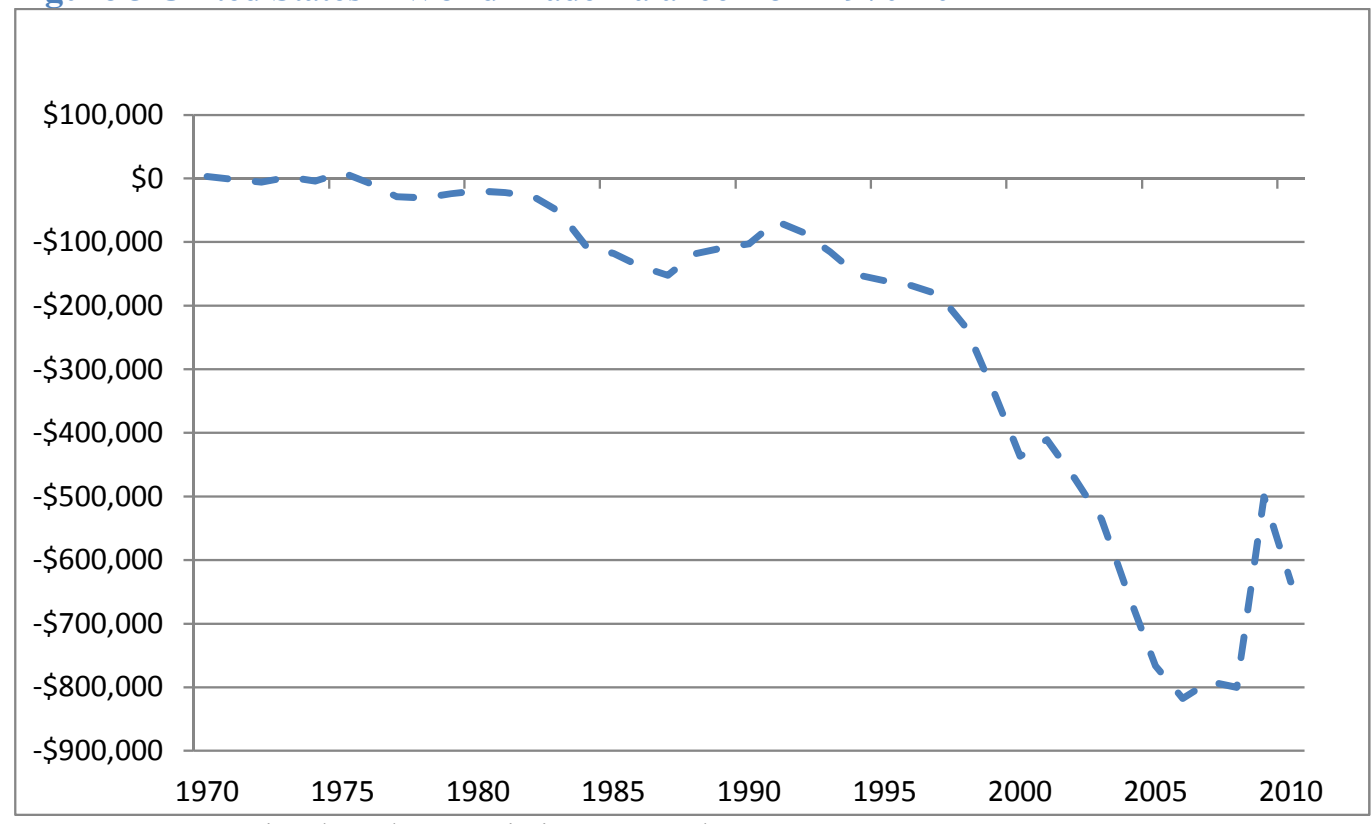

Source: US International Trade Commission Data Web

Admittedly, within American discourse deficit discussions sometimes turn introspective, with analysts and pundits pointing to American interest rates, spending 
habits and declining productivity as causes for concern. Nevertheless, a great deal of this discourse emphasizes the dirty tricks of an Other. While there have been a variety of potential culprits (for example Germany in the 1980s and India today), during each of these periods of economic insecurity, an East Asian economic competitor quickly emerged as the biggest villain. Partly to deflect blame from Americans themselves, the economic competitor has often been accused of deliberately creating and sustaining the bi-lateral trade imbalances that so significantly contribute to the U.S.' large sustained global trade deficit. The accusations have been remarkably similar in both casesranging from cultural causes to the foreign government's inability or unwillingness to solve the problem. Americans have frequently charged each competitor with deliberately employing mercantilist or "unfair," trade policies and have utilized, as evidence, numerous examples of "cheating," by the East Asian companies or their governments. Since Americans have expressed a great deal of concern about the trade deficit in both cases, we might reasonably expect that American' attitudes toward economic competitors would worsen as the deficit increases over time. Since Japan and China have been the countries with which the U.S. has had the largest trade imbalances we could expect that they might take the brunt of American frustrations. Therefore, to the extent that Americans blame East Asian competitors for trade deficits we should expect that American hostility toward each country would increase in tandem with the decrease in trade balance between the United States and the competitor.

\section{U.S.-Japan Trade Issues}

In the early 1970s the United States had intermittent trade deficits and trade surpluses. The first sign of serious trouble appeared in the mid 1970s, when the trade 
deficit almost quadrupled over the previous year from negative $\$ 7,820$ billion in 1976 to a deficit of more than $\$ 28$ billion in 1977. Rather than seeing a return to surpluses The United States saw deficits increase to negative $\$ 106,702$ billion in 1984 and then to negative $\$ 152,119$ billion in 1987 (See Figure 3). While Americans would be thrilled to see trade deficits this low today, in the 1980s these shifts in America's trade were alarming and often seen as indicators of America's declining economic power.

As soon as it became apparent that the days of American trade surpluses were behind them, Americans began voicing concerns about the U.S.-Japan trade gap, which comprised a majority share of the American trade deficit (see Figure 4). Beginning in the late 1970s and continuing into the early 1990s American economists and politicians emphasized the need to close this gap, yet it continued to grow throughout most of this period. There were several reasons given for the inability of Americans to improve their trading position vis-à-vis Japan. Among these were historically low American savings rates, an overvalued dollar, and "unfair" trading practices by the Japanese. The latter became an even bigger source of blame when, in the late 1980s, the value of the dollar dropped but the size of the trade deficit did not. 
Figure 4 United States-Japan Trade Balance 1980-2000

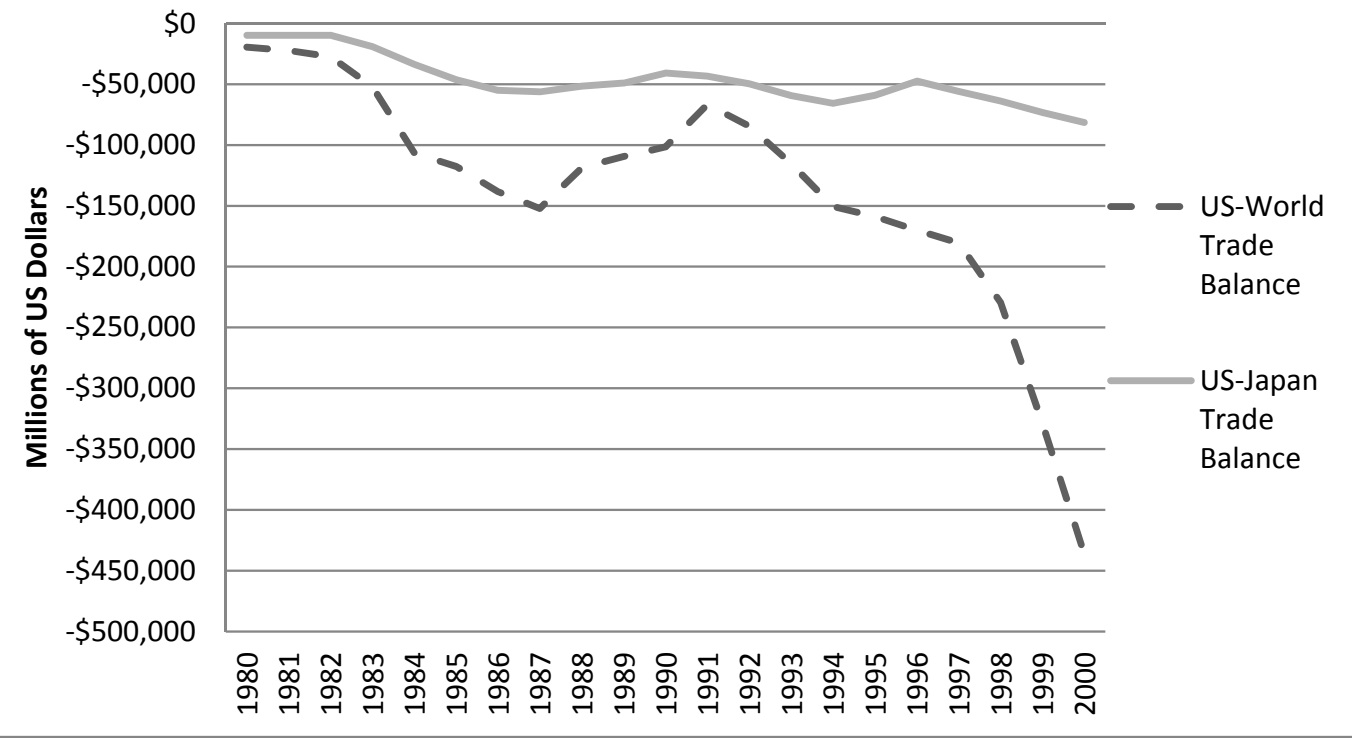

Source: US Department of Commerce Census Bureau *Census Based

While it was generally accepted that Japan did not use illegal tariffs and quotas to protect their markets, this did not mean that Japan was viewed as an open economy. In fact, in 1982 tensions had risen so high that when Foreign Minister Yoshiro Sakurauchi's stated that Japan has 'one of the most open markets in the world,' at a Geneva meeting for the General Agreement on Tariffs and Trade (GATT), he was greeted with open laughter (Pine and Lehner 1983). American businesses frequently complained that the Japanese were guilty of employing numerous non-tariff barriers that in effect, kept their economy closed to American exports.

American anger at the Japanese increased as round after round of negotiations and agreements failed to generate any real changes in the trade balance. Despite the introduction of numerous so-called "market opening packages" Many Americans did not believe that East Asian officials were really trying to solve the problem (Ahearn 1989). For example, the Japanese government introduced three such packages in 1982 and 1983, 
each intended to calm American animosity toward Japan and to prevent the protectionist sentiment from causing a trade war. While each of these was full of measures to reduce both tariffs and non-tariff barriers, Americans were mostly ambivalent in response for three reasons (1) none of the packages addressed American demands that Japan increase its import quotas for important American agricultural products such as beef and citrus (Kanabayashi and Lehner 1983), (2) Americans had come to doubt Japan's ability or willingness to follow through on its commitments, due to poor follow through on previous package promises (Pine and Lehner 1983), and (3) some saw the package as a strategy to ameliorate congressional animosity toward Japan without actually doing anything to solve the problem (Kanabayashi and Lehner 1983). The result of trade negotiations was often dissatisfaction on the part of Americans who felt that the resolutions were too weak, not enforced by the Japanese, and ultimately useless at solving the problems (Nanto 1982).

As the 1980s progressed, trade tensions continued to strain relations between Japan and the United States. It was widely believed that the trade deficit could be resolved through a shift in the yen-dollar exchange rates that would make American exports cheaper and Japanese imports more expensive. The trade tensions ultimately led to the Plaza Accord, an agreement signed in September 22, 1985, between five countries (the United States, W. Germany, Japan, Britain, and France) to intervene in the currency markets in order to depreciate the value of the dollar in relation to other currencies (particularly the Japanese Yen and the German DM). While this controlled depreciation was wildly successful, it did not have the intended effect. The American trade deficit did decline against Europe in general and Germany in particular. On the other hand, while 
there was initial reduction in the trade deficit with Japan, this trend was reversed in 1988, resulting in a resurgence of American frustration toward that country (Sanger 1988).

There are several theories as to why the weakening dollar did not result in a rebalancing of trade between the United States and Japan: The "blame-Japan theory" suggests that there were structural impediments to fair trade. American companies continued to report restricted access to Japan's market, with explanations for these restrictions pointing to everything from social and cultural causes to political and economic differences between Japan and the United States (Ahearn 1989). Some pointed to increases in Japanese productivity, which far outpaced productivity increases in the U.S., while others argued that American companies were to blame for not taking advantage of the new opportunities (Sanger 1988).

While trade tensions were never officially resolved, the dispute lost much of its steam as the 1990s progressed. The reasons for this are many including the increases in Japanese Greenfield investments in the United States that led to the creation rather than the exportation of American jobs, the improving conditions of the American economy in the late 1990s, and the worsening conditions of the Japanese economy during the same period. Ultimately, the United States trade deficit with Japan remained approximately the same size throughout the 1990s and the 2000s but became a much smaller percentage of the overall deficit as Americans increased their imports from other countries. Among these other countries, China quickly became the most significant.

\section{U.S.-China Trade Issues}

Americans first became concerned about Chinese economic power due to dramatic shifts in the trade balance between the two countries. This trade deficit wasn't 
really an issue, however, until the late 1990s. The United States experienced its last trade surplus in 1975, and by 1990 Americans had become somewhat accustomed to having a trade deficit. In fact, the United States' general trade deficit began to decrease in 1988, reaching just under $\$ 67$ billion in 1991 . When the deficit began to grow again, the pace was initially quite slow and garnered relatively little media attention. However the rate of deficit increase accelerated at the turn of the millennium, doubling from negative $\$ 233$ billion in 1998 to negative $\$ 470$ billion in 2002 and almost doubling again to just under $\$ 818$ billion in 2006 (see Figure 5). As would be expected this was a cause of great alarm, and just as they had done with the Japanese in the 1980s, Americans sought someone to blame. China was the obvious scapegoat.

Figure 5 United States-China Trade Balance 1985-2011*

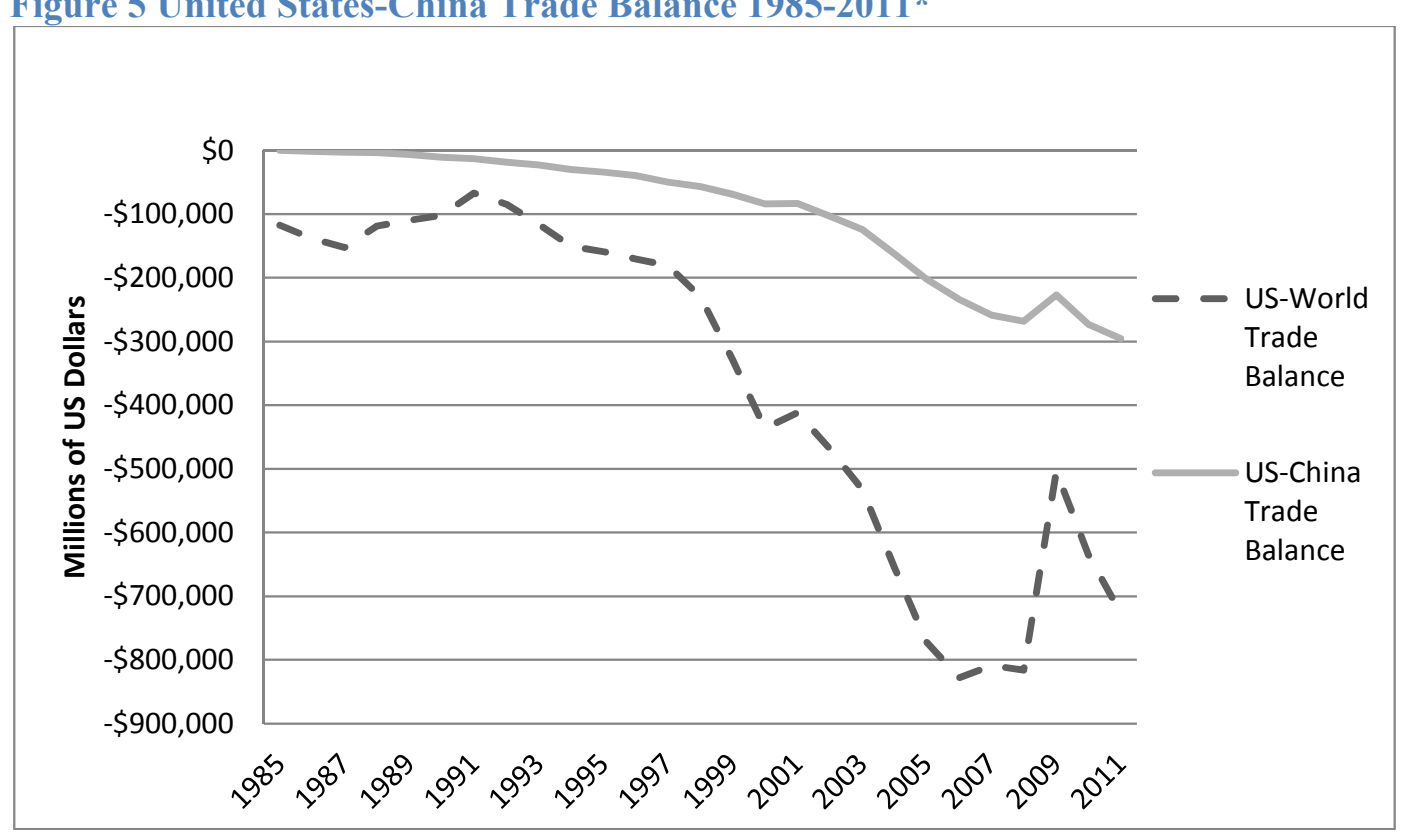

Source: US Department of Commerce Census Bureau *Census Based

It seemed as if almost overnight "made in China" became synonymous with "cheap products." As Chinese goods began to dominate the shelves of American retailers like Target and Wallmart, Americans began worrying that cheap labor in China was 
causing an exportation of American jobs. This discussion was further exacerbated by the increasing number of American factories being opened in China. While economists typically point out that these manufacturing jobs were actually moving from other parts of the developing world, and had left the United States long before, the popular media tended to add the increase of American FDI into China to the increasing trade deficit and conclude that China's cheap labor, and undervalued currency equaled American unemployment. One final factor that contributed to this discourse was the ubiquitous conversation about China's potential, and then actual, membership to the WTO in 2001. In 2000, as Congress debated whether to permanently normalize trade relations with China, the final obstacle in China's bid for accession to the WTO, the national discussion focused on whether Chinese membership would be in America's best interest. Critics never hesitated to point to the trade deficit, often speculating that this deficit would only worsen with Chinese WTO membership (Levinson 2000; Francis 2000; Chandler 2000).

Considering the growing importance of the Chinese market to the American economy over the last decade, it is far less common for pundits, analysts, and business people to complain that China is a closed economy than it was in the case of Japan. Nevertheless there are those that complain that Chinese companies have an unfair advantage over American companies both within China's market and abroad (Samuelson 2009; Bradsher 2012).

Again currency issues play a dominant role in discussions about the trade deficit. Despite the fact that a similar effort did not have the intended effect when applied in the late 1980s, many observers believe that the trade imbalance could be successfully addressed through a shift in the Yuan-Dollar exchange rates (Krugman 2011). One 
important difference in this case is that, unlike the floating exchange rate of the yen, China has a type of managed float known as a crawling peg. While the United States government has come short of officially accusing China of currency manipulation, most observers agree that Chinese intervention in the currency market is keeping the Yuan far below a fair market value, thus giving Chinese exporters an unfair advantage over American exporters. Frequent accusations that China is winning by "cheating," challenge American beliefs about fair play, and equal opportunities for all (Romney 2011).

This fervor over the China-U.S. trade deficit is far from over. However it did lose some of its steam in the late 2000s as the U.S. trade deficit halted in 2006 and showed decreases in 2007 and 2009 (see figure 5). Additionally, as time has progressed and China proved itself to be a reasonably responsible member of the WTO, its trade relationship with the U.S. has become a somewhat less contentious issue. ${ }^{22}$ While future increases in the trade gap are likely to spark new hostilities toward China, economic fears have recently focused on different aspects of the economic relationship. Therefore, to the extent American conceptions of economic threat are primarily driven by trade concerns, we should expect that attitudes toward China should dip dramatically in the late 1990s and begin to rebound slightly in 2007.

\footnotetext{
${ }^{22}$ There are generally mixed views as to how well China has complied with its WTO obligations. Some observers have been significantly impressed with Chinese progress (Bhat 2009). On the other hand, some, including the American government have increasingly expressed frustrations. The US-China Relations Act of 2000 requires the United States Trade Representative (USTR) to annually compile a report to Congress assessing China's WTO compliance. While acknowledging China's many accomplishments since its accession to the WTO in 2001, these reports tend to focus on areas where China has failed to meet its obligations. Two of the biggest complaints are China's lack of transparency and its continual infringement on intellectual property rights (U.S. Trade Representative 2003, 2011).
} 


\section{Foreign Investment and American Debt}

The third factor that is likely to have a negative impact on American attitudes toward these countries is the perception of each as "buying" America. From 1978 to 1984 the United States national debt to foreigners almost tripled from $\$ 98$ billion in 1978 to $\$ 268$ billion in 1984 . Five years later it had tripled again to $\$ 847$ billion. The increases in debt continued through the 1990s and by 2000, Americans owed foreigners more than three and a half trillion dollars. Over the last decade it has continued to rise with the United States owing more than $\$ 10$ trillion dollars in short and long term securities to foreigners by 2008 (see Figure 6).

Figure 6 Foreign Holdings of US Long Term Securities 1974-2010

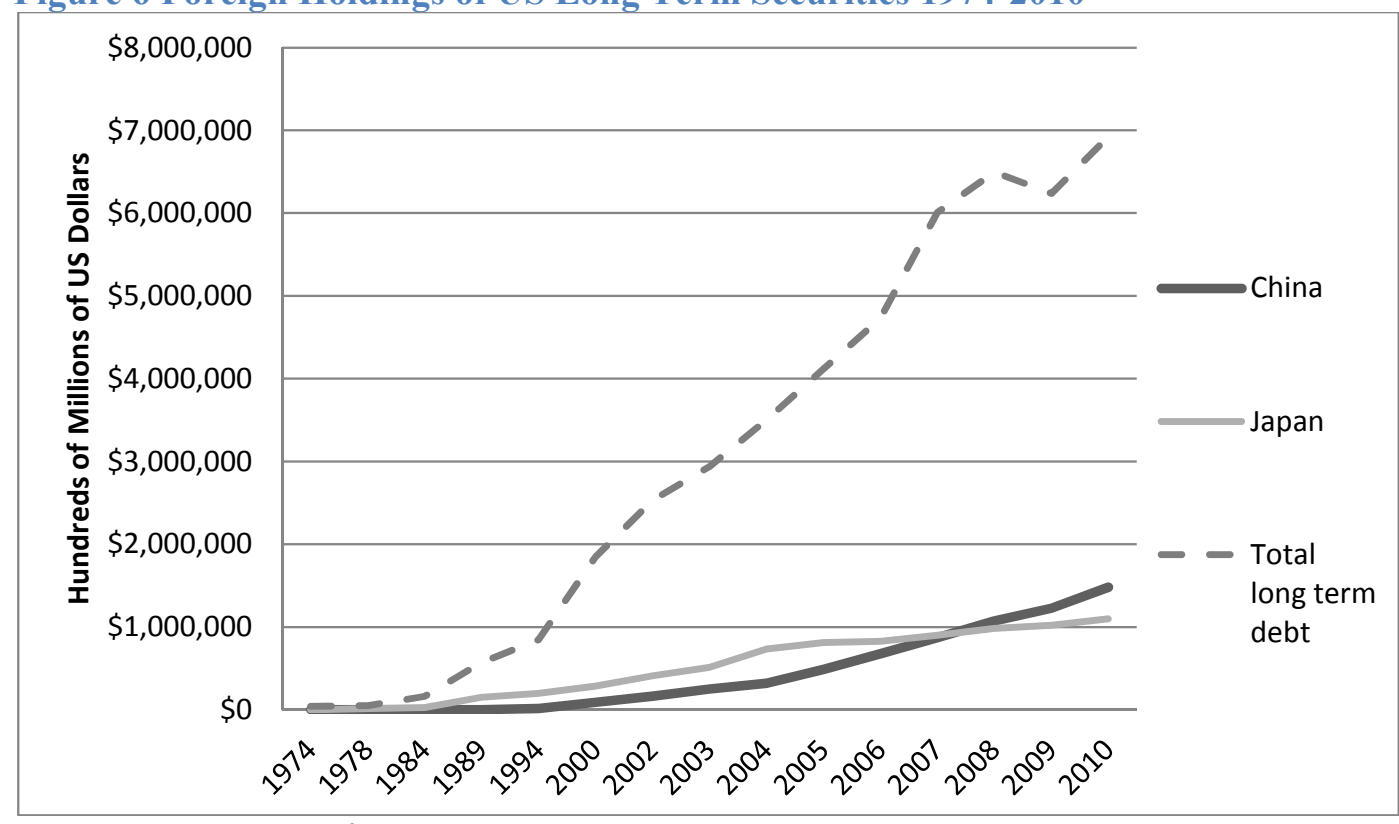

Source: US Department of Treasury

* Based on survey results available for 1974, 1978, 1984, 1989, 1994, 2000, and 2002-2010

This debt has impacted Americans in a number of ways. It threatens Americans' sense of self in addition to their economic security. The debt is often touted as a sign of growing American weakness and has elicited perennial concerns about the stability of the dollar. Since the 1980s, Americans have been subjected to periodic threats that the 
dollar's special international status is likely to be revoked if the debt is not dealt with. The result may be anxiety both about America's economic stability and its hegemonic status. In addition, the perceived economic dependence of the United States on economic competitors is often seen as humiliating. Lastly, the debt issue has not only caused Americans to feel economic insecurity but, in both cases, has been touted as a potential national security issue.

Japanese Investment

The Japanese have always been one of the biggest purchasers of American debt. In fact despite the relative lack of media attention when compared to China, Japan has remained one of the most important purchasers of long and short term American securities over the last decade. As the American debt increased in the late 1970s and throughout the 1980s, Americans voiced serious concerns over Japanese investments in the United States. However, while concerns about portfolio investment were present throughout this time period, they existed mostly on the fringes of discourse, in academic and policy circles. The popular imagination was much more inflamed by high rates of Japanese direct investment, particularly in the late 1980s when the yen rose against the dollar and American assets became a relatively cheap investment for Japanese businessmen.

Some of the problems of the late 1980s were the result of unintended consequences of previously signed trade agreements. The Plaza accords raised the value of the yen which did not have the significant long term impact on America's trade balance that was expected. On the other hand, it did serve to give Japanese investors incentives to invest in the United States rather than at home and it gave Japanese 
companies incentives to export cash rather than goods. Ultimately they found it better to enhance market share through acquisitions and mergers in the U.S. rather than through domestically produced exports. This did little to improve the relationship and actually contributed to rising American hostility toward Japan

In the early 1980s Japan had only been the seventh biggest direct investor in the United States, but by 1988, it had surpassed Canada to become the second biggest investor behind Great Britain (see Figure 7). What was perhaps more significant than the rate at which Japanese capital flooded into the United States was the types of assets the Japanese were buying. Many of these had symbolic importance. Some examples include the acquisition of Colombia Pictures in 1989, controlling interest in Rockefeller Group which owned Rockefeller Center and Radio City Music Hall and the Regal Biltmore Hotel in Los Angeles which was famous as the birth place of the Academy awards (Douglas and Collins 1989, 2-3).

Figure 7 Japanese Direct Investments in the United States 1980-1995

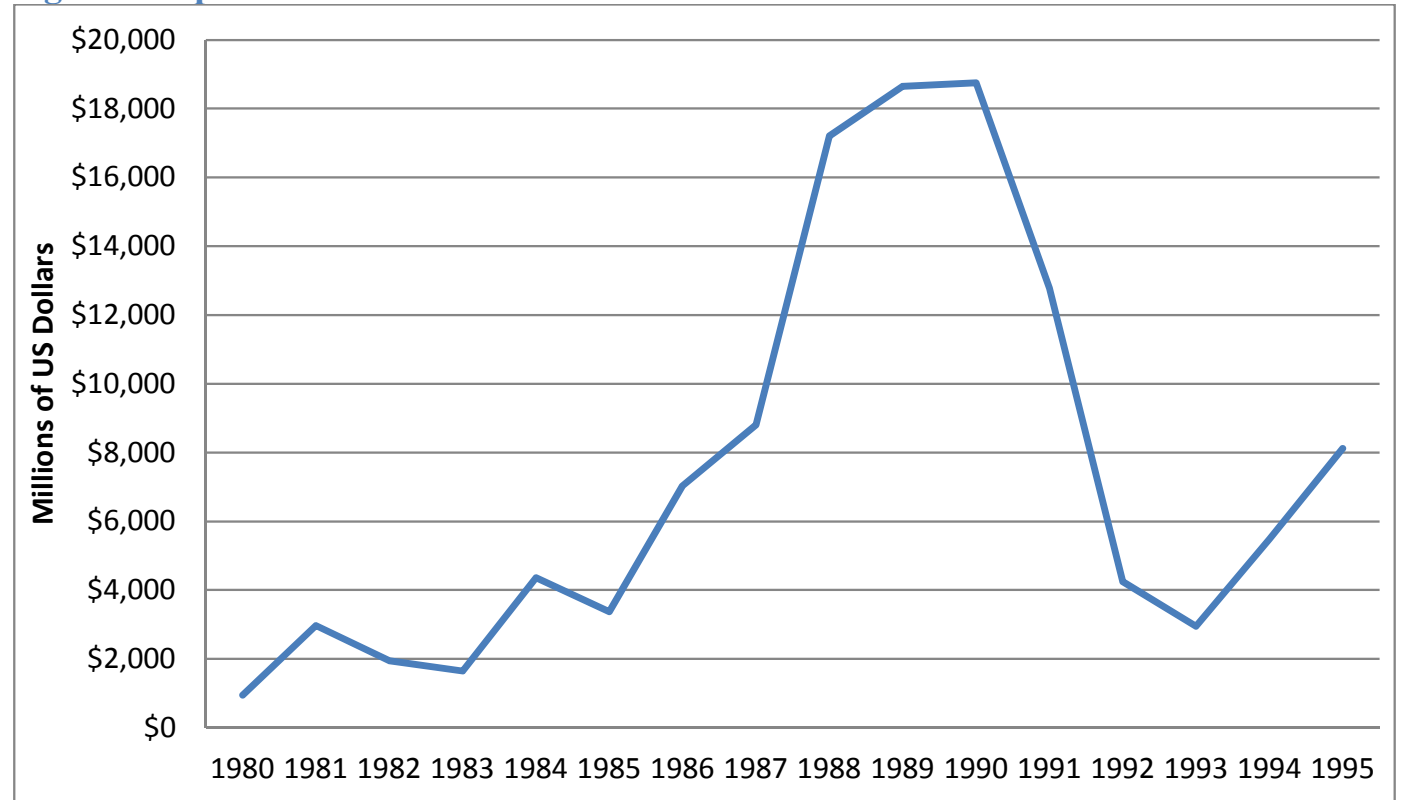

Source: US Department of Commerce Bureau of Economic Analysis

*Financial inflows without current cost adjustment 


\section{Chinese Investment}

Chinese direct investment in the United States has remained paltry, when compared with that of Japan in the late 1980s. Peaking at \$1,169 million in 2010 (a tiny fraction of the Japanese peak of $\$ 18,754$ million in 1990), it dropped back down to $\$ 576$ million in 2011. The American media has been fairly quiet on the issue of Chinese FDI with the exception of a brief uproar in 2005, when China's state-owned oil company CNOOC put in a competitive bid to purchase the American oil company UNOCAL. Even though total Chinese direct investment in the United States was only \$146 million at this time, the national response to this particular bid was highly vocal and highly negative. The purchase of American oil reserves by what was essentially the Chinese state was perceived by some as a national security threat (Berman and Gold 2005; Brownstein 2005; Grier 2005; Richter 2005). This move brought a successful bid by Chinese company Lenovo Group Ltd. to take over the personal computing section of IBM in 2004, as well as an unsuccessful bid by the Chinese company Haier to purchase the American appliance company Maytag in 2005, into the public discourse. Concerns about surging Chinese FDI proved unfounded, however, and the media quickly turned its attention back to the much larger issue of Chinese portfolio investment in the United States.

Even though the U.S. has only just begun to borrow from China, the latter has quickly become the biggest foreign source of American revenue (See Figure 8). China became a net creditor in 2003 and its net foreign assets passed the trillion dollar mark in 2007. According to the 2011 Report to Congress on International Economic and Exchange Rate Policies, China’s state sector currently holds approximately $\$ 3.4$ trillion 
in foreign currency assets (U.S. Treasury Department 2011a, 15). While the average American may not fully understand the nature of this relationship, the fact that the United States is in debt to China has become painfully clear. It would have been difficult for even the most apathetic American to remain ignorant of the heated congressional debate about raising the debt ceiling in 2011. As this fierce political disagreement took center stage in American discourse, references to China as America's banker became ubiquitous.

Figure 8 China's Holdings of US Treasury Securities as a Percent of Total Foreign Holdings

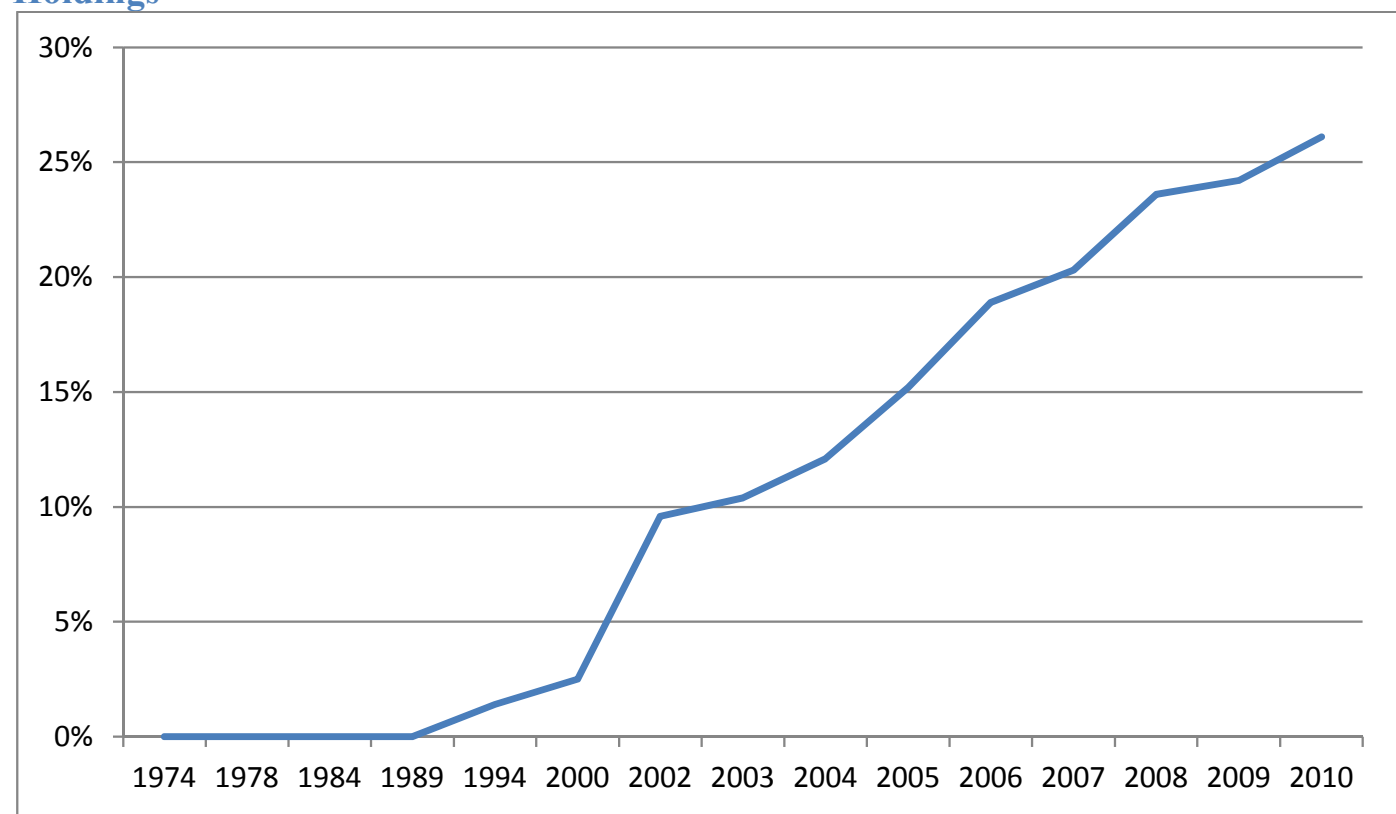

Source: U.S. Treasury Department: year-end data and annual surveys of foreign held Securities

It remains to be seen how these concerns affect public attitudes toward China. The average American may not fully comprehend the debt-creditor relationship that currently exists between the two countries. Yet the implication that this relationship gives China too much power over the United States is certainly becoming an important component to the American China discourse. It is reasonable to assume that this might lead Americans to feel animosity toward its Asian banker. To the extent that concerns 
about this issue outweigh other economic concerns we should expect a dip in American attitudes toward China beginning sometime after 2003.

\section{Attitudinal Response to Economic Threat}

How do Americans respond to these threats? To answer this question, I examined a large set of polling data from 1977-2010 for each case. Since no polling institution has annually asked Americans how they feel about either country for the entire period under analysis, my study utilizes data from 93 different polls or surveys, conducted by 19 different organizations and agencies. ${ }^{23}$ Searching for those questions, which best elicited American attitudinal responses to Japan and China, I eliminated questions in which either the wording or the answer options were unique enough to elicit atypical responses. To see a list of polls and surveys used refer to appendices A and B. There were some years in which several different polling agencies asked the same question about American attitudes. To address the discrepancy in data volume, all results were averaged together for each year in order to make a single data point. Lastly, to make various polling data as comparable as possible, I eliminated all noncommittal responses such as "I don't know," "no opinion," and "neutral," leaving only positive (i.e. "favorable," "mostly favorable,") and negative (i.e. "unfavorable," "mostly unfavorable") responses. Figure 9 displays the trend in attitudes toward Japan from 1977-2011 and Figure 10 displays the trend in attitudes toward China from 1977-2011. ${ }^{24}$

\footnotetext{
${ }^{23}$ The survey results reported here were obtained from searches of the poll Databank and other resources provided by the Roper Center for Public Opinion Research, University of Connecticut.

${ }^{24}$ Since what we are looking for are trends in American attitudes over a lengthy period of time, a trend line has been imposed on figures 9 and 10 to demonstrate the two year moving average.
} 
Figure 9 American Attitudes toward Japan 1977-2010*

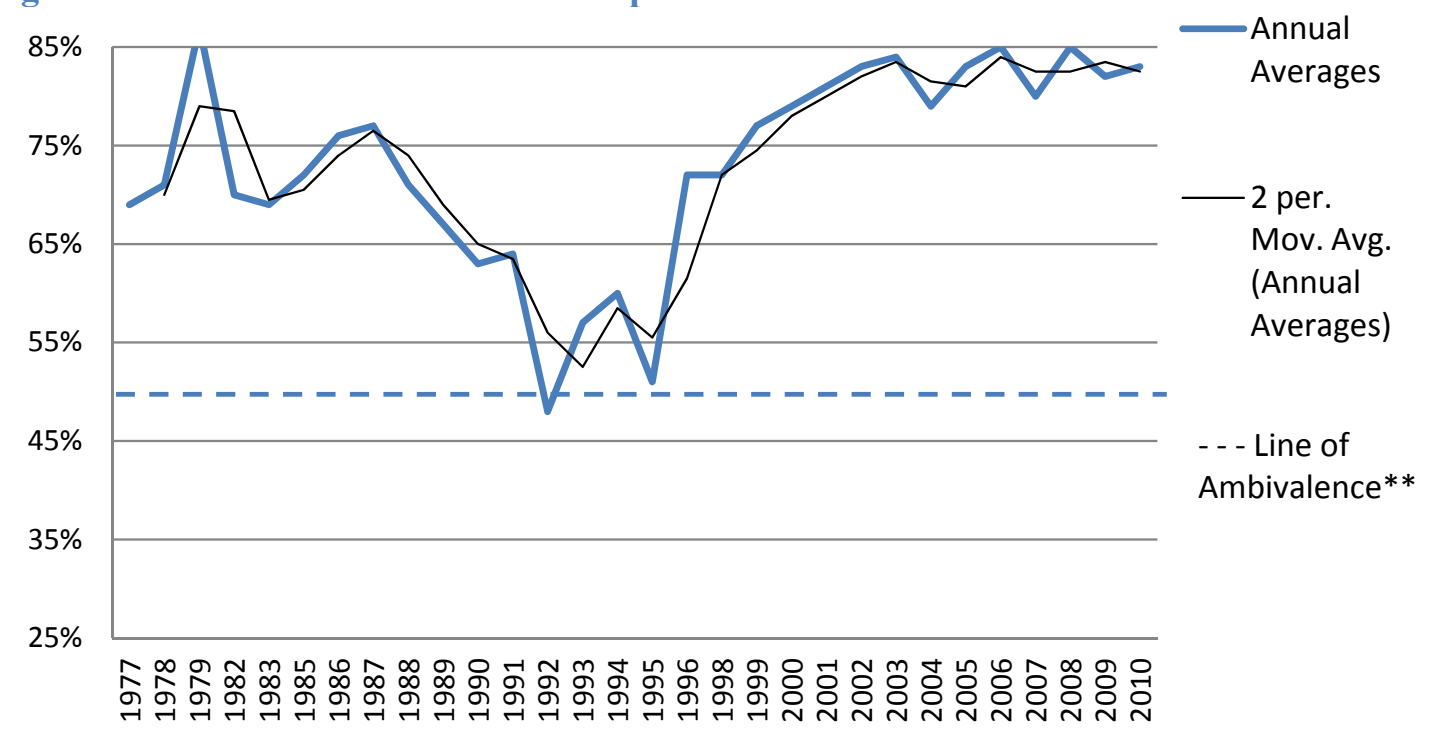

Source: i-poll database

*Positive responses as a percentage of all responses excepting "neutral" or "I don't know"

**Line at which an equal percentage of respondents expressed favorable and unfavorable opinions

Figure 10 American Attitudes toward China 1977-2011*

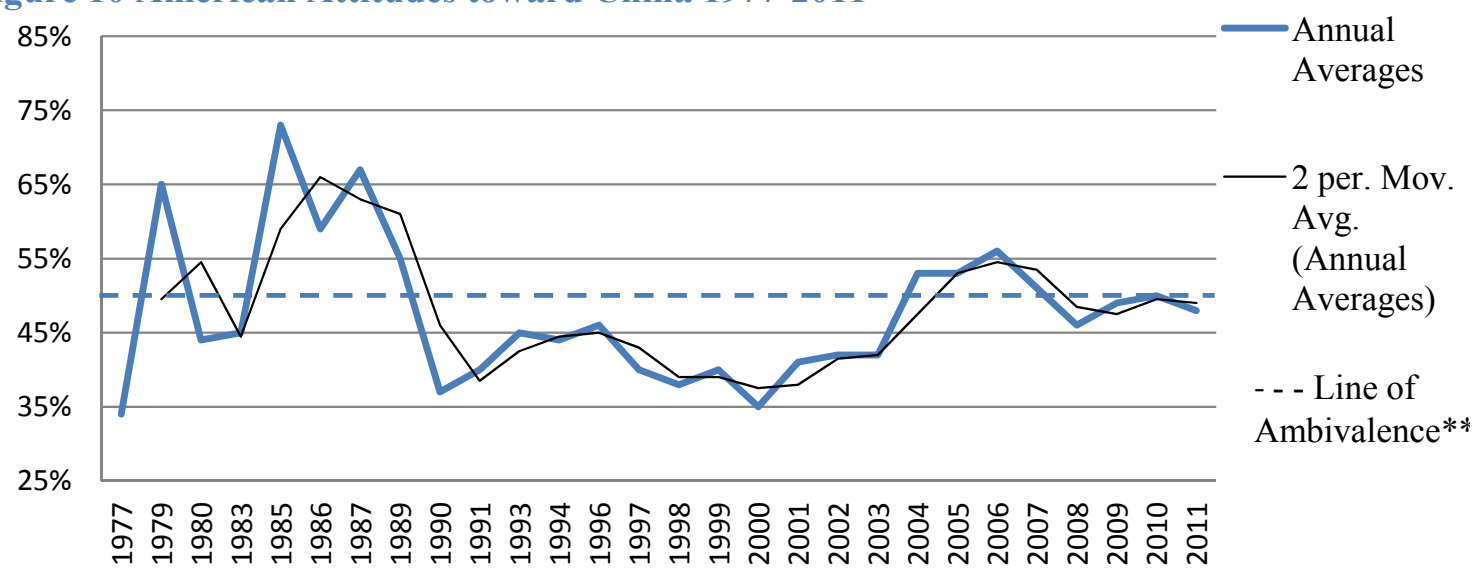

Source: i-poll database

*Positive responses as a percentage of all responses excepting "neutral" or "I don't know"

**Line at which an equal percentage of respondents expressed favorable and unfavorable opinions

\section{Discussion}

While American attitudes toward Japan appear somewhat volatile in the early 1980s, it is impossible to get a certain picture of what was happening then due to a dearth of available polling data. What is clear is that the percentage of Americans who felt positively toward Japan doesn't dip below 70\% until 1986. At this point attitudes show a 
downward trend that bottoms out in 1992 when less than half of respondents express a favorable attitude toward Japan. We then see a gradual climb in positive attitudes toward Japan throughout the 1990s, with positive attitudes resting just above $80 \%$ throughout the 2000s.

In some ways the evolution of American attitudes toward Japan mirrors what was happening in the economic milieu, thus supporting hypothesis \#1, which predicts that American attitudes toward economic competitors are predominantly shaped by shifts in the competitor's economic capabilities. On the other hand, American attitudes toward China do not appear to support this hypothesis. In the latter case we see that the biggest changes in American attitudes precede China's economic rise. Throughout the late 1980s we see attitudes improving in tandem with American rapprochement with China and then we see attitudes dip sharply in response to the government-led massacre in Tiananmen in 1989 (Hirshberg 1993b). Since China could not reasonably be considered an economic competitor of the United States until the 1990s, it is at this point that trends become relevant to hypothesis \#1. However, while we do see declining attitudes in the late 1990 s, these attitudes actually rise as competition heats up in the early 2000s.

This discrepancy does not necessarily undermine hypothesis \#1. There are several reasons to believe that increases in Chinese economic capabilities will eventually lead to rising American hostility toward China, just as it did with Japan. First, since the emergence of both trade frictions between Japan and the United States, and perceptions of Japan as a hegemonic threat, preceded rising hostility toward Japan by well over a decade, we might surmise that American attitudes toward economic competitors shift slowly and only in response to sustained threat over an extended period of time. 
Subsequently we might expect that American attitudes toward China are just delayed and we are soon likely to see the rising hostility toward China that characterized American attitudes toward Japan from 1986-1992. ${ }^{25}$

Second, one economic indicator, increases in Japanese foreign direct investment (FDI), corresponds particularly well with American attitudes toward Japan. We might therefore expect increased Chinese FDI into the United States to have a similar effect. In both cases Americans saw rapid increases in debt and in both cases the East Asian competitor purchased a great deal of that debt. While Chinese purchases of American treasury securities have garnered far more media attention than similar Japanese purchases ever did, in both cases, American attitudinal responses are either delayed or minimal. On the other hand, to the extent that the Japanese case serves as a good example, we can predict that, if the Chinese shift their investment strategies toward the actual purchases of American businesses, we will see much more hostility. In the mid 2000s we saw some limited attempts by the Chinese to invest directly in the United States and while these attempts did not result in significant attitudinal shifts, they did result in a large public outcry. If the Americans succeed in pushing the Chinese to significantly appreciate the Yuan, we might see continued efforts in the future.

Last, an economic factor that not only distinguishes China from Japan, but also from other typical cases of economic competition against the United States, is the fact that China is, in many ways, still a developing country. While Americans likely feel just

\footnotetext{
${ }^{25}$ While its too soon to tell, the slight dip in attitudes toward China in 2008 (see figure 10), might be an indication that American attitudes are beginning a similar downward trend. Of course this may also be a short-term response to the economic insecurity arising from the 2008 financial crisis. The trend in attitudes from an average of $51 \%$ positive in $2007,46 \%$ in $2008,49 \%$ in 2009 , and $50 \%$ in 2010 , suggests that this latter explanation is the most likely.
} 
as threatened by the Chinese as they did the Japanese, in terms of rising economic power, the Chinese do not compete with the United States directly. It is difficult to measure how much of an impact direct Japanese competition, in important industries like automobiles, and semi-conductors, had on the American psyche. Even though typical Chinese competition has been in low-tech, high labor industries, in which the United States does not have a comparative advantage, this is likely to change.

China, like Japan before it, has been slowly moving up the production ladder. While the United States has traditionally imported low-value, high labor products from China such as textiles and toys, the import mix has been gradually shifting toward advanced technology products (ATP). According to the U.S. Census Bureau, the percentage of American imports from China that were ATPs jumped from 19.2\% in 2003 to $23.4 \%$ in 2010 (Morrison 2011, 8). While the early 2000s saw Chinese competition hurting countries with advantages in labor intensive low value goods, especially Mexico and countries throughout Central America, China has lately been taking increasing market shares from industrialized countries. For example, Japan's share of electronic exports to the United States has dropped from 18\% in 1999 to $7 \%$ in 2009; much of this has been blamed on Chinese competition (Barboza 2009). ${ }^{26}$ While the majority of Chinese exports compete with countries other than the United States, there is sufficient evidence to suggest that this could change quickly. The PRC has explicitly stated its intention to support industries in which the United States currently has, or hopes to soon have, a competitive advantage. These include biotechnology, alternative energy, next-

\footnotetext{
${ }^{26}$ One of the reasons for this shift in the makeup of Chinese exports is China's position in the global value chain as the country of final assembly. Therefore China is credited with exporting goods that have been largely manufactured elsewhere, suggesting that perhaps China is not advancing as quickly as it appears at first glance.
} 
generation information technology, and clean energy vehicles (Casey and Koleski 2011,

8).

This analysis neither proves nor disproves Hypothesis \#1. What it does do however, is demonstrate how we might look at American responses to economic threat emanating from Japan in the 1980s and 1990s in order to better understand and predict how Americans are likely to respond to future sustained economic threat emanating from other economic competitors in general and from China in particular. ${ }^{27}$ The predictions gained from such an exercise are pretty grim. If Americans respond to economic threat from China in the same way that they responded to economic threat from Japan, then all signs point to rising hostility in the years to come. On the other hand, the extent to which these predictions are relevant depends on a better understanding of how this one factor (economic capabilities) interacts with other relevant factors (military capabilities, threat or opportunity, and political culture) to shape American attitudes. This interaction is explored in chapter four.

\footnotetext{
${ }^{27}$ The Japan case offers other lessons that may be helpful in successfully managing economic relations between China and the United States. For example, many of the problems plaguing the Japan-US relationship in the late 1980s were the unintended consequences of agreements meant to resolve earlier issues. The Plaza accords, for example, led to increases in Japanese direct investment, which greatly contributed to rising hostility in the United States. So-called Voluntary Export Restraints also had negative consequences (Sanger 1988). In the auto industry, as the supply of Japanese cars was reduced the price increased. This was also a result of the 1986 Chip agreement. While the reduction in exports of Japanese made chips did not result in the expected re-emergence of an American chip producing industry, it did lead to a reduction in the number of Chip producers in Japan. As the limited supply of chips threatened the American computer industry prices increased dramatically. The result was a Japanese "cartel" of chip producers that continued to limit production even after the Americans no longer saw this as a positive (Pollack, 1988).
} 


\section{WHAT OTHER FACTORS EXPLAIN AMERICAN ATTITUDES TOWARD ECONOMIC COMPETITORS?}

The previous chapter provides three important questions that will be addressed in this chapter. First, what accounts for the lack of negative attitudinal responses to the rising economic capabilities of Japan and China? American attitudes fail to trend downward, for sustained periods of time, despite changes in the Other's economic capabilities. While hostility toward Japan begins to rise in the latter half of the 1980s, this is after more than a decade of increases in Japan's economic capabilities, which resulted in trade tensions and Americans' hegemonic insecurity. In the case of China, attitudes have actually trended in a positive direction, especially since 2001 , even as increases in Chinese economic capabilities have brought the China threat debate to the forefront of American discourse. One explanation for this was suggested in the previous chapter: American attitudes may be relatively stable over time and it might subsequently take decades of increases in a competitor's economic capabilities before Americans' images of that competitor actually begin to shift. An alternative explanation however, is that increases in economic capabilities have a weaker impact on American attitudes toward Others, than do other factors such as increases in military capabilities, perceptions of the relationship between the United States and the competitor, or perceptions of the Other's political culture.

A second question is: what accounts for the disparity in attitudes toward two different economic competitors that each provides such similar types of economic threat? Admittedly, as discussed in chapter three, there may be similarities in the way Americans are responding to these two cases that have not emerged yet. While in many ways 
perceptions of China's economic capabilities rival perceptions of Japan's capabilities in the 1980s and early 1990s, there were facets of the Japanese threat that are only just beginning to emerge in the case of China. Specifically these include increases in direct Chinese competition with American dominated industries and increases in direct Chinese investment in the American economy. On the other hand, attitudes toward China are, in two ways, significantly different than attitudes were toward Japan. First, attitudes toward China have been trending in a positive direction over the last decade (see Figure 10). Second, attitudes toward China are, generally more negative than attitudes toward Japan during the entire period under investigation. If we look at all polling data available from 1977-2010, we find that on average 48\% of Americans feel favorably toward China. If we do the same for Japan during the same time period we find that on average $73 \%$ of Americans feel favorably toward Japan. What accounts for these differences? The previous analysis of each country's evolving economic capabilities offers no clues. Again, it seems likely that other factors such as increases in military capabilities, perceptions of the relationship between the United States and the Other, or perceptions of the Other's political culture, are having a dominant impact on attitudes.

The third question that this chapter seeks to answer is: assuming that American attitudes toward economic competitors are changeable, what factors are likely to precipitate that change? Chapter three offers some clues to the answer and suggests that, to the extent that economic capabilities drive American attitudes, we should expect Americans to become more hostile toward China in the near future, either as a delayed response to sustained economic threat, or as a response to increases in direct Chinese investment or direct Chinese competition in manufacturing. These findings raise an 
important question, however, as to the extent to which this independent variable (economic capabilities) acts and inter-acts with the other independent variables described above. To answer these questions, I present the results of a social psychological experiment designed to test the independent and interactive effects of these variables on American attitudes toward other states.

\section{The Experiment}

This chapter reports the results of a social psychological experiment in which subjects are first exposed to a series of scenarios describing relations between the United States and a hypothetical Other and then asked to report their feelings toward that Other.

${ }^{28}$ While this type of experiment is relatively common in psychological studies it is somewhat rare in IR. Nevertheless, social psychological experiments have been used successfully by IR scholars to test cognitive factors that help to explain international conflict or cooperation. These include: the determinants of regime perception and the extent to which foreign policy and perceptions of similarity (between Self and Other) affect public approval of the use of force (Geva and Hanson 1999), the nature of images and the links between these images and foreign policy approval (Herrmann, et al. 1997), the extent to which individuals are concerned about relative (as opposed to absolute) gains under varying circumstances (Rousseau 2002), and the impact of value similarity and power on perceptions of threat (Garcia-Retamero, Muller and Rousseau 2012). Each of these studies has provided knowledge that might be unobtainable through alternative

\footnotetext{
${ }^{28}$ The experiment was approved for the use of human subjects by the Institutional Review Board with an "Exempt" status. The IRB approval number was 120109-03.
} 
methods, and has demonstrated the value of experimentation as an important tool for the IR scholar.

The current experiment is divided into three parts, each of which is designed to answer the questions raised in chapter three and to test the three hypotheses laid out in chapter two. ${ }^{29}$ Part I tests the extent to which subject responses to hypothetical Others is determined by (1)whether they are seen as a threat or as an opportunity, and (2) whether they are perceived as having a similar or different political culture. Assuming that subjects are likely to have some degree of concern regarding increasing capabilities, part II tests whether either or both of the first two variables are likely to have a moderating impact on that concern. While many of the subjects were not even alive to react to the rise of Japan in the 1980s, it is possible to determine the extent to which subject attitudinal responses predicted in parts I and II actually fit attitudinal responses to China. In order to accomplish this, Part III of the experiment measures the relationship between subject perceptions of China and subject attitudes toward China and compares these findings with those found in parts I and II.

The experiment was designed to test how three independent variables perceptions of the Other's capabilities, perceptions of the relationship between the United States and the Other, or perceptions of the Other's political culture, affect individual attitudes towards Others. Participants were student volunteers from "Introduction to International Relations" courses at Florida International University. 123 students participated; two

\footnotetext{
${ }^{29}$ Hypothesis \#1 predicts that American attitudes toward China should become more hostile as China's capabilities increase relative to the U.S. Hypothesis \#2 predicts that American responses to China should be determined by the degree to which China is seen as a threat or as an opportunity. Hypothesis \#3 predicts that American responses to China should reflect perceptions of the political culture of the Chinese government.
} 
surveys were later removed resulting in an $\mathrm{N}$ of $121 .^{30}$ There were 60 males and 61 females. $91.7 \%$ of subjects were between the ages of 17 and 26.64 subjects identified themselves as American. ${ }^{31}$

The problems of ensuring external validity when using a student sample of this kind are well known. It could easily be argued that the specific characteristics of the subject pool such as age, education level and nationality might make it difficult to generalize the results. Many IR scholars have addressed this problem through replicating their experiment with different populations (Garcia-Retamero, Müller, \& Rousseau, 2012; Geva \& Hanson, 1999; Mintz \& Geva, 1993; Rousseau, 2002). The current study uses alternative methods to test for external validity. For parts I and II of the experiment a MANCOVA test was conducted which revealed that age, level of education and nationality had no significant impact on results. Since part III investigates how Americans feel about China, separate analysis was conducted focusing solely on the American sample. In addition, the results of this experiment were compared with the results of a Gallup Poll conducted during the same month and year, which showed that in terms of one key variable — attitudes toward other countries - the subject pool was typical of Americans in general (See Figure 16).

\footnotetext{
${ }^{30}$ The first questionnaire was removed because the subject had participated in an earlier post-survey discussion and was therefore aware of the purpose of the experiment. The second questionnaire was removed because it was incomplete.

${ }^{31}$ Some subjects demonstrated confusion about the term "nationality," describing ethnicity instead (i.e. white, Hispanic, anglo-hispanic) suggesting that the number of Americans might actually be higher. Two subjects did not respond
} 


\section{Part I the Impact of Threat, Opportunity, and Political Culture on Attitudes}

The first part of the experiment was designed to test the independent and interactive impacts of threat or opportunity, and political culture on subject attitudes. For the sake of clarity, each variable was operationalized into a dichotomous pair representing the positive and negative extremes. To prevent the distorting impact of previously established images, variables were abstracted through reference to hypothetical countries. An example of each manipulation is given in Appendix C.

The decision to separately measure the impacts of both factors in each milieu led to the creation of two separate tests, each with a factorial design of 2 (political culture) $\mathrm{x}$ 2 (relationship). The current study had a nested $2 \times 2 \times 2$ design with the third factor (economic or security milieu) being a within-subjects factor. Subjects were asked to read two scenarios: one describing positive or negative economic relations with an authoritarian or democratic state, and the other describing positive or negative security relations with an authoritarian or democratic state. To control for order effect, variable order was systematically mixed for each scenario. After each scenario subjects were asked to respond to a number of questions designed to determine the attitudinal impact of both factors within each milieu. First, subjects were asked to give their feelings toward each hypothetical state according to a 7 point Likert scale, with responses ranging from "very favorable" to "very unfavorable.",32 Subjects were then asked to explain the reasons behind their answers.

\footnotetext{
32 The questionnaire was designed so that " 1 " corresponded with "very favorable" and "7" corresponded with "very unfavorable." The intermediate response categories were "favorable," "somewhat favorable," "neutral," "somewhat unfavorable," and "unfavorable." The scale was later reversed for the sake of clarity in graphic representation. In this report anything higher than 4 indicates a positive response, anything lower than 4 indicates a negative response, and 4 indicates a neutral response.
} 
Table 1. Mean Attitudes as an Independent Function of Each Variable

\begin{tabular}{|c|c|}
\hline Variable & Mean \\
\hline & Economic Milieu \\
\hline Positive Economic Relationship & 4.48 \\
\hline Negative Economic Relationship & 3.75 \\
\hline Democracy & 5.27 \\
\hline Authoritarian & 2.96 \\
\hline Positive Security Relationship & Security Milieu \\
\hline Negative Security Relationship & 4.40 \\
\hline Democracy & 2.88 \\
\hline Authoritarian & 4.69 \\
\hline
\end{tabular}

Higher mean scores indicate more positive feelings toward the hypothetical country

A $2 \times 2$ ANOVA was conducted for each scenario to evaluate the main effects of the political culture and the economic or the security relationship on attitudes, as well as the interactive effects between them. The means standard deviations for attitudes as a function of both dimensions are presented in table 1. The results for the ANOVA indicated that all main effects were significant. Specifically, positive relationshipseconomic or military - led to more positive attitudes toward a hypothetical Other than did negative relationships. In other words, subjects were more likely to feel favorably toward a hypothetical country that was described as providing economic opportunity through trade than one that was described as economically threatening through references to job losses and trade [in]balances. Subjects also felt more favorably toward a hypothetical country that was described as supportive of the American international security agenda then they did toward a hypothetical country that was described as unsupportive. Lastly, subjects had more positive attitudes toward democratic Others than toward authoritarian Others, and again this was true in both the economic and security domains. While these results were to be expected, what was particularly surprising was the significant interaction effect between the two independent variables (relationship and political 
culture) in the economic milieu. A more detailed description of the separate analysis for each case is discussed below.

Security Milieu

To test the impact of each variable on attitudes in the security milieu, a 2 (security relationship) x 2 (political culture) ANOVA on attitudes towards Country Y was conducted. The main effects of the security relationship $F(1,117)=30.83, p<.001$, partial eta $\mathrm{sq}=21$, and political culture, $F(1,117)=57.37, p<.001$, partial eta sq $=.33$, were both significant. However, the effects of the security relationship were not moderated by political culture, as the interaction of the security relationship and the political culture was not significant, $F(1,117)=0.12, p=.734$, partial eta $\mathrm{sq}=.12$. Across both political cultures, the mean attitudes for a positive security relationship was $4.41(\mathrm{SE}=0.19)$, which was substantially higher than for the negative security relationship ( $M=2.88$, $\mathrm{SE}=0.20$ ). As Figure 11 demonstrates, subject attitudes correlate neatly with what one would expect—Americans feel most favorably toward democracies that cooperate with the U.S international security agenda and least favorably toward authoritarian states that do not. 
Figure 11 the Impact o Political Culture and Security Relationship on Attitudes

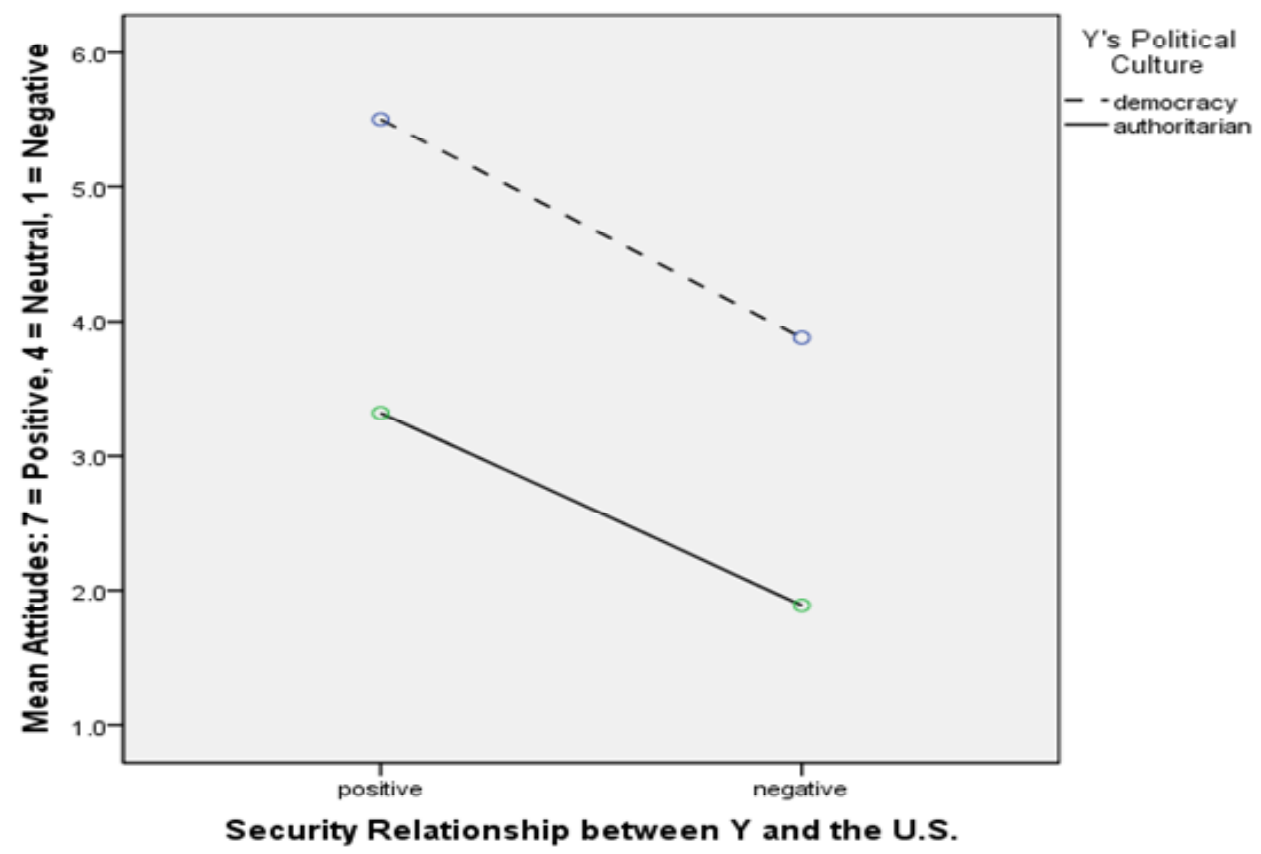

\section{Economic Milieu}

In the economic milieu, a 2 (economic relationship) x 2 (political culture)

ANOVA on attitudes toward hypothetical country $\mathrm{X}$ was conducted. The main effects of the economic relationship, $F(1,117)=8.05, p=.005$, partial eta $\mathrm{sq}=.06$, and the political culture, $F(1,117)=80.00, p<.001$, partial eta sq=.41 were both significant. Of particular interest was the significant interaction of the economic relationship and the political culture $F(1,117)=16.55, p<.001$, partial eta $\mathrm{sq}=.12$, suggesting that the effects of the economic relationship were moderated by the effects of the political culture. Since there was a substantial interaction effect, follow-up tests were carried out to determine the differences in attitudes toward $\mathrm{X}$, between the positive and negative relationships for each of the two political cultures separately, using Holm's modified Bonferroni procedure with overall alpha $=.05$ to control for the probability of a Type 1 error. The 
results indicated that when hypothetical country $\mathrm{X}$ is described as democratic, the subjects' attitudes towards X are dramatically impacted by the nature of the described economic relationship, with a mean attitude of 6.2 when the relationship is positive and a mean attitude of 4.4 when the relationship is described as negative $p<.001$. However, for an authoritarian country there is no significant difference in attitudes towards the country regardless of whether the economic relationship is described as positive $(\mathrm{M}=2.8)$ or negative $(\mathrm{M}=3.1), p=.770$. In other words, the perception of economic opportunity did not have a positive impact when subjects were responding to authoritarian Others.

\section{Figure 12 Attitudes toward X}

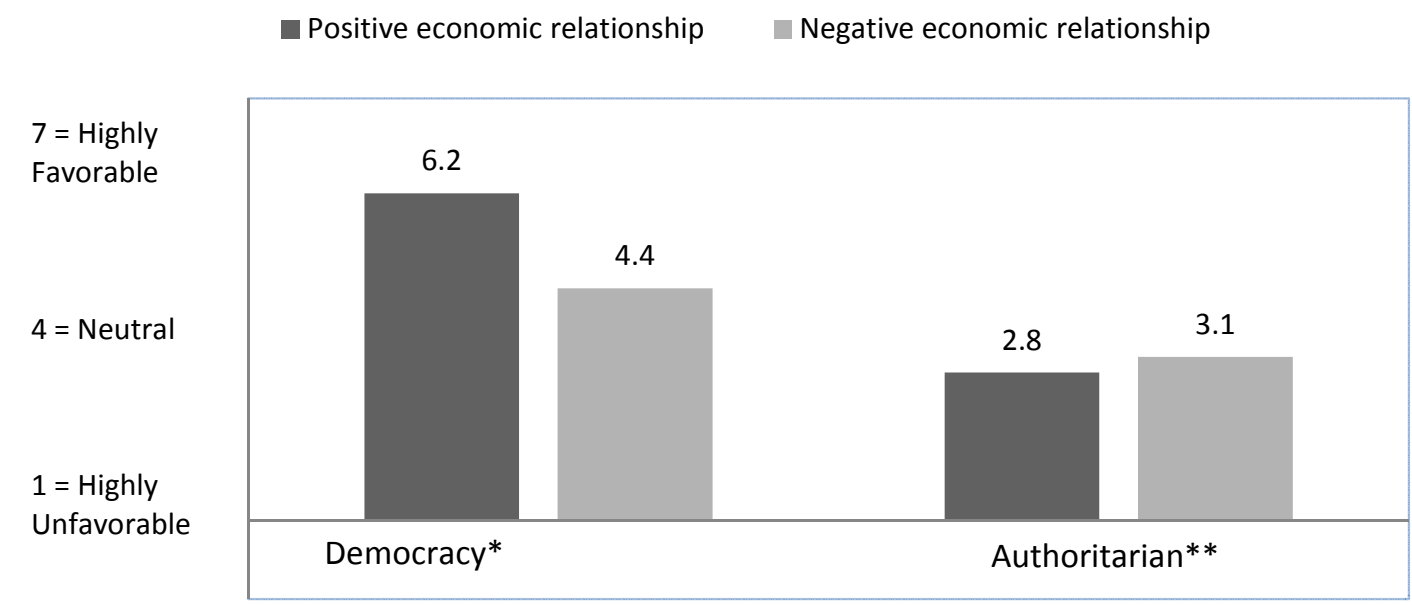

*Results are significant at .001 levels **Results are not significant

As Figure 12 demonstrates, subject attitudes toward democracies were significantly impacted by the presence of economic threat or economic opportunity. On the other hand, when asked to report their feelings toward authoritarian states, subjects showed very little change in their attitudes regardless if the relationship was cooperative or conflictual. We can infer from these findings that the purported moderating impact of economic opportunity on the potential for cooperation among states may be limited by 
the perceived political culture of the states involved. The moderating impact of political culture on attitudes can be seen in Figure 13.

Figure 13 the Impact of Political Culture and Economic Relationship on Attitudes

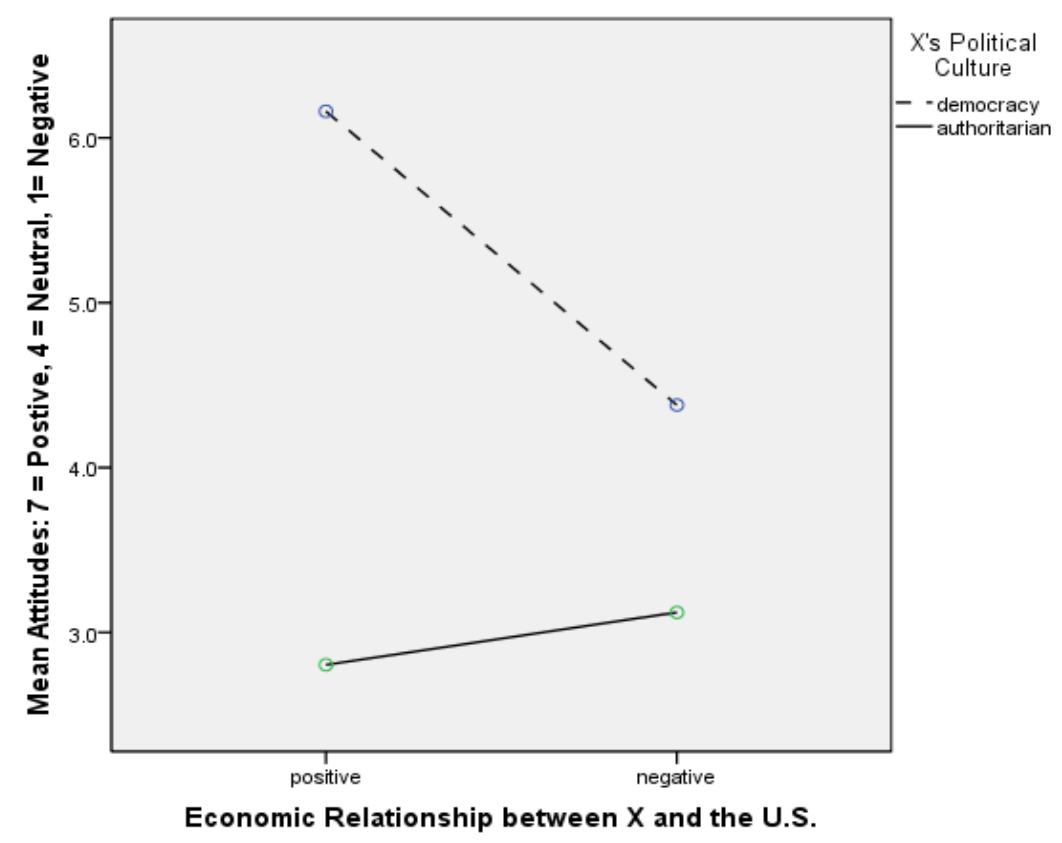

\section{Part II the Impact of Political Culture and Relationship on Concerns about Capabilities}

The second part of the experiment was designed to test the impact of either of the first two dimensions (political culture and the presence of threat or opportunity) on concerns about rising capabilities. To this end subjects were asked to re-read the same two scenarios and to respond on a scale from 1 to 7 , with 1 being "very worried," and 7 being "very happy," to each of the following questions: ${ }^{33}$

\footnotetext{
33 The questionnaire was designed so that "1" corresponded with "very happy" and "7" corresponded with "very worried." The intermediate response categories were "happy," "somewhat happy," "neutral," "somewhat concerned," and "worried." The scale was later reversed for the sake of clarity in graphic representation.
} 
Question \#1: How would you feel if it seemed that Country $\mathrm{X} / \mathrm{Y}$ was becoming as economically powerful as the United States?

Question \#2: How would you feel if it seemed that Country $\mathrm{X} / \mathrm{Y}$ was becoming as militarily powerful as the United States?

Figure 14 Mean Level of Concern about Rising Capabilities

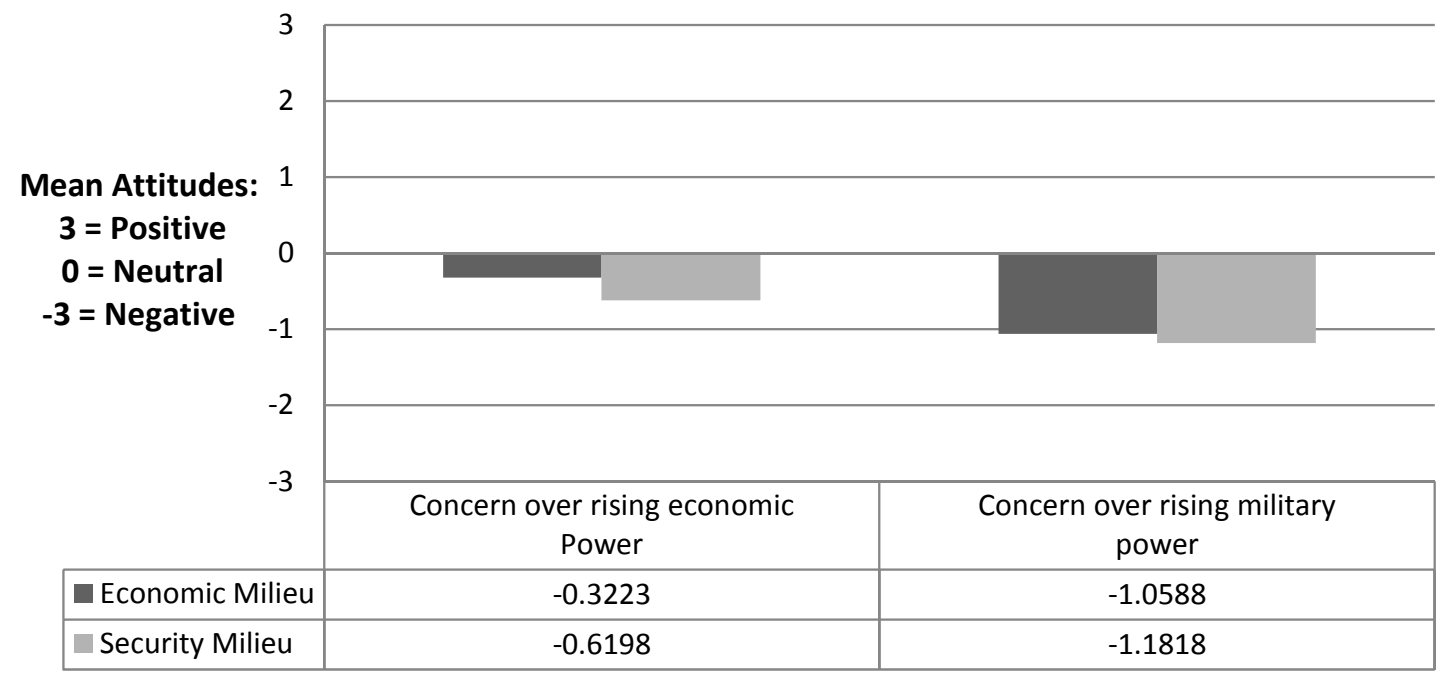

Answers are adjusted in order to graphically depict the distance from neutral of mean responses.

A 2(relationship) x 2(political culture) MANOVA was performed for each question, in both the economic and security milieus. The results showed that neither the perception of threat nor the perception of opportunity had much impact on the dependent variable (concerns about rising capabilities) regardless of the milieu. The main effect of the perceived economic relationship on concerns about capabilities was not significant $F$ $(2,114)=1.80, p=.171$, and the main effect of the perceived security relationship was only marginally significant, $F(2,116)=2.84, p=.062$. Nor were there any significant interaction effects; in the economic milieu the interaction effect was $F(2,114)=1.39$, $p=254$ and in the security milieu, $F(2,116)=.402, p=.670$. 
On the other hand, political culture had a significant main effect on the dependent variable (concern about rising capabilities) in both cases. In the economic milieu the effect of political culture was significant at $F(2,114)=9.69, p<.001$ and in the security milieu it was significant at $F(2,116)=18.12, p<.001$. Since the MANOVA main effects of political culture were significant, the univariate main effects of political culture were examined. In the economic milieu both change in economic power $F(1,115)=19.36$ $p=<.001$, partial eta sq $=.14$, and change in military power $F(1,115)=10.32, p=.002$, partial eta $\mathrm{sq}=.08$, were significant. Also, in the security milieu both the change in economic power $F(1,117)=4.97 p<.001$, part eta sq $=.179$, and change in military power $F(1,117)=5.11, p=<.001$, part eta $\mathrm{sq}=.235$ were significant. Mean responses as a function of the political culture in each milieu are displayed in Figure 15. 


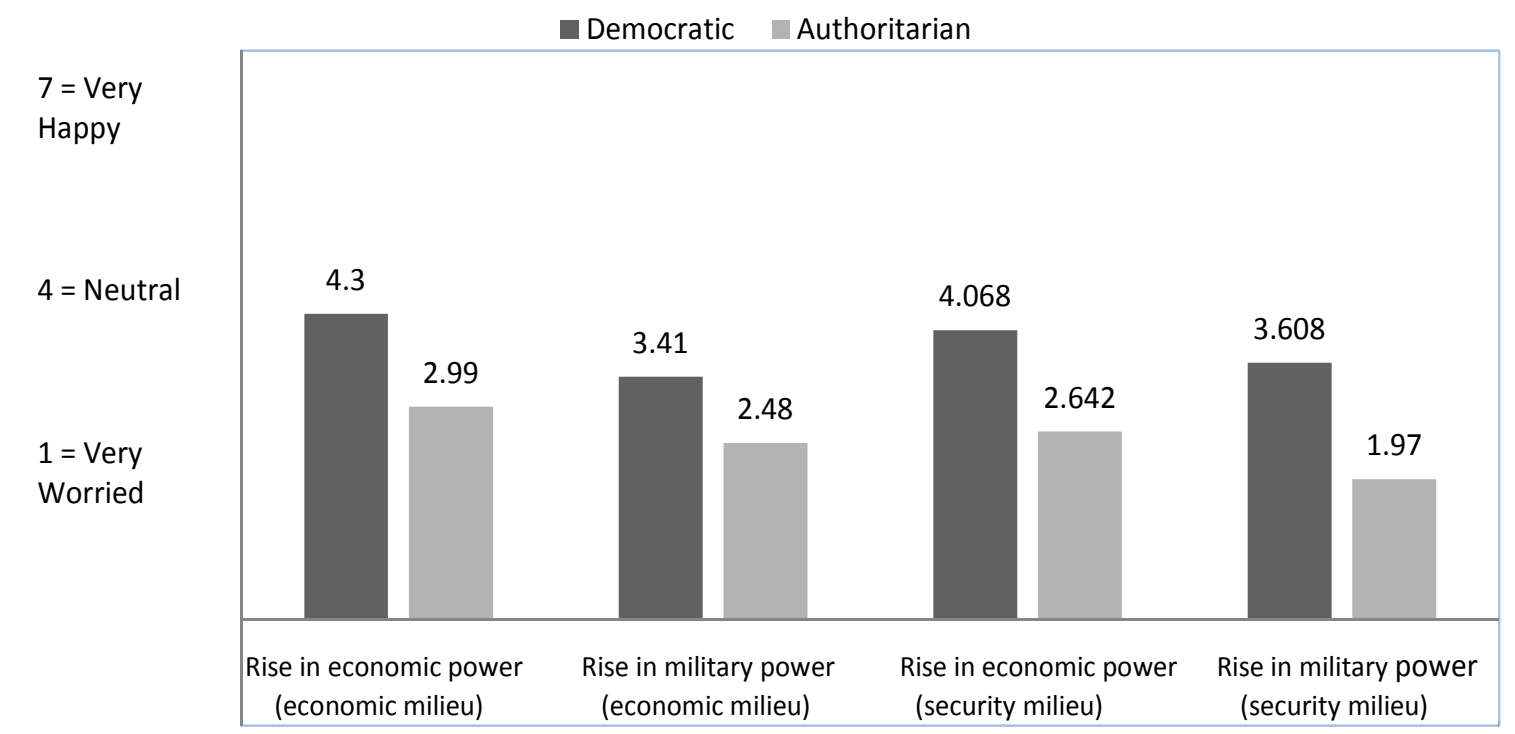

All results are significant at .001 levels

\section{Part III Attitudes toward Specific Countries}

The third part of the experiment utilized a qualitative approach to determine what factors shaped subject attitudes toward actual countries. The goal here was to test the extent to which subject attitudes toward China were based on perceptions of China as a threat or as an opportunity, perceptions of China's political culture, and perceptions of China's relative capabilities in the ways predicted by parts I and II of the experiment. To control for within subject effects, subjects were also asked questions about France and India. $^{34}$

In order to determine their attitudes toward these countries, subjects were first asked to rank their feeling toward France, India and China on a scale from 1 to 7 , with 1

\footnotetext{
${ }^{34}$ Despite the hypothetical nature of the manipulations in the first two parts of the experiment, there was some concern that subjects might recognize China in some cases and that this would influence answers in Part III. To minimize this potential effect subjects were told that any resemblance to actual countries in parts I and II was completely coincidental. To reinforce the impression that the experiment was designed to test attitudes about countries in general and not about China in particular, questions about two other countries, France and India, were included in part III.
} 
being "very unfavorable," and 7 being "very favorable." Responses were compared to recent national polling data from Gallup Polls in order to determine whether the attitudes represented by this subject pool represented typical American attitudes toward each country. Attitudes were reasonably similar in all three cases (See Figure 16).

Figure 16 American Attitudes toward Other Countries

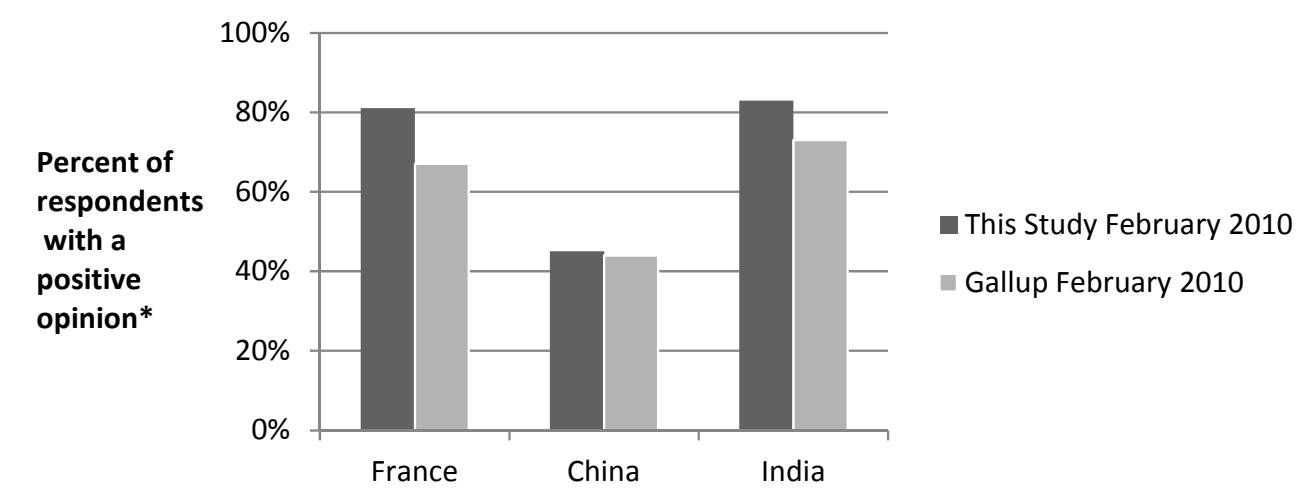

*As a percentage of all respondents who expressed an opinion; For the sake of comparison, "neutral" and "I don't know" responses were omitted.

Next, to determine the extent to which they were preoccupied with each of the three dimensions of IR, subjects were asked to name three things that they thought of in relation to each country. To analyze the results subject responses were coded and placed into seven general categories: (1) Economics, (2) Physical Properties, (3) Social Properties, (4) Culture, (5) Politics, (6) History, and (7) Other. Each of these seven general categories was broken down further into sub categories, many of which corresponded to one of the three dimensions of international relations discussed above.

Last, the results were analyzed to determine how preoccupations with particular cultural, economic, and political factors correlated with attitudinal responses. Analysis was conducted for both the entire sample and for just the sixty-four Americans. Results showed very little variation between the two samples so the discussion below focuses on 
reporting results for the American sample. ${ }^{35}$ Pearson's Chi Square tests were conducted to look for significant correlations between relevant categories (and sub categories) of responses and subject's stated feelings toward China. While there were some interesting results in relation to France and India, these countries were initially included as controls and therefore the analysis below focuses solely on subjects' attitudes toward China.

American subjects seemed relatively unconcerned with the first dimension of international relations, capabilities, which garnered few relevant mentions. Military capabilities were not mentioned once directly. The more general sub-category "power/hegemony" was mentioned by eleven subjects. Economic capabilities, referenced in terms of "economic power," were only mentioned four times. With a less obvious relationship to economic capabilities, "growth and development" was the more popular sub category — mentioned by eight subjects. None of these sub categories were significantly correlated with attitudes toward China.

American subjects were more preoccupied by the second dimension — threat or opportunity. While there were very few mentions of anything that could conceivably be categorized as security related threat or opportunity, economic issues were mentioned frequently enough ( $24 \%$ of all mentions) to suggest a potential impact of perceived economic threat or opportunity on subject attitudes. Nevertheless, most economic responses were value neutral (i.e. "growing," "markets," "industrialization," "mixed economy," "major exporting," "manufacturing," etc.), so it was difficult to ascertain

\footnotetext{
${ }^{35}$ Within the two samples a similar percentage of subjects mentioned each of the categories discussed below. In addition, while the power of the tests decreased slightly with the smaller sample size, the same categories were found to be significantly correlated with attitudes. There are two exceptions which will be noted below. All other discussion focuses on the American sample.
} 
whether subjects were mentioning a perceived threat, a perceived opportunity, or something in between. Breaking responses down further promised a closer look at this relationship, so responses were divided into seven sub-categories: (1) economic characteristics, (2) economic power \& wealth, (3) growth \& development, (4) poverty \& underdevelopment, (5) exports, (6) sector \& occupations, and (7) international political economy (IPE) issues. Results showed that neither the general economic category nor any of the subcategories correlated significantly with attitudes towards China. ${ }^{36}$

The third dimension — culture — was the most fruitful in terms of both the level of preoccupation (number of mentions) and the significant correlations between this preoccupation and attitudes. While the focus of the first two parts of the experiment emphasizes political culture, many culture related responses did not fit neatly in this category. This fact offered an opportunity to compare the impact, of various types of cultural awareness, on attitudes toward others. Issues related to political culture were placed in the general category of "politics" while all other cultural references were placed in the general category "culture." This latter made up 16\% of American responses and correlated positively with American attitudes toward China at $(p=.011)$.

The most interesting results are found when looking at the general "politics" category. The category encompassed $29 \%$ of all American responses and had significant negative correlations with attitudes. In other words, those who thought about political issues were significantly more likely to have negative feelings toward China $(p=.017)$.

Breaking the general category "Politics" down further demonstrates that the major areas of contention lie along the lines of political culture. One important political sub

\footnotetext{
${ }^{36}$ In the larger sample, the sub category "exports" correlated positively with subject attitudes ( $\left.\mathrm{p}=.021\right)$.
} 
category was "political characteristics" ("authoritarian," "communism," etc.), which was mentioned by $16 \%$ of all American subjects. ${ }^{37}$ The most import sub category was "domestic politics" ("one child policy," "no freedom," "strict government," "limited human rights," "big government," "censorship," "strict control," etc), which was mentioned by 26 Americans and significantly correlated with negative attitudes toward China at $p=.004$. The other three subcategories ("international politics," "power \& hegemony," and "military," were not significantly correlated with attitudes.

\section{Discussion}

These results answer many of the questions raised in chapter three. They also offer some interesting insights into our current understanding of American relations with economic competitors in general and with China in particular. While some of the results are unsurprising, there are facets of the analysis that call into question several of our widely held beliefs about why Americans feel the way that they do about other countries.

\section{Finding \#1: when discussing hypothetical countries subjects appeared more}

\section{concerned about political culture than about the U.S.-Other relationship.}

The relative impact of political culture on attitudes toward Others seemed to be unexpectedly large. ${ }^{38}$ The fact that subjects respond more negatively to an authoritarian state than to a democratic state is unsurprising. However, one might not expect this variable to have so much more of an effect than other aspects of the relationship. In the

\footnotetext{
${ }^{37}$ While this category did not correlate significantly with American attitudes toward China, it did correlate significantly with general attitudes toward China in the larger sample $(\mathrm{p}=.013)$.

${ }^{38} \mathrm{I}$ am indebted to an anonymous reviewer for pointing out the problems with interpreting effect size. It is impossible to be absolutely certain of the impacts of size effects since subtle variations in experimental design can have unpredictable impacts on this effect. Therefore, this support for finding \#1 should only be considered together with the other support that follows.
} 
security milieu the main effects of political culture $(F=57.37)$ were almost double the main effects of the security relationship $(F=30.83)$. This result could suggest that subjects cared whether the Other was described as cooperating with the U.S. international security agenda but only half as much as they cared if the Other was a Democracy. The disparity in effect size is even more note-worthy in the economic milieu. One might expect that the recent media preoccupation with economic threat emanating from China would reflect, if not cause, intense feelings of economic insecurity among the general public. Yet, this difference in effect size might suggest that subject attitudes toward a hypothetical Other were much more likely to be affected by the Other's political culture $(F=80.00)$ then by the Other's economic relationship with the U.S. $(F=8.05)$.

Political culture also had a much bigger impact on subject concerns about rising capabilities than did perceptions of threat or opportunity. As was expected subjects were more concerned if an authoritarian state is gaining in capabilities than if the state is described as democratic. What was surprising was that subjects were relatively unconcerned about the rising capabilities of Democracies. In contrast, the rising capabilities of authoritarian states caused great concern, even if those states were described as providing economic opportunities for the United States or supporting the American international security agenda (See Figure 15).

Political culture played the greatest role in concerns about military power. While the second part of the current study suggests that subjects are generally unhappy about the rising military capabilities of any hypothetical country, these concerns increase greatly when the country is perceived as authoritarian. We should therefore expect a greater potential for conflict between the United States and militarily powerful 
authoritarian states. This finding lends some support to the realist prediction of likely conflict between the United States and China (Mearsheimer 2010). However, it calls into question the realist assumption that it is capabilities alone which make this conflict likely.

This finding further suggests that the degree to which relative military gains are seen as threatening are significantly influenced by perceptions of the Other as authoritarian or democratic. An example of this influence might be seen in disparate reactions to the military buildup of East Asian powers. Reports about Chinese military advances often imply evidence of revisionist intentions. On the other hand, American analysts frequently perceive Japanese military buildup in the Pacific as an opportunity to gain from Japanese assistance in protecting itself and its allies from threats in the area. Another example would be the great variation in American responses to different emerging nuclear powers (Hayes 2009).

Theoretically, the finding that subject attitudes toward Others are shaped in large part by perceptions of political culture offers a potential alternative and complementary explanation for the democratic peace phenomenon. While most theorists working on this puzzle have posited either normative or institutional explanations, others have called for a closer look at psychological causes (Hermann and Kegley 1995). Since the importance of public opinion is a central tenet of institutional explanations of the democratic peace, the finding that public attitudes are greatly influenced by perceptions of political culture is worth further exploration

Additional support for the importance of political culture in shaping American attitudes toward Others can be found in history. In the case of China it is possible to find historical examples of how changes in American perceptions of the PRC's political 
culture have impacted the Sino-American relationship. The most obvious of these changes is of course the Tiananmen Square Massacre, which had a dramatic impact on American attitudes. In fact, American feelings toward China have never returned to the pre-Tiananmen peak of $85 \%$ favorability. ${ }^{39}$ As one would expect, this event also had an important impact on American policy toward China (Mann 2000, 194-255).

\section{Finding \#2: Subjects were less concerned about rising economic capabilities}

\section{than one might expect.}

The above results alone do not suggest that Americans are indifferent to the rising economic capabilities of Others, but rather that their attitudes toward Others are far more likely to be affected by perceptions of political culture. On the other hand, results from the second part of the current study do seem to imply that Americans are far less concerned with the economic capabilities of powerful Others than one might expect. When subjects were asked how they would feel if the hypothetical Other was becoming as economically powerful as the United States, the mean response was barely below neutral- 6 points below neutral in the security milieu and .4 points below neutral in the economic milieu (see Figure 14) Contrary to expectations, subjects were relatively unconcerned about the possibility that a powerful Other could approximate the United States in economic power- regardless of that Other's political culture or its current relationship with the United States.

This finding suggests that even though China's economic power receives a great deal of media attention, and although there are powerful interest groups that are likely to

\footnotetext{
${ }^{39}$ As a percentage of those polled who gave either a positive or a negative response (based on responses to the Gallup Public Opinion Poll February 28-March 2, 1989).
} 
respond very negatively to this power, such power has a limited impact on public attitudes toward Others. ${ }^{40}$

Finding \#3: When discussing hypothetical countries, the moderating impact

\section{of economic opportunity was only present in relationships with other democracies.}

Another interesting result is found when comparing how subjects reacted to the two different milieus (security and economic). Each subject was exposed to two different scenarios--one describing a threatening or cooperative economic relationship with an authoritarian or democratic state, the other describing a threatening or cooperative security relationship with an authoritarian or democratic state. Aggregate results demonstrate that a significant interaction effect occurs between the two variables only in the economic milieu. Theoretically this finding lends credence to the neoliberal suggestion that the presence of opportunity, in the economic milieu, can have a positive moderating effect on state relations. Nevertheless, this assumption seems to be limited to cases involving relationships with Democracies, as subjects did not seem affected by the presence of opportunity (or threat) when reacting to an authoritarian Other (See Figures 12 and 13).

This result further emphasizes the importance of political culture in shaping state relationships by casting doubt on the promise of liberal trade to prevent conflict between the United States and authoritarian states such as China. Theoretically the current study addresses the concern expressed by Edward D. Mansfield and Brian M. Pollins (2001, 835) who lamented that "Scholars have yet to resolve in what form and in what sense

\footnotetext{
${ }^{40}$ I am grateful to an anonymous reviewer for pointing out that the age and socio-economic background of the subject group might skew these results away from what might be typical American concerns about the economic capabilities of powerful others. This caveat brings to light the importance of further testing these results through content analysis.
} 
interdependence is expected to influence conflict of which type and at what level of intensity." While it is not the purpose of my study to examine this link, these results do begin to address one of Mansfield and Pollins primary concerns that "more effort should be devoted to identifying the boundary conditions of the effects of economic exchange on belligerence" (Mansfield and Pollins 2001, 835). Political culture may be one such "boundary condition." These results suggest that whether or not the perceived benefits of interdependence are likely to ameliorate conflict may be contingent on the regime type of the interdependent states. This of course assumes that public opinion plays a role in the causal relationship between interdependence and peace.

If we accept that the presence of threat or opportunity does have a moderating impact on economic conflict, but only in the case of relationships with other democracies, then we should expect different reactions, to similar economic threats, depending on the political culture of the threatening state. This potential limitation to the neoliberal thesis is further substantiated by looking at the differences in attitudinal responses to economic threat emanating from democratic Japan 1975-1995, and the economic threat emanating from authoritarian China 1990-2010. While alternative explanations for these differences have been suggested, this finding raises an interesting hypothesis that can be further tested through content analysis in chapter five.

Finding \#4 there was a significant correlation between subject preoccupation with China's political culture and negative attitudes toward China.

American subjects were generally preoccupied with the political culture in China with $61 \%$ of respondents mentioning political issues as at least one of the three things that they think about when they think about China (19\% mentioned political issues twice 
or three times). Of these responses, the majority, are focused on the nature of China's political regime, or on the lack of civil and human rights enjoyed by China's citizens. What is of even more interest here is the strong correlation between the preoccupation with the PRC's domestic politics and negative feelings toward China. These results suggest not only that many subjects perceive China as an authoritarian state but that this is the most important characteristic with which many identify China. As the first part of the current study predicts, those who perceive China as an authoritarian state tend to have a negative image of China in general.

However, many American subjects showed no preoccupation with China's political culture. Subjects were not just asked for the first thing that comes to mind, but were, rather, asked to list three things they think about when they think about China. This phrasing was meant to elicit a relatively deep level of consideration from the participants, and to get at a better understanding of the various factors that influence each individual's perceptions of China. This makes it all the more significant that $39 \%$ of respondents did not mention political factors at all. It is reasonable to infer that many of these respondents don't tend to think about China's political culture but rather see China in different terms. We can plausibly suggest that $39 \%$ of subjects' responses toward China were shaped by other factors that either correlate with positive feelings toward China or don't elicit any strong emotions. Analysis suggests that the two most likely candidates are Chinese culture (33\% of subjects mentioned non-political cultural factors) and Economics (52\% of subjects mentioned economic factors). The former correlates significantly with positive attitudes toward China, which helps to explain some of the variance in attitudinal responses. 


\section{Finding \#5 subjects showed virtually no preoccupation with China's military}

\section{capabilities.}

An explanation for a lack of outright hostility toward China is suggested by what subjects are not thinking about—Sino-American security relations. Parts I and II of the current study suggest that subjects who perceive an Other as both authoritarian and as a rising military power should feel deep animosity toward that Other. One factor that might be preventing the emergence of such hostility is the fact that subjects are not in any way preoccupied with China as a military power - at least not in terms of military size or capability. This is most likely due to a lack of awareness of Chinese capabilities, but this in itself is curious. We might ask why subjects would be so much better informed about China's political culture and/or economic power than they are about its military capabilities. If, as some analysts have suggested, China's rising capabilities pose a threat to the achievement of America's national interest, it might be worth exploring the extent to which the national discourse has neglected to emphasize this threat, as well as the reasons behind this neglect.

These findings suggest an interesting interpretation of the evolution of American attitudes toward Japan and China discussed in chapter three. It has been suggested here that rising economic capabilities, in and of themselves, have a negligible impact on attitudes, but that the perceptions of those capabilities as threatening (as opposed to providing an opportunity) has a significant impact on attitudes toward Democracies. Subsequently, we can hypothesize that American attitudes did not respond to the rising capabilities in either case, but responded to increases in perceptions of threat in the case of Japan 1986-1991. This explanation answers the question posed at the beginning of 
this chapter: what accounts for the lack of negative attitudinal responses to the rising economic capabilities of Japan and China?

On the other, hand these findings suggest that such representations of economic threat should not have an important impact on American attitudes toward authoritarian states like China. Nor should we expect attitudes to be overly influenced by increases in China's economic capabilities. These findings suggest that the two factors that should have the most dramatic effect on American attitudes toward China should be perceptions of political culture and perceptions of military capabilities. The importance of perceived political culture in shaping American attitudes toward others goes a long way toward explaining the great discrepancy in general attitudes toward Japan and China over time. However, this does not necessarily imply that as long as China is an authoritarian state Americans will feel negatively toward China

It is important to acknowledge that what is at stake here is perception. The findings of parts I and II of the current study are not sufficient to explain either the general ambivalence Americans currently feel toward China, or the reasons why Americans are likely to feel more negatively toward China in the twenty first century than they felt toward Japan in the 1980s. It is not enough simply to state that (A) Americans have negative feelings towards authoritarian states with military capabilities approximating those of the U.S. and (B) China is an authoritarian state with military capabilities approximating those of the U.S. therefore (C) Americans are likely to have negative feeling toward China. We must first ask whether Americans perceive China as an authoritarian state and whether Americans perceive China's military capabilities as approximating those of the United States. While the design of this survey experiment did 
not allow for a deeper understanding of American perceptions of a historical case study like Japan, it was able to address these questions about how Americans perceive China. Since China has been an authoritarian state for most of its modern history, it might be easy to assume that this is how Americans are likely to perceive it. Nevertheless, In the case of China in the 1980s, there are many examples of those who responded so favorably to signals of change in China's political culture that they chose to see the PRC as other than it was. One of the more famous examples of this was Ronald Reagan's reference to China as a "so-called Communist country," when speaking to reporters on his way back from a visit in 1984 (Quoted in Mann 2000, 147). Also, as Figure 10 demonstrates, despite the fact that the PRC was indisputably communist and authoritarian in the years leading up to the Tiananmen incident, the percentage of Americans who had favorable feelings toward China at that time exceeded the average percentage of Americans who had positive feelings toward Japan over the entire period under consideration. Considering these examples it is worth asking how the political culture of China is currently perceived.

Part III of the experiment attempts to gain a better understanding of how China is perceived by looking at what subjects think of when they think of China. What we find is that subjects, tend to think of China along cultural, economic or political lines with only the latter having a significantly negative impact on attitudes. These findings suggest the importance of perceptions of China's political culture as a factor determining present and future attitudes toward China. This factor not only impacts attitudes directly, but also shapes the way Americans respond to Chinese military capabilities. In chapter five, content analysis is used to further confirm the dominance of political culture as a factor 
shaping American attitudes toward China. It does this by answering three questions:

First, to what extent is the illiberal nature of China's political culture emphasized within the American media? Second, how important are these representations in shaping popular and elite discourse? And third, how do these representations correlate with negative or positive attitudes toward China. 


\section{HOW HAVE AMERICAN REPRESENTATIONS OF CHINA'S POLITICAL CULTURE CHANGED OVER TIME?}

"...the growth of economic freedom in China is the best way to produce political freedom...The Great Wall of China is very thick. All of you who have been there know that. It's difficult to be heard when you're inside the wall. It is impossible to be heard when you are outside the wall."

"China's economic modernization program has had little impact on the country's formal political structures... there is no sign of any fundamental change in the official human rights policy or in aspects of the legal system which foster abuses...The world cannot ignore what is happening to a fifth of its people. What happens in China is an important measure of the state of human rights internationally. ",42

"Few causes inspire Americans more strongly than the promotion of human liberties. It is a central part of our national identity, a product of our history. We attach great importance to individual rights, to a democratic form of government and to freedoms of speech, assembly and the press...Threatening China is not a policy that will work. "43

These quotes are representative of a grand debate within American China

discourse over whether it is better to engage with China or to try to contain it. Over the

last decade, as China's global power and economic wealth has increased steadily, and as

China's ability to challenge American hegemony in numerous issue areas has become a

real and generally accepted possibility, Americans have responded in unexpected ways.

Even though American discourse has been filled with these debates about the pros and

cons of engaging an increasingly powerful Other, American attitude toward China have

\footnotetext{
${ }^{41}$ Richard Nixon, speaking at a Luncheon in his honor on April 21, 1993 (see "Fragile Friendship").

${ }^{42}$ Dr. William F. Schulz, Executive Director of Amnesty International USA speaking about the human rights consequences of unconditionally renewing China's MFN status, before the House international Relations subcommittee on International Operations and Human Rights on June 19, 1996 (U.S. House 1996b).

${ }^{43}$ Maurice R. Greenberg, Chairman and Chief Executive Officer of the American International Group, speaking on Sino-American relations, before the House Committee on International Relations Subcommittees on Asia and the Pacific and International Economic Policy and Trade on May 161996 (U.S. House 1996a).
} 
been trending in a positive direction. Through historical process tracing, polling data analysis, and a social scientific experiment, previous analysis has demonstrated a significant cause for this surprising trend. Taken together the results of the analyses reported in chapters three and four suggest that, rather than perceiving Chinese threat simply as a corollary to changing Chinese capabilities, American attitudes toward China are instead shaped by evolving perceptions of China's political culture.

These findings suggest that in order to understand American attitudes toward China we must first understand how Americans perceive China's political culture, as well as how and why these perceptions have evolved over time. The social psychological experiment reported in chapter four demonstrates a significant correlation between many subjects' perceptions of China as an illiberal regime and their negative attitudes toward China. Since the 1980s and 1990s are too far in the past to enable me to use the same methodology to measure American perceptions of Chinese political culture during those years, this chapter further demonstrates that link through content analysis. By first demonstrating a relationship between American attitudes toward China and media representations of China's political culture over the last twenty-six years, and by then exploring the nature of those representations, my study uses content analysis to further demonstrate the extent to which perceptions of China's political culture shape American attitudes toward China. This method is then used to further explore other trends in media representations of China over the same time period in order to best understand how representations of China's political culture interact with other aspects of the China discourse in shaping American images of China. 
Through national discourse individuals come to share many similar ideas that shape their perceptions of Self and Other in ways that are both stable over time and subject to change. Through analyzing this discourse it becomes possible to determine how these perceptions are constructed and how they evolve. My study uses social constructivist analysis, which focuses on discourse in order to "understand how reality comes to be constituted in human interactions and in language, including written text (Krippendorf 2004, 17).

There are many ways that a researcher can analyze texts for answers to the way meaning making is accomplished within society. A discourse analyst can ask numerous questions of particular texts including, but not limited to, what social event, genre(s) and discourse(s) is the text a part of, what voices are included and how are they attributed, and what existential, propositional or value assumptions are made? Analysts can further examine the mood of the text, the way that agency is articulated or avoided, or the semantic connections and types of statements within the text (Fairclough 2003).

While this sort of "thick" analysis of individual texts has numerous benefits, it is through examining numerous texts in relation to one another that the analyst can determine how identity is shaped through social discourse. In other words the possible meanings of an identity, shaped by social discourse, may only be understood after numerous texts have been analyzed inter-textually. According to Ted Hopf $(2002,25)$, "The trick is to remain ontologically open for as long as possible before imposing an analytical theoretical order, or closure, on the numerous ambiguities and differences in the texts." 
The limits to such an interpretivist approach are obvious. Hopf points out that "a constructivist account of identity based on an interpretivist epistemology can offer robust claims to reliability, narrow claims to generalizability and predictability, and [only] tentative claims to validity" (29). Therefore, to improve the validity of results, my study first uses the interpretivist inductive approach discussed above, and then utilizes a quantitative approach to a larger sample of texts. Through coding words and phrases in such a way that numerous researchers or computer software can analyze myriad texts with similar results the validity of inferences is measured and replicablity is ensured. As this latter method does not offer the depth and reflexivity of discourse analysis, it was beneficial to apply both methods for a study that is both rich and broad. The results of both methods are reported below.

\section{Apparent Correlation between Media Representation and Public Opinion}

Before testing how China's political culture is represented in American media, I first sought to determine the extent to which media images of China were truly representative of American attitudes toward China. This necessitated measuring the evolution of media representation of China from 1985-2011, and then depicting this representation in a way that was comparable to the trend in American attitudes as illustrated in Figure 10. To this end, I analyzed New York Times coverage of SinoAmerican relations over the entire period. To collect a sample, I first searched for all articles dealing with the subjects "China" and the "United States" and then chose the first article for each month, beginning with January 1985 and running through December 2011. This resulted in 324 monthly observations. 
I then coded the data, looking for evidence of negative or positive feelings/attitudes towards China either as expressed by the author or as reported by the author. In the latter case, negative or positive attitudes might be reportedly held by the American public in general, by certain groups within the U.S., or by individuals. I also looked for negative attitudes toward the United States that were reportedly expressed by China, Chinese groups, or Chinese individuals toward the United States. Lastly, I looked for evidence of tensions in the Sino-American relationship. For a more detailed description of coding decisions see the code book in Appendix D.

To code the data, I first broke each article into passages ranging from 135 to 160 words (see Appendix E for detailed rules on framing passages). I then coded the representation of China in each passage as either positive $(+)$, negative $(-)$, neutral $(\mathrm{N})$, or non applicable (NA). If every passage in an article was coded with an NA, I discarded the document and chose the next one for that month. I then calculated a value for the entire article by first assigning values to each category ( $\mathrm{NA}=0$, Negative $=1$, Neutral $=5.5$, Positive $=10$ ) then adding the total and dividing by the number of applicable paragraphs. ${ }^{44}$

To guarantee coder reliability, I had two additional coders code a subset of the entire data set. To ensure that articles were coded in ways accurately representative of a typical American reading of the texts, coders who are not China scholars were chosen. Each of these two additional coders was asked to code a subset of the larger sample initially coded by me. Sampling was conducted by choosing the first article for each of

\footnotetext{
${ }^{44}$ For Example: Consider an article with 20 paragraphs, 10 paragraphs are NA, 5 paragraphs are negative, 3 paragraphs are neutral, and 2 paragraphs are positive.10 NA @ 0 pts $=0,5$ negative $@ 1 \mathrm{pt}=5 \mathrm{pts}, 3$ neutral @ 5 pts=15pts, 2 positive @ 10 pts=20 pts. The result: $0+5+15+20=40 / 10=4$ giving the entire article a ranking of 4 (slightly lower than neutral/ slightly negative).
} 
the first six months of the years 1992, 1996, 2000, 2004, and 2008 for a total of 36 articles, or 207 passages. Inter-coder agreement between coder \#1 and coder \#2 was $67 \%$, between coder \#1 and coder \#3 was $68 \%$, and between coder \#1 and coder \#4 was $72 \%$. The average inter-coder agreement between me and each of the three additional coders was $69 \%$. To find the mean correlation between myself and the other three coders, I conducted a conducted a Pearson's Correlation test. ${ }^{45}$ The results showed a mean score of .88. All results were significant at the .001 level. ${ }^{46}$

\footnotetext{
${ }^{45}$ This test required that all codes fit along a scale. To accomplish this it was necessary to collapse both codes of neutral (N) and not applicable (NA) into a single category. Positive codes were then re-coded as 1 , neutral and not applicable codes as 0 , and negative codes as -1 .

${ }^{46}$ To further demonstrate the level of agreement amongst all coders I conducted a Pearson Correlation Test to find the mean scores amongst all pairs of coders. This resulted in a mean of .84. Again results were significant at .001 level.
} 
Figure 17 Comparison of American Attitudes with Media Representations of China
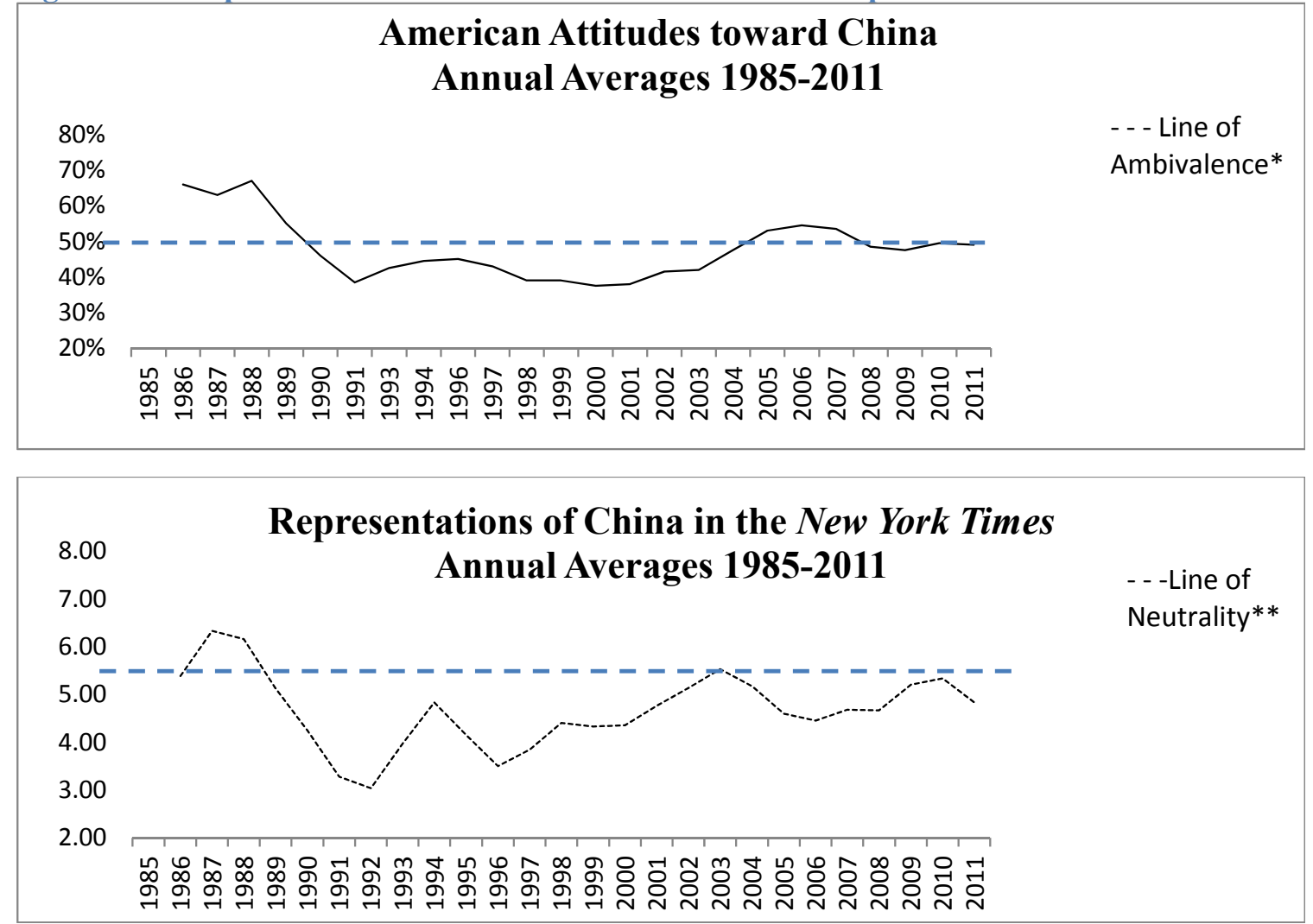

*The line at which polls showed that exactly half of respondents who expressed explicit opinions felt favorably toward China while the other half felt negatively.

**The line at which the average representation of China in the New York Times was Neutral

As figure 17 demonstrates, the trends in the New York Times representations of

China, over the last twenty-five years, follow a similar path to the trends in American attitudes toward China during the same time period as measured by public opinion polls and discussed in chapter three. ${ }^{47}$ The average annual representation of China in the New York Times was positive throughout the second half of the 1980s. Then, in 1989, representations of China dipped significantly, reaching their lowest point in 1992. Images of China remained negative throughout the 1990s and were generally neutral

\footnotetext{
${ }^{47}$ Since what we are looking for are trends in representations of China over a lengthy period of time, a two year moving average trend line has been used in all figures in this chapter. This has the effect of smoothing out the occasional peaks and valleys in order to better demonstrate the general trend.
} 
from 2000-2004, after which they dipped to negative again, rebounding in 2006 and trending positively ever since.

The parallels between the results of the two studies are obvious. While the New York Times coverage of China appears to be more volatile than do American attitudes, the general trends are remarkably similar. This adds weight to other studies that have sought to demonstrate the influence that elite rhetoric has on public opinion (Baum and Groeling 2010). More importantly, this similarity supports validity claims as to the efficacy of using discourse analysis to explain variations in public opinion. By looking more closely at how China's political culture is represented in the New York Times, and other media sources, my study is able to better explain the puzzles of American attitudes toward China over the last twenty-five years.

\section{Representations of China's Political Culture over Time}

Considering the diversity of American views on China, the current study analyzes texts from three different sources, each meant to broadly represent a different group of American stakeholders, in order to analyze how representations of China's political culture in American discourse have evolved over time. First, the Federal News Service (FNS) database was used to collect texts representative of the American political elite's discourse on China. The FNS database includes Presidential statements, U.S. official policy statements, White House briefings, Congressional hearings, select National Press Club speeches, special briefings transcripts, and remarks by "top ranking officials." ${ }^{, 8} \mathrm{~A}$ sample was collected of all texts with the subject "China," and the subject "United

\footnotetext{
${ }^{48}$ This database excludes transcripts from the Federal News Service that were broadcast on ABC, CBS, NBC, CNN or FOX after December $6^{\text {th }} 2010$.
} 
States," for the years 1988 through $2011 .^{49}$ The average number of texts per year was 172.

Second, articles from the Wall Street Journal were collected to analyze the American business elite's discourse on China. The Wall Street Journal was chosen because it is a reputable newspaper with a large American circulation, and because it is widely read by America's business community since it places particular emphasis on business and economic issues. Because of the idiosyncrasies of the ProQuest Database, from which this data was collected, subject search filters were not available for this source. Therefore, the following search terms were used to collect texts for the years 1986-1992: "China," (title) and "United States" (full text). In addition, the publication title "Wall Street Journal Online" were excluded as were certain types of articles including "Obituary," "Market Research," Review," and "Correspondence," and only articles with "full text" were included. This search resulted in an average of 129 articles per year, all of which were selected for analysis. The same search with above filters for the years 1993-2011, returned too much data (an average of over 350 articles per year) so the following filters were added to make the data set more manageable: "Location" $\rightarrow$ "China," and "the United States," and "U.S.." The number of articles still averaged over 300 per annum, so a smaller sample was selected by first sorting the results according to relevance, and then choosing the first 100 articles for each year.

Lastly, a sample of articles from the New York Times was chosen to represent a broader American discourse on China. ${ }^{50}$ These articles were collected via the following

\footnotetext{
${ }^{49}$ Unfortunately, no data was available for the years 1985-1987 in the Federal News Service Database.
} 
search terms: "China" (subject), and "United States" (subject). In addition, the publication title "New York Times Online" was eliminated as were articles that included only an abstract. This search resulted in an average of 140 articles per year, all of which were selected for analysis. These three data sets were then imported into Nvivo (a text analysis software program), which enabled me to analyze the texts both quantitatively and qualitatively in order to trace the evolution of the representation of China's political culture in American discourse over the last twenty-six years.

The first step in analysis was to use a "key word in context" (KWIC) search to trace the use of certain key adjectives (and nouns) commonly used to describe China's political culture. The four terms that I chose were "communis*," "authoritarian," "repress*" and "pragmatic." 51 A survey of the results suggested that all terms, except “pragmatic," were used regularly in representations of China. Exceptions were discarded and analysis of the term "pragmatic," was discontinued. In order to trace preoccupation with illiberal actions by the Chinese government, I also searched for the term "Human Rights." I then calculated the number of articles which had at least one use of the particular term as a percentage of all articles dealing with Sino-American relations for each source. The results are depicted in Figures 18-21.

\footnotetext{
${ }^{50}$ Texts, from a fourth source, Time Magazine, were also gathered to represent a less elite reading public. Unfortunately, Time had relatively few articles dealing with China, with an average of less than twenty-five articles per year. With so few data points, the resulting analysis was inconclusive and therefore was not reported in this study.

${ }^{51}$ The asterisk represents a "wild card" function that allows the software to search for terms with a variety of endings. The search term "communi*" finds both "communist" and "communism," and the search term "repress*" finds both "repressive" and "repression."
} 
Figure 18 Percentage of Articles that Use the Terms "Communist" or "Communism"

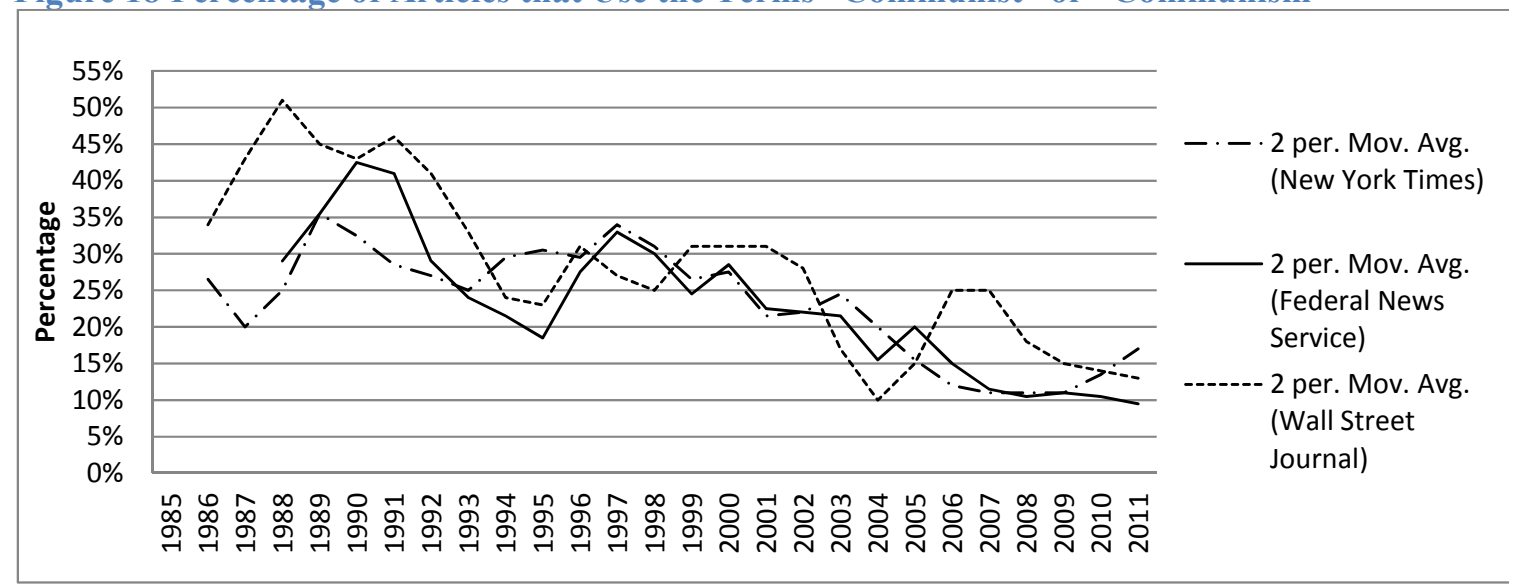

As figure 18 demonstrates, within American discourse, the use of the term “communist" to describe China has been decreasing steadily since $1985 .{ }^{52}$ This trend is not surprising for two reasons. First, while the Chinese government is still run by the socalled "Communist Party," the economic aspect of the term "communist" has gradually ceased to apply. Second, the term has less significance for a growing number of Americans who have no personal memories of the Cold War. This finding does not necessarily indicate a reduction in negative representations of China's political culture, as the term "communist," might be gradually being replaced with another, more common yet equally negative term-“authoritarian."

However, by analyzing the use of the term "authoritarian," we see that its usage within American China discourse has not increased (see Figure 19). In fact, analysis demonstrates that, within all three sources, the term has been used far less often than the terms "communist," or "communism," and its usage has remained relatively stable over the last twenty-six years. Taken together, these two analyses suggest that within

\footnotetext{
52 This KWIC search also included the term "communism," which is not directly used as an adjectival descriptor of China. Nevertheless, its use in discussions about China clearly indicates the speaker's preoccupation with this aspect of China's political culture.
} 
American discourse, the use of negative representations of China's political regime has been gradually decreasing.

Figure 19 Percentage of articles that use the term "authoritarian"

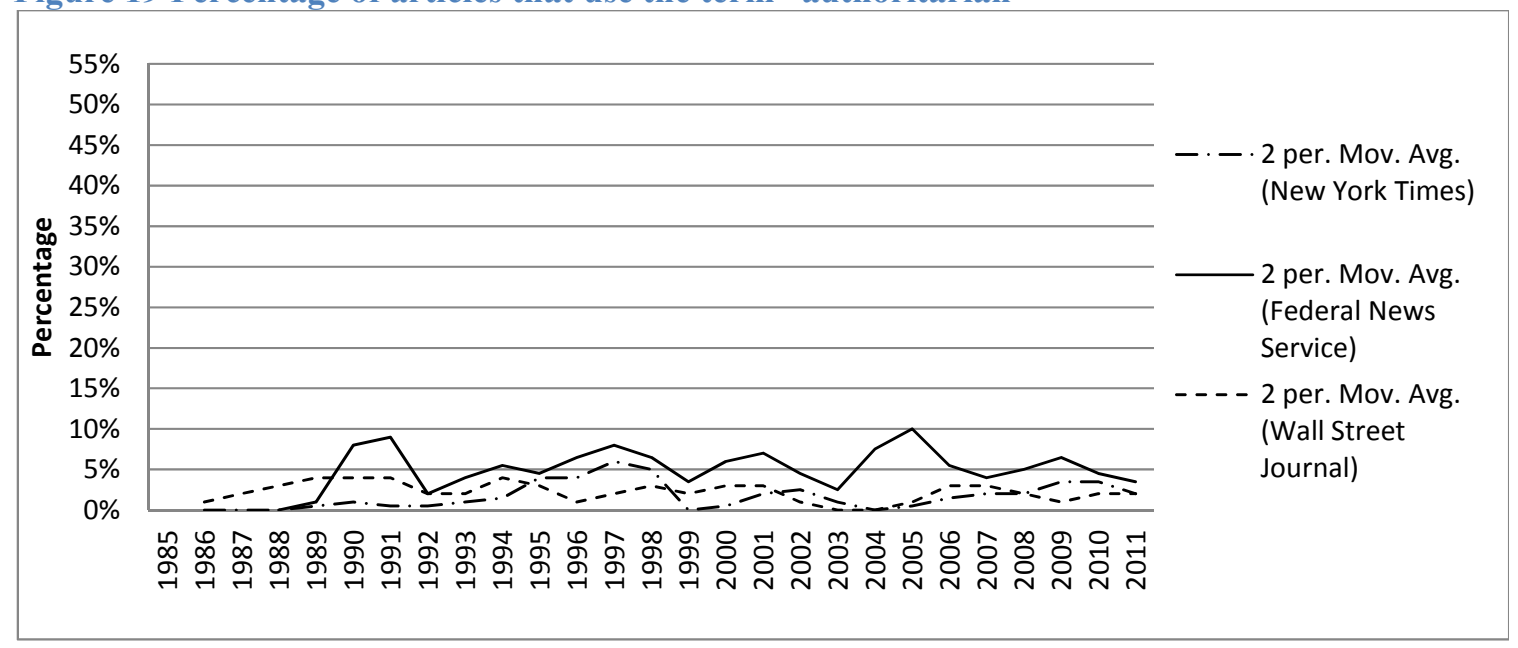

The significance of these results is further clarified by analyzing American preoccupation with the most illiberal aspects of China's political culture. In order to do this I conducted a KWIC search of all data sets looking for the terms "repress*," and "human rights." The terms "repression," or "repressive," are commonly used when an American speaker wants to discuss the absence of liberal values expressed by another individual, country or government. In the case of China, this term has been used often, to describe the PRC's actions towards its people. The shift in its use over time, as depicted in Figure 20, clearly indicates the evolution in American images of China as an illiberal state. It is apparent that media representation of China as a repressive state was rare prior to $1989 .{ }^{53}$ Use of the term rose dramatically in 1989 and 1990 and has been decreasing ever since.

\footnotetext{
${ }^{53}$ Note that data is not available from the Federal News Service prior to 1988
} 
Figure 20 Percentage of articles that use the term "repression," or "repressive"

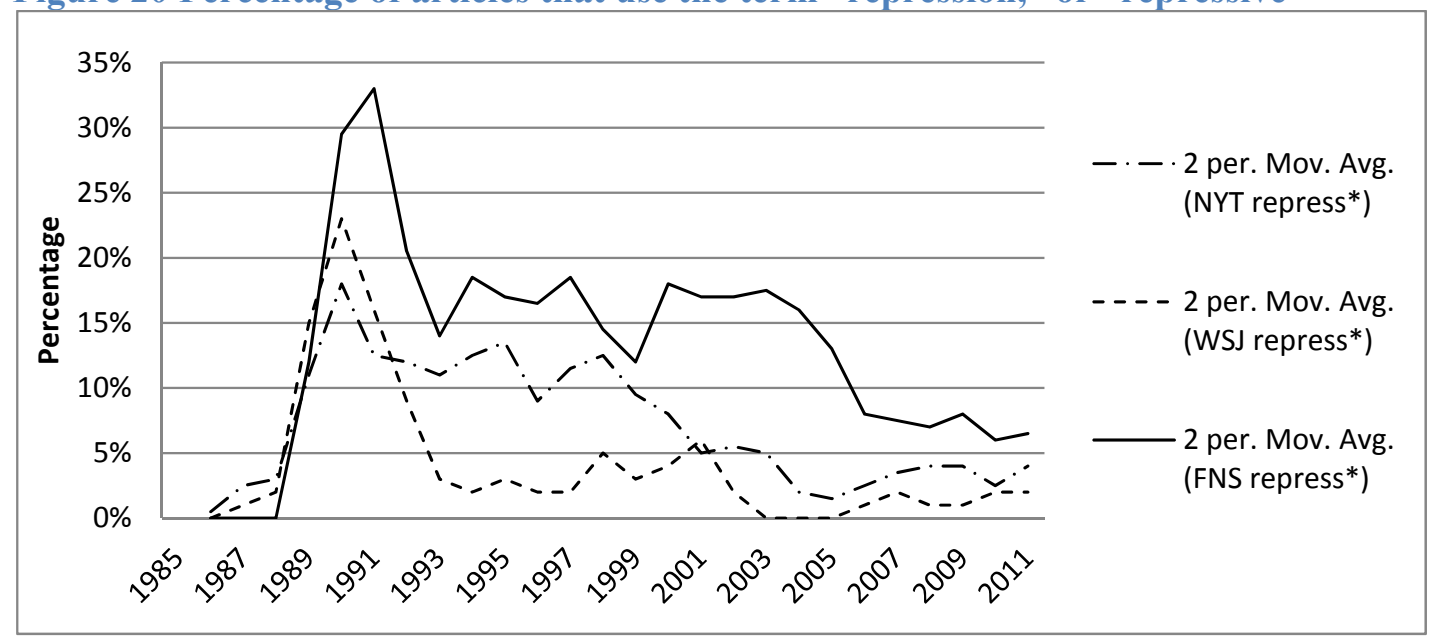

It is interesting to note the difference in representation among the three sources.

While reference to China as repressive has lessened substantially in the New York Times and the Wall Street Journal, the discourse of the political elite as represented by the Federal News Service has continued to use the term liberally. While this might suggest that the political elite have more negative perceptions of China's political culture than do other segments of American society, it might also be a simple artifact of the medium. Since both the Wall Street Journal and the New York Times are news sources, we should expect that, excepting opinion pieces, the texts from these sources make some attempt to be dispassionate in their representations of China. On the other hand, the texts gathered from the Federal News Service are mostly transcripts of speeches, in which passionate language is often expected. Nevertheless, even in these texts, we do see a decrease in representation of China as repressive - especially in the latter half of the 2000s.

Figure 21 shows that, indicative of one of Americans' biggest concerns about China, the term "human rights" has appeared far more often than any other. At its peak in 1991, the term was used in 53\% of the New York Times coverage of Sino-American 
relations, $34 \%$ of Wall Street Journal coverage, and a whopping $72 \%$ of texts representative of elite political discourse about China. While the terms usage was somewhat uncommon prior to 1989 , human rights issues became clearly relevant to the American people immediately following the events in Tiananmen on June $4^{\text {th }}$ of that year, and remained so for more than a decade. It wasn't until 2003 that references to "human rights," dropped significantly in all sources, particularly in the New York Times, which mentioned human rights in $11 \%$ of its coverage of China after 2002, (compared with an average of 44\% from 1990-2002), and the Wall Street Journal, which mentioned human rights in only $7 \%$ of its China coverage after 2002 (compared with an average of $21 \%$ from 1990-2002). Again it seems to be the political elite that are most pre-occupied with the illiberal actions of the PRC, with "human rights," appearing in more than half of the texts in the years from 1990-2002 and an average of 33\% since then.

\section{Figure 21 Percentage of Articles that Use the Term "Human Rights"}

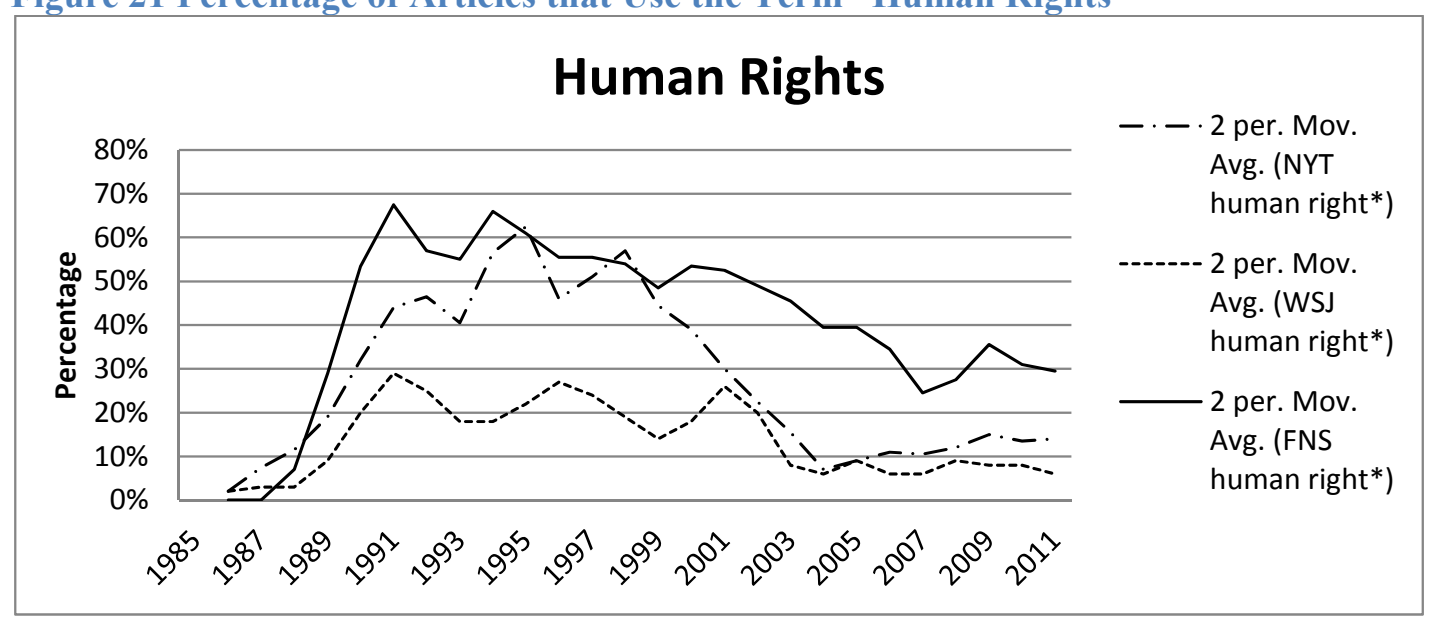

In both of the preceding analyses, media preoccupation with the illiberal aspects of China's political culture rose in 1989, peaked by 1993 and has been declining since. When we compare these results with Figure 10, they offer additional support for the 
hypothesis that shifts in the rhetorical representations of China's political culture within American discourse reflects and/or influences national attitudes toward China.

Nevertheless, it is difficult to gain a full picture of the nature of these representations through a purely quantitative analysis. The purpose of the following discussion, therefore, is to take a closer look at how images of China have evolved, in media discourse, over the last twenty-six years

\section{Trends in American Discourse on China}

The current study explores the trends in the tone of American discourse on China, and seeks to uncover the topical themes and underlying beliefs that shape this discourse. To this end a smaller subset of texts was chosen for a deeper discourse analysis. To select an appropriate sample I first examined a sample of 324 articles, spanning twentysix years of New York Times coverage of Sino-American relations, looking for those topics which appeared to dominate the discourse. This analysis demonstrated three different topic focal points that gained strength at particular points in history but remained relevant throughout the majority of the twenty-six year period. These were: the link between Chinese economic reforms and political liberalization, the issue of human rights in China, and the issue of Chinese power as an impetus for Sino-American cooperation. The second step was to take a closer look at how these topics are treated in the discourse by first selecting a sample of texts from each of the three sources (the New York Times, the Wall Street Journal, and the Federal News Service Database) for a closer reading. To this end I first did KWIC searches for the terms "economic reform," "human 
rights," and "cooperation China." ${ }^{54}$ I then skimmed the results looking for those articles that best represented the China discourse. Choosing no fewer than one and no more than three articles per source, per search, per year, a total of 128 articles were selected for a deeper reading.

\section{The promise of liberalism}

The 1980s witnessed a growing American excitement about the success and stability of Chinese economic reforms. Even though China's economic engagement with the United States was already eliciting some rumblings from the American textile industry, the economic rivalry between the two economic super-powers was yet to appear. The general enthusiasm about China's economic “opening," to the West often focused on the exchange of high level officials, products, and ideas that accompanied this process, and the subsequent prospects for extensive political reforms. This latter was pervasive, even in reports about other issues, and tended to put upward pressure on representations of China even in the immediate aftermath of the events of June 3-4 1989.

While the first era of Chinese domestic reforms initiated by Deng Xiaoping in 1978 were mostly economic, American observers were generally optimistic that these reforms would have liberal ramifications in China's political sphere as well. In February1988 Martin Lasater of the Wall Street Journal, argued that "It is in U.S. interests to encourage China's reforms, because they probably will lead to a more moderate regime in Beijing and an improved life style for the Chinese people." Western enthusiasm for China's modernization process is reflected in this sentiment which appeared in the New York Times in June of 1988: "In addition to adhering to ancient ways

\footnotetext{
${ }^{54}$ For the latter I conducted a proximity search ("China cooperation" 10 ) looking for references in which the term "cooperation," appears within ten words of the term "China."
} 
and traditions, the country brims with excitement and experimentation, its people exploring new things and new ways to bring China into the modern world" (Kesper 1988).

This enthusiasm culminated in the spring of 1989, when Americans watched enthralled as pro-democracy demonstrators, most of them students, gathered in Tiananmen Square to demand liberal political changes from the Chinese government. Many Americans believed that this was the beginning of the political liberalization expected to accompany what had been sweeping economic changes in China. In the months leading up to the events of June 3-4, Americans were feeling pretty good about China, and its democratic prospects. On May $22^{\text {nd }}, 1989$, Secretary of State James A. Baker had told Congress, “...we are pleased with the improvement in relations between the United States and the People's Republic of China over the past several years. That improvement in relations has been brought about in part at least by the fact that China is opening up. Its opening up its economy and had begun opening up, of course, its political system (U.S. State Department 1989). While discussions about the Chinese government were only cautiously optimistic, there was a tendency to identify with and even venerate, the Chinese citizens who were protesting in Tiananmen Square. On May $19^{\text {th }}$, A.M. Rosenthal (1989) wrote in the New York Times, "Who does not feel love, watching Chinese students, workers, teachers, journalists; young people and their parents, hearing them speak with such yearning for the freedoms that sustain our own lives?"

On June 3-4 however, Americans were quickly disillusioned as the PRC put a brutal and deadly end to the demonstrations. The impact of these events on American perceptions of China was dramatic. Initial outrage was tempered by a persistent 
optimism that China was still on its way toward a liberal political culture. Immediately following the massacre, an article in the Wall Street Journal suggested that by "violently suppress[ing]" the protestors, Deng Xiaoping and Prime Minister Li Peng had "created hundreds -- perhaps thousands -- of martyrs to the cause of the rebellion, a rebellion that few believe will now die" (Sterba et al., 1989). One week later a "senior U.S. official" reportedly implied that the crackdown was only a detour from Deng's path toward reformation, suggesting that "having moved to his right to regain stability, Deng may now move to his left to co-opt the reformers, defuse the alienation and try to regain popular support" (Greenberger, 1989). Approximately one month later, Carl Ford, the Principal Deputy Assistant Secretary for International Security Affairs in the Department of Defense, told Congress that the exchanges between the United States and China had contributed to "forces" working in China "to have more reform, a more modern society, a more modern government" adding that "I, for one, happen to believe that those forces are still alive in China, that those ideas can't be killed...," (U.S. House. 1989).

As the summer of 1989 progressed, Americans were slow to assess the implications of the Tiananmen Square Massacre. The media representations of the event varied as a wide debate circulated over the future role of democracy in China. While Chinese leadership was calling the protestors "counter-revolutionaries," in the United States the event was intermittently called "the Tiananmen Massacre," or the "Tiananmen Crackdown." The days leading up to the event were referred to as either the "Tiananmen demonstrations," or the" pro-democracy movement," the latter typically described as having been "crushed" or "repressed." Throughout the summer, American discourse reflected shock and outrage, while those at the very top immediately tried to calm the 
citizenry by advocating "a measured response." The extent to which discussions of these events dominated American discourse in the 1990s is depicted in Figure $22^{55}$

Figure 22 Percentage of articles that refer to the June $4^{\text {th }}$ incident in Tiananmen Square

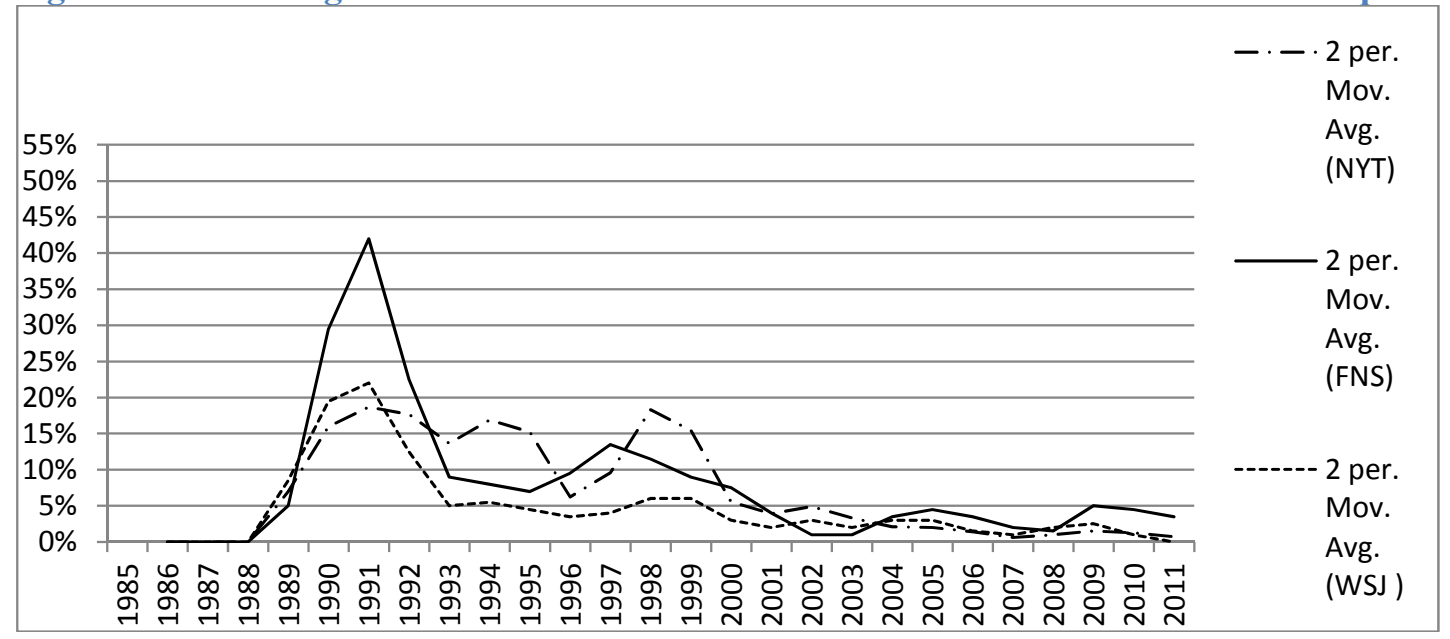

As 1989 turned into 1990 and then 1991, it gradually became apparent that the Chinese democracy movement had been effectively crushed. While reporters continued to discuss the "pro-democracy movement," in the present tense even months after, the June 3-4 events, by 1992, all discussions of these events were largely absent any hope of a democratic resurgence in China. In May 1992, Robert S. Greenberger of the Wall Street Journal encapsulated views about Democracy's prospects in China by quoting Deng Xiaoping saying "Once the forces of turmoil reappear in the future, we will not hesitate to use any means to eliminate them as soon as possible." In December of 1992 A.M. Rosenthal argued that "American buyers of Chinese goods and propaganda tell us that Communist economic progress leads inevitably to political freedom. As where? I heard that line when I was a correspondent in Poland during the coldest days of Stalinist

\footnotetext{
${ }^{55}$ These results were gained by first doing a KWIC proximity search of the following: "Tiananmen crackdown" $\sim 10$, "Tiananmen massacre" $\sim 10$, "Tiananmen protests" $\sim 10$, and "pro-democracy movement," and then calculating the number of articles that mentioned one of these four terms as a percentage of all articles collected each from the New York Times, the Wall Street Journal, and the Federal News Service.
} 
Communism, and ever since. The people of the evil empire achieved liberty not when it grew richer but when it collapsed under rebellion, corruption -- and Western pressure." This pessimism contributed to the darkest days of the Sino-American relationship since the 1972 rapprochement. American attitudes toward China reach their lowest point in 1991. The low-point in relations was further evidenced by American sanctions against China and congressional attempts at anti-China legislation.

Nevertheless, American optimism about the potential for democracy in China proved resilient. While 1990-1993 was a time of great pessimism and anger, belief that political reform was inevitable, especially if the United States would continue to engage with China economically, gradually returned to the American China discourse. In a 2001Wall Street Journal article Paul Gigot credited Harry Rowen, whom he called "one of the original Cold Warriors," with the claim that if China were to succeed in opening its economy without opening its politics it would be the "first country in history," to do so, excepting the "marginal case," of Singapore. In 2005, an article appearing in the Wall Street Journal claimed that "Free trade also helps build a Chinese middle class that will eventually demand more political freedom" ("China's Oil"). This optimism continues to put upward pressure on attitudes toward China and keeps the containment argument from gaining traction.

\section{The Human Rights issue}

As demonstrated in the previous analysis, the 1980s saw only limited discussion of human rights, and practically no reference to repression in China. While there was some reporting of government crackdowns on pro-democracy movements leading up to Tiananmen, there was a general tone of optimism that these were the birth pangs of the 
democratization process that had been promised by China's economic liberalization. However, the violent repression of protestors on June 3-4 1989 brought the topic of human rights immediately to the fore-front of American discourse on China. Even though American outrage over these events was sufficient to engender a vociferous and lengthy national discussion on the issue, there was another set of circumstances that guaranteed not only that the issue of human rights in China would be hotly debated for a decade, but also that, in American minds, the issue would be indelibly linked to the SinoAmerican economic relationship. A relic of the Cold War, the Jackson-Vanik amendment, passed in 1974 as a response to the Soviet Union's restrictions on emigration, provided that the U.S. President could only grant non-market economies temporary most-favored-nation (MFN) status and only after an annual review proved that these countries had sufficiently liberal emigration policies. After 1989, this previously obscure legal connection between China's human rights record and Sino-American trade, took on a new significance in American China discourse.

Prior to the 1989 crackdown, China was regularly granted MFN status without any political contestation and with very little public acknowledgment. Out of $780 \mathrm{New}$ York Times and Wall Street Journal articles discussing Sino-American relations from 1985 through 1988, China's MFN renewal was mentioned only twice, both times in passing. After the pro-democracy movement was quashed, however, it became an annual catalyst for engagement debates with the topic of human rights playing a prominent role in the argument on both sides. ${ }^{56}$

\footnotetext{
${ }^{56}$ This situation is reminiscent of the current debt ceiling debates. In both cases an arguably unnecessary federal law requiring a government body to make an annual decision of some import, is obeyed for years in relative obscurity as the necessary decision is made quietly and without serious contestation. In both cases
} 
This debate raged for a decade with the pro-MFN contingent, including current administration officials and transnational capitalists, favoring unconditional renewal of China's MFN status, and the opposition, including (especially in the early 1990s) a congressional majority, human rights activists, and American economic interests hurt by the growing trade deficit with China, arguing that MFN status should be granted only with certain conditions. While there were many issues behind the debates, the nature of the Jackson-Vanik amendment, combined with the national furor over Tiananmen, ensured that the issue of "human rights" was central. The annual tussle had mostly negative results on representations of China. While it often prompted administration officials to argue their case through praising Chinese reform progress and Chinese liberal potential, many congressmen and others used this as an opportunity to let loose a barrage of vitriolic sentiment about China's repressive political elite and the weak willed Americans with whom they do business.

The first signs of what would become the annual MFN debate emerged immediately following the crackdown in late June of 1989, when Senator Jesse Helmes proposed a provision on a spending bill that would suspend China's MFN status indefinitely. President Bush argued repeatedly that engagement with China would ensure a return to moderation by China's political elites and thus an improvement in China's human rights situation. However, over the next several months as newspapers were replete with reports of harsh sentences for pro-democracy demonstrators meted out by the PRC, as well as other acts of repression clearly designed to silence other would be

a particular set of circumstance transforms the law into an annual lightning rod of political debate with serious implications for the national interest. 
dissidents, criticism of the Bush administration accompanied a growth in criticism of the policy of engagement to achieve political reforms.

The debate gained national attention as the first post-crackdown deadline for MFN renewal approached (coincidentally) on the anniversary of the event- June $3^{\text {rd }}$ 1990. In October of that year, The U.S. House of Representatives had overwhelmingly approved legislation that would make renewal contingent upon specific human rights improvements. As the anniversary drew near, media speculation that President George H.W. Bush would veto this legislation raised the debate to fever pitch. In April, William Safire (1990) of the New York Times condemned what he called " our obsequious cheekturning," pointing out that despite promises to the contrary it had not led to the relaxation of Chinese repression. In May, Democratic Representative Samuel Gejdenson was quoted in the Wall Street Journal saying, "Bush's policy has been an embarrassment for the country...The president's longtime relations with the leaders of China seems to cloud his ability to see what's in the best interest of the Chinese people" (Greenberger 1990). That same month the former American Ambassador to China, Winston Lord, stated that "the situation in China has greatly deteriorated this past year: executions, purges, imprisonment, surveillance, political indoctrination, the rollback of many economic reforms - all cloaked in the Big Lie. The xenophobic regime has launched attacks on Western values and crude invective against the U.S. It muzzles foreign correspondents and jams the Voice of America" (U.S. House 1990).

While the argument was temporarily put to rest by Bush's decision to grant unconditional MFN status renewal to China in June 1990, it re-emerged in the spring of each of the following years. In May 1991, President Bush reportedly argued that granting 
unconditional MFN status would lead to improvements in Human Rights as normal trade relations "is a means to bring the influence of the outside world to bear on China," (Rosenthal 1991b). The New York Times quoted Bush saying, "Though there are major problems in China, things we don't like about their system, things are an awful lot better than they were back in 1975" (Rosenthal 1991a). The opposition was clear. Senator Moynihan's opinion about granting China MFN status was, "We don't want to reward them for behavior we find evil" (Rosenthal 1991b). Robert S. Greenberger of the Wall Street Journal argued that "President Bush just can't get over his case of unrequited love for China. He bestows benefit after benefit on Beijing, and China breaks promise after promise" (1992). Thomas L. Friedman, quoted an administration official who "acknowledged that the Chinese have made few improvements in human rights during the past year, and in recent months have taken actions that almost seemed designed to 'to rub our nose in it'"(1992a).

The 1992 presidential election, which culminated in the election of Bill Clinton as the United States' $42^{\text {nd }}$ President, highlighted what seemed to be a very big difference between Bush and Clinton, in regards to Human Rights in China. As a candidate, Bill Clinton was seen as the leader who would be toughest on China over the human rights issue. Supportive of attaching human rights conditions to the renewal of MFN status, he famously criticized the Bush administration for "coddling dictators" (Friedman 1992b). However, as time passed, it quickly became apparent that President Clinton's China policies were very similar to Bush's. Frequently, searching for evidence that engagement was improving the human rights situation in China, Clinton faced down congressional opposition and renewed China's MFN status every year. When on May 26, 1994 
President Clinton announced that he was delinking the issue from the annual renewal of China's MFN status, he argued that the "best path for advancing freedom in China is for the United States to intensify and broaden its engagement with that nation" (U.S. White House. 1994).

As the memory of Tiananmen began to recede the debate became less volatile, and discussions about human rights in China became more optimistic. In 1995, Assistant Secretary for East Asian and Pacific Affairs Winston Lord reported "trends in China that promise a brighter day for human rights" (U.S. State Department. 1995).

Over the last decade, the emphasis on human rights has diminished as the China discourse has become ever more ubiquitous in the American media as well as much broader in scope. One area of increasing focus has been the Sino-American economic relationship. This is apparent when one looks at the most recent example of the American tradition, which occurs every four years, whereby Presidential candidates chastise the current administration for being "soft on China." In 2011 Mitt Romney was the first such candidate in 20 years to make little mention of China's human rights record, choosing instead to castigate President Obama for "feckless economic policies," that allow China to get away with gaining a trade advantage through "cheating" (Romney 2011). While negative images of China are common in the reporting of economic issues, the vitriol with which Chinese repression was reported in the 1990s is largely absent.

American concerns about human rights in China are unlikely to disappear. Nevertheless, the tone of the discussion has certainly changed since the years initially following the Tiananmen Square crackdown. For example, in 1995, At a White House Press Conference with both President Jiang Zemin and President Clinton, the latter 
expressed some views about human rights in China that were much more abrasive than anything that would currently be said by an American government official in the presence of a high ranking Chinese official. After President Zemin's statements about the "necessary measures," taken by the PRC on June $3-4^{\text {th }} 1989$, Clinton responded by stating that "I think it should be obvious to everyone that we have a very different view of the meaning of the events at Tiananmen Square. I believe that what happened and the aftermath and the continuing reluctance to tolerate political dissent has kept China from politically developing the level of support in the rest of the world that otherwise would have been developed." When asked if the United States would soon drop post Tiananmen sanctions Clinton replied that "The depth of the view in the United States I think is nowhere better exemplified than in the so-called Tiananmen sanctions. We are the only nation the world, as far as I know, that still has sanctions on the books as a result of the events of eight years ago" ("Press Conference" 1994). These statements were reflective of the national feelings about China and human rights at the time. While American elites continue to broach the topic of human rights with Chinese officials, the tone has become quite different.

Not only are changing attitudes reflected in the changed tone of elites speaking to Chinese about Human Rights, even more telling is the change in the tone of reporters covering these comments. In 2011 Jeff Sommer reported approvingly that in a joint news conference in Washington D.C. President Obama "chided," Chinese president Hu Jintao, about human rights issues, "but did so gently," because he was treating him with "the respect due a man who represents the second-largest economy on the planet." Without scorn, reporter Mark Landler (2011) described Secretary of State Hilary 
Clinton's comments on human rights in China as "a polite criticism." These shifts in tone are not only because of the temporal distance of the Tiananmen Square incident, but also to some degree reflective of the third trend shaping American China discourse- growing Sino-American interdependence.

\section{Power, interdependence, and the need for cooperation}

By far the most ubiquitous trend in representation of China since 2000 has been an increase in the identification of China as an important player in global politics, and a subsequent enhanced recognition of American dependence on Chinese cooperation in a number of important issue areas. What is most interesting about the highlighting of China's growing global importance is that it has not provided quite as much of an impetus for negative representations of China as one might expect. Certainly discourse focused on this topic tends to represent China far less negatively than what was seen in debates about the human rights issues in the 1990s. While conflicts in areas as diverse as intellectual piracy, currency values, UN sanctions, and relations with Taiwan put downward pressure on representations, these are balanced by the positive representations of China made by numerous politicians, defense experts, academics, economists, journalists and China-watchers repeatedly make the case that the United States can and should cooperate with China.

The impact that the Sino-American interdependence has on American China discourse is exemplified in a 2005 Wall Street Journal article in which anger toward China is expressed by Democratic Senator Byron Dorgan who argues that "China wants us to be a sponge for all their trinkets and trousers and shirts and shoes and all the things they produce, including high-tech, and yet, they don't want to open their market to us." 
This obviously negative view is balanced by the authors Jay Solomon and Greg Hitt, who first acknowledge that "the Bush administration is caught in a complex balancing act: bashing Beijing enough to appease critics in Congress and stir action -- without provoking a trans-Pacific backlash," and then points to the problem of chastising China on whom it is dependent for cooperation in important strategic issue areas. "the U.S. is exerting pressure on economic issues and criticizing China's human-rights policy and belligerence toward Taiwan, just as it is begging Chinese leaders for more help in curbing nuclear weapons in North Korea and hoping China won't cozy up to anti-American governments in places such as Venezuela."

This trend is not completely new - the strategic importance of maintaining a cooperative relationship with China has been a dominant theme in policy circles ever since Nixon first argued that engagement with China was in the U.S.' national interest, because China was needed as a counterweight to Soviet power. However, the growth in Chinese power and influence at a time when the world is becoming ever "flatter," ensures that China and the United States have become remarkably more interdependent since 1972. Interdependence combined with a belief that Chinese cooperation is attainable has shaped the discourse in mostly positive ways and as awareness of Chinese power and influence has grown this trend has only accelerated.

By the mid-1990s proponents of unconditional MFN status renewal were already emphasizing China's growing importance in world affairs. Senator Max Baucus (D-MT), for example, highlighted what the United States stood to lose by not granting China MFN status. The list included jobs, as well as Chinese cooperation in the UN Security Council 
and on the environment, North Korea, missile sales, Iraq and the Middle East ("National

Press Club" 1994). That same year Senator Charles S. Robb (D), argued that

"China has the potential to become a true super power early in the 21 st Century. With that in mind, and in view of the country's massive economic expansion and modernization, its burgeoning military, its continued population growth, and the mantle of leadership it has seized in the most prosperous part of the world -- East Asia -- I believe it is important for the United States to seek common ground with Beijing, where possible, and to address differences in the context of the overall relationship. I would submit that it is in our national strategic interest to engage mainland China, now and in the future" (U.S. Congress 1994).

Like the human rights issue and the linking of economic and political liberalization, the emphasis on the need for Chinese cooperation has become a major component of the engagement debate. In 1995, William Perry the Secretary of Defense argued that "whatever our differences with China, we also have important common interests, and that these interests make dialogue more rational than confrontation." In 1996, the President of the United States Business Council Robert A Kapp argued that "in a small and shrinking world, where the United States and China simply cannot avoid constant interaction, it would appear self-evident that a bilateral relationship of regular communication, concerted efforts at mutual understanding, and ever-increasing peaceful contact in trade, academic life, and the many arenas of global cooperation is in the deepest interest of the United States" (U.S. House. 1995). In 2004, Don Evans of the Wall Street Journal approvingly reported that "President Bush believes that open markets and a level playing field are vital to job creation and economic growth. That is why the president rejects economic isolationism and why this administration is continuing to aggressively engage with China." 
Often the response to criticism toward China on numerous issues is deflected by those who point to the benefits of Sino-American cooperation. On May 20, 2005 the Wall Street Journal accused the United States of "ragging" China about its currency, and criticized Congress for "yammering" about the same issue, arguing that "The U.S.-China relationship has contributed to global economic growth -- which reached nearly $5 \%$ last year -- and has increased the possibility that China will evolve into a responsible democratic nation" ("Feeding").

\section{Discussion}

American attitudes toward China are largely shaped by American perceptions of China's political culture and it is clear that representations of China's political culture have shifted over time in ways that clearly reflect the changes in American attitudes toward China. Ever since December 1942, when Japanese bombs effectively ended the American isolationist movement, the U.S. role as champion of democracy and liberal values everywhere has had an important place in American discourse. While this aspect of American self image has played a role in discussions about all types of international issues, nowhere has it been so prominent and had such an impact as is the case with SinoAmerican relations. By many sectors of society, it is largely taken for granted that America's China foreign policy decisions should always be made with an eye toward how these decisions will impact the potential for political reforms in China. It is not that the Chinese domestic politics are seen as more important than American national interest, but rather that they are seen, by many, as one in the same.

Discussions about China's political culture have not disappeared, but they have slipped into the background of discourse. The fact that China is authoritarian is 
somewhat taken for granted but the implications of this are not as prominent in American China discourse as they once were. The memory of the Tiananmen Square massacres has faded, and discussions of human rights have faded right along with it. In addition, China has been granted permanent normal trade relations ensuring that the debates about whether the PRC is too repressive to trade with will no longer capture the nation's attention every spring. Nevertheless, the legacy of these circumstances lives on. Evidence of American pre-occupation with China's domestic political culture is still readily available in discussions about China at every level. The issue of human rights is mentioned by the American official in every high level visit between the two states. The American media continues to take a particular interest in stories about Chinese dissidents and their treatment by the PRC. Most importantly, There are still suggestions within American discourse that American policies toward China should be linked to the effect that these policies are likely to have on political reform in China. Nevertheless, the extent of this preoccupation has lessened over time, as has the degree of hostility expressed in American criticism of the PRC.

To some extent, the emphasis on China's domestic politics within American discourse has shifted to concerns about China's international politics. As China continues to gain economic, political, military and "soft" power, in international relations, American discourse has focused increasingly on what Chinese power means for the United States' ability to achieve its national interests in the present and in the future. While realist theory would suggest that this changing power relationship would lead to increased tensions between the two countries, the above analysis demonstrates that American hostility toward China, while definitely present, is frequently lessened by an 
acknowledgment that the United States not only needs China's cooperation to achieve its objectives, but also that it is possible to obtain this cooperation. Throughout the last twenty-six years, American hostility toward China has been tempered by the argument that the United States can get what it needs from China only through engagement. Whether the goal is a more liberal Chinese government, a Chinese vote in America's favor at the United Nations, or a reduction in Chinese piracy. As long as the majority of Americans believe these gains are possible, the engagement rhetoric will continue to keep American hostility toward China in check. The necessary beliefs that underlie all others, however, are that China is fundamentally "like us," that the people place a high value on economic and political freedom, and that the government is rational, values the international status quo, and is willing and able to compromise. Many of these beliefs were seriously shaken in the aftermath of the Tiananmen Square incident. While these beliefs have proved resilient, they could be destroyed, and this would have an incredibly damaging impact on Sino-American relations. 


\section{WHAT DO THESE FINDINGS MEAN FOR UNDERSTANDING AND PREDICTING THE SINO-AMERICAN RELATIONSHIP?}

American images of China have an important impact on the Sino-American relationship because they enable certain elite actions while prohibiting others. Whether Americans view China through a lens of friendship or one of animosity determines how they are likely to view Chinese motives and Chinese actions, which subsequently determines what U.S. policy responses will be deemed appropriate. Images, therefore, play a determinant role in the extent to which the two countries are able to negotiated difficult circumstances and cooperate to resolve potential problems. The power and importance of both China and the United States, in addition to their current state of interdependence, ensure that there will continue to be numerous potentially contentious issues arising between them for the foreseeable future. How Americans view China will be a decisive factor in whether and how such issues are resolved.

Yet the contemporary American image of China is difficult to define and not very well understood. While it is generally accepted that Chinese economic growth is making China a super-power, Americans are not sure how to feel about this fact. The SinoAmerican relationship is certainly a complex and important relationship but is it a "partnership," “a competition," or "a rivalry?" Despite the significance of the question, there is no general consensus in the American mind as to the answer. Americans do not see China as an "enemy," but neither do they see China as a "friend," rather they see China as something undefined, which exists in the nebulous middle ground between these two archetypical images. The result is that disagreements about whether China should be 
treated with wary skepticism or with cautious optimism are ubiquitous at even the highest levels of policy making.

This inability to clearly define the American image of China is not attributable to a dearth of effort. Exploration of American images of China date back more than four decades. In a 1950s study conducted prior to the Sino-American rapprochement, Harold R. Isaacs (1958/1980) analyzed polling data and textual data to demonstrate that American's have archetypical images of Asians, both positive and negative, which are intermittently applied to either the Japanese or the Chinese, depending on with whom Americans are getting along. While his study is somewhat dated, many of Isaacs' observations continue to shed light on American perceptions of both countries. In 1987 John Dower analyzed numerous texts to demonstrate the role of racism in shaping American images of Asians. Despite the fact that Dower's War without Mercy focuses mainly on American images of Japan and the Japanese people, many of his observations can be applied to American views about Chinese at certain points in history. More recently, Jianwei Wang (2000) uses surveys to explore the mutual images that American elites have of China and Chinese elites have of the United States, how these images have evolved over time, and the extent to which profession and interaction influence these images. Wang's study provides some interesting observations about the way that businessmen from both countries see each other. For example, he finds that while both sides perceived numerous differences in the ways of doing business, the Americans attributed these differences to the Chinese social environment, while the Chinese attributed them to differences in personality (69). 
Each of these studies explores the role of stereotyping in shaping American images of Asians in general and of Chinese in particular. Nevertheless, even though these insights are helpful in explaining some of the idiosyncrasies of American images of Chinese they don't explain current levels of ambivalence towards China. They also fail to shed any light on what might cause this ambivalence to pivot toward amity or enmity in the future. These are the questions that my study seeks to answer. By exploring factors that greatly influence the process of threat construction and Other identification within the American national consciousness, this study explains the basis of American images of China as well as how and why those images have evolved over time. This is accomplished by exploring the independent and interactive impacts of three different independent variables on American attitudes toward economic competitors in general, and toward China in particular. These variables are: perceptions of the Other's capabilities, perceptions of the threat or opportunity that the Other provides, and perceptions of the Other's political culture. This analysis is conducted with the belief that understanding the reasons behind Americans current ambivalence toward China will not only enable a better understanding of the current Sino-American relationship but also enables academics and decision makers to make better predictions about its future course.

This is not to say that American images of China are the only, or even the most important factor influencing Sino-American relations. Obviously, there are numerous exogenous factors that will impact the relationship in ways that will be difficult to predict. Also, Chinese attitudes and actions will play their part in how the relationship evolves. What is clear, however, is that American attitudes toward China will necessarily impact how exogenous events are approached and how Chinese attitudes and actions will 
be perceived. For example, the 2008 financial crisis was an exogenous event that could have led to a worsening of the Sino-American relationship. Had American decision makers perceived China as an enemy or as a threat, the potential for cooperation would have been seriously diminished. As it happened, though, the Chinese were perceived both as willing and as capable of contributing to a quick global recovery, and SinoAmerican cooperation through the G-20 (and what some have termed the G-2) has been largely credited with preventing "the next Great Depression."

It must also be acknowledged that there are numerous different groups within the United States that are likely to have distinctly different attitudes toward China. If one were to disaggregate the American population, one might find that there are distinct differences in these attitudes along numerous fault lines. For example, there might be regional differences due to variations in populations of Chinese Americans. Or there might be differences along political lines with republicans feeling more or less positively toward China than do Democrats. While my study does not explore these divisions among the American people, it does demonstrate that there are differences in the extent to which the illiberal nature of China's political culture is emphasized within the discourse of three American groups. The business elite, as represented by texts gathered from the Wall Street Journal, tend to de-emphasize China's illiberal political culture, while the political elite, as represented by texts gathered from the Federal News Service, demonstrate a much higher level of pre-occupation with the negative aspects of the PRC. The general elite, as represented by texts gathered from the New York Times sits somewhere in the middle (see figures 18-21). 
In addition, there are numerous forces within the United States that are likely to shape and constrain the construction of American attitudes, rhetoric, and policies toward China. The personality, belief system, or even the ethnic heritage of American decision makers may shape their responses to China in particular and predictable ways (Holsti 1970; Holsti and Roseneau 1983; Walker 1990; Creed and Rosati 1997; T. Breslin 2011). In addition, powerful stakeholders such as big business, have huge incentives and numerous methods for shaping American foreign policy toward China (Cox and Lee 2012). Nevertheless, whatever factors are shaping individual actor's motives and actions, these actors are also constrained in a very real way by the sentiments of public opinion.

The connection between public opinion and foreign policy has been sufficiently proven in a multitude of empirical and theoretical studies. While early public opinion research concluded that public opinion was too misinformed, reactionary, or disorganized to influence foreign policy, more recent analysis has demonstrated that the opposite is actually true, public opinions on foreign policy tends to be rather "prudent" (Shapiro and Page 1988, Jentleson 1992) Democracy Peace theorists have shown the importance of public opinion in shaping elite foreign policy decisions in democratic countries like the United States, particularly those decisions that are likely to lead to war ( Mintz \& Geva, 1993). Others studies have further proven that a significant corollary often exists between public opinion and foreign policy (Monroe 1979, Hinckley 1988, Foyle 1999, Sobel 2001). While analysts disagree about the extent to which public opinion constrain elites in other countries, there has emerged a general consensus that when it comes to American foreign policy, public opinion matters. 
Once one has accepted the importance of public opinion to shaping and constraining American foreign policy, then public opinion itself becomes an important topic of research. While there have been some excellent studies that analyze current American opinions of China (Page and Xie 2010), these quickly become dated and tell us little about how the relationship is likely to evolve over time. What has been missing is an understanding of the basis of American attitudes toward China that would further enable us to understand how certain representations of China are likely to influence the evolution of American rhetoric and policy towards China, through their impact on public opinion. This is the gap that my study seeks to fill.

The current study contributes to our understanding of how images of Others are constructed in American discourse by analyzing how American perceptions of three different components of bi-lateral relationships act and interact in shaping American attitudes toward those Others. I began by testing three hypotheses, each predicting that a different component of bi-lateral relationships would be the most important in determining American attitudes. Hypothesis \#1 predicted that American attitudes are driven primarily by the rising capabilities of powerful Others. Hypothesis \#2 predicted that American attitudes toward Others are shaped primarily by perceptions of the U.S.Other relationship, and Hypothesis \#3 predicted that American attitudes are shaped primarily by perceptions of the Other's political culture.

As discussed in chapter three, the first test had mixed results. Historical process tracing and analysis of polling data was used to test the extent to which hypothesis \#1 holds true under varying circumstances. First I traced the dramatic increase in economic capabilities of two important American competitors—Japan and China — over the fifteen 
year period in which each rose to economic prominence (for Japan this was 1977-1995, and for China this was 1996-2011. Then I analyzed shifts in American attitudes toward each competitor over that same period. The results demonstrate (1) that Americans do not automatically respond negatively to economic competitors, even when an Other's economic capabilities begin to approach those of the United States, and (2) Americans respond very differently to similar types of economic threat emanating from different competitors such as Japan and China.

While realists argue that threat perceptions are a function of rational individual calculations about the material balance of power, my study finds that American attitudes toward Others do not always trend in ways that can be explained by a simple reaction to changes in this power relationship. By first tracing the evolution of Japan's economic capabilities (1977-1995) and then analyzing public opinion polling data about American attitudes toward Japan over that time period, we see that Americans did exhibit rising hostility toward Japan in the late 1980s, but this was only after they had failed to respond to changes in Japan's economic capabilities for more than a decade of significant economic competition between the two countries. By conducting the same analysis with China for the years 1996-2011 we find trends that are even more surprising. Even as China's economic strength and international clout have been increasing steadily over the last fifteen years, Americans have not responded with increases in hostility. What we see instead is a general positive trend in attitudes over that period. When we zoom out further to look at the last twenty-five years, we see positive attitudes in the latter half of the 1980s, negative attitudes throughout the 1990s, and ambivalent attitudes throughout the 2000s. In fact, over the first half of the decade as China's economic power was 
growing along with China's abilities to challenge the United States in numerous issue areas, we see a general improvement in relations, only recently seeming to stabilize at the line of ambivalence.

While the first test neither proved nor disproved hypothesis \#1, it did raise an interesting question as to why Americans were responding so differently to these two economic competitors. Not only did attitudinal responses trend differently in the two cases, but attitudes toward China were generally much more negative than were attitudes toward Japan. To explain these differences and to further test all three hypotheses, I designed an experiment to test the basis of subject attitudes toward other countries in general and toward China in particular. The first and second parts of the experiment showed that attitudes toward Other countries are shaped in large part by perceptions of that Other's political culture, the implication being that perceptions of China as a repressive authoritarian regime puts downward pressure on attitudes, and influences how Americans feel about other aspects of the relationship.

These tests provide ample evidence to support the hypothesis that political culture is the dominant factor driving American attitudes toward economic competitors. This doesn't mean that the other components of bilateral relationships are unimportant, just that American perceptions of political culture are the prism through which these other components are viewed. How Americans respond to a competitor's changing capabilities is greatly impacted by whether that competitor is seen as an authoritarian or democratic state. The likelihood that the perception of opportunity will ameliorate negative feelings toward an Other is greatly increased when the Other is perceived to be a Democracy. This latter can also have the opposite impact. The results of the experiment suggest that 
the fact that Japan was perceived as having a liberal political culture might have contributed to the extent of the negativity that Americans felt toward Japan when it was perceived to be a threat in the late 1980s and early 1990s.

The link between American attitudes toward an economic competitor and perception of that competitor's political culture is most easily demonstrated in the case of China. Because of the historical nature of the Japan case, it is impossible to design survey methods to accurately test this relationship. ${ }^{57}$ However, this was possible for the China case and was done in part three of the social psychological experiment discussed in chapter four. This analysis demonstrates a significant correlation between a subject's preoccupation with the illiberal nature of China's political culture and a subject's negative attitudes toward China.

While, the findings discussed in chapter four do help to explain why changes in Chinese capabilities are not clearly reflected in changing American attitudes, they beg the question: why have American attitudes changed so dramatically over a period in which the Authoritarian nature of the Chinese government has changed very little? In fact, there is much evidence to suggest that China's political culture has remained fairly stable over the entire twenty-six years under investigation. Two organizations monitor the globe for trends in liberal political changes. The first, Freedom House, is an American nongovernmental organization that calls itself an "independent watchdog...dedicated to the expansion of freedom around the world." Freedom House rates countries according to two different indicators: Political Rights (PR) and Civil Liberties (CL) and also gives

\footnotetext{
${ }^{57}$ Since Japan is not currently seen as an economic competitor, current subject attitudes toward Japan would not be relevant. Even if subjects were old enough to remember the period of extreme economic competition between Japan and the United States (1977-1993), it would be highly unlikely that they would accurately remember their perceptions of Japan at that time.
} 
countries a ranking of Free (F) or Not Free (NF). Following Deng's 1978 reforms, Freedom House gave China a bump in both the PR and CL scores raising China from the most autocratic score of 7 to the still far from liberal score of 6 . The scores again hit bottom after the events of June 3-4, and while China's Civil Liberties score once again improved to a six after 1998, its Political Rights score has remained a seven since 1989. China has been stamped clearly NF for the entire period ("Freedom in the World" n.d.). The second organization, the Polity IV Project, which measures political regime characteristics for all countries annually, has shown even more stability in China's political culture over time. The Project measures political regime characteristics on a twenty-one point scale ranging from -10 (fully institutionalized autocracy) to +10 (fully institutionalized democracy). The Project has given China a score of -7 every year since 1978 (Marshall and Jaggers n.d.).

It must be acknowledged, therefore, that it is not changes in the reality of China's domestic political institutions or behavior that affect American attitudes, but rather the evolution in American perceptions of China's political culture as becoming more or less liberal. Other studies have demonstrated the importance of perception when it comes to the influence of regime type on relations between states. John Owen (1994, 95-97), argues that it is not the fact of democracy within two countries that ensures peaceful relations between them, pointing out that the democratic peace phenomenon only works when citizens in one democratic country (the United States) recognize the political culture of the other country as liberal. Owen points to several cases where American liberals felt animosity toward other purported democracies simply because they perceived their political culture as not democratic. These situations ultimately culminated in the 
War of 1812, the American Civil War, and the Spanish-American War (95-97).

Additional evidence suggests that when gauging the liberal credentials of an Other, Americans look beyond the existence (or lack there-of) of liberal institutions and instead respond strongly to events that indicate an authoritarian Other is moving towards or away from liberal values. For example, Mark Haas $(2007,169)$ has demonstrated that the United States changed its policy towards the Soviet Union in response to Gorbachev's proposal to adopt institutional changes rather than the existence of any actual liberal institutions, which would take years to become a reality.

Therefore, the question becomes how, and why, have American perceptions of China's political culture followed the course that they have. Following this line of inquiry, the investigation leads to a textual analysis of American representations of China over an extended period of time. First, coding a sample of New York Times articles over a twenty-six year period reveals a close parallel between national attitudes toward China and media representations of China. Second, content analysis - extensively covering the discourse of America's general elite (the New York Times), business elite (the Wall Street Journal), and political elite (the Federal News Service) — shows the extent to which a preoccupation with the illiberal nature of China's political culture in the 1990s, mirrored negative attitudes toward China during that time, while an absence of this preoccupation mirrored the more positive attitudes toward China in the late 1980s, and a lessening of this preoccupation mirrored the improvement of attitudes toward China in the early 2000s.

Lastly, through discourse analysis, my study more closely analyzes a smaller sample of texts, spanning all three sources and covering the entire twenty six-years, in 
order to better understand the different trends in American discourse that have shaped American representations of China over that time period. This analysis uncovered the presence of four assumptions that run like a thread through American discourse on China and that reflect and shape how Americans perceive China's political culture, as well as the general Sino-American relationship, over time:

(1) It is generally assumed that it is the American responsibility, as champions of democracy and liberal values, to actively promote the observation of those values in China.

(2) There is an assumed linkage between domestic political actions taken by the PRC and American foreign policy actions taken toward China-particularly in regards to the Sino-American trade relationship.

(3) It is generally accepted, despite a great deal of evidence to the contrary, that successful economic liberalism will ultimately result in political liberalism in China and that active American "engagement," is necessary to sustain the former and thus guarantee the latter.

(4) It is also assumed that the U.S. can and must obtain and maintain cooperation from China on numerous issues of strategic importance to the United States. Not only do these results further support the conclusion that perceptions of political culture is the dominant factor shaping American attitudes toward China, but they also illuminate the way that this shaping occurs. The first and second assumptions ensure that China's political culture will remain an aspect of American discourse on China for the foreseeable future. It also ensures that perceptions that the PRC is becoming more or less repressive will have an important effect on images of China in general. This explains 
the dramatic impact that the events of June $4^{\text {th }} 1989$ had on American attitudes toward China and the persistence of negative attitudes toward China throughout the 1990s.

The bigger puzzle is why American attitudes toward China have remained so stable over the last decade even though there have been numerous issues that could reasonably be expected to cause American images of China to take a turn for the worse: First, China has remained an authoritarian regime guilty of regular human rights violations. While nothing resembling the events of June 3-4, 1989, has occurred, reports of Chinese repression have continued to litter the backdrop of the China discourse. Second, there have been numerous issues of contention between the two countries. In addition to the regular complaints about currency values, trade imbalances, intellectual property violations, Chinese support of "rogue" regimes, environmental concerns, and competition over natural resources, there have been periodic crises that could certainly have had long-term negative effects on the Sino-American relationship. The U.S. bombing of the Chinese embassy in Belgrade, and the crashing of a U.S. spy plane over China are two examples that quickly spring to mind. Yet despite these issues, American attitudes have remained stable.

The answer to understanding American's long-term ambivalence toward China lies in understanding how these four assumptions interact in constraining American reactions to these points of contention. First, as long as Americans believe that engagement with China will lead to democracy in China they are likely to make and accept arguments for continued engagement. All Americans don't believe this. There is a small group, which occasionally gets both larger and louder, that claims that engagement either doesn't work or that it has the opposite of the intended effect. This 
argument was made often in the years immediately following the Tiananmen Square incident (a point in time when attitudes toward China were at their lowest). While the resiliency of the belief in the power of engagement to promote democracy is thoroughly demonstrated in the analysis in chapter five, one might seriously question how Americans would respond if they were now forced to face another equally dramatic display of Chinese authoritarianism after more than thirty years of American engagement and an increasingly liberal Chinese economy. If this belief in the inevitability of democracy in China were to be shattered, it could have serious repercussions for the Sino-American relationship.

Second, as long as Americans believe that they can expect future Chinese cooperation on one important issue area they will continue to make and accept the argument that they should cooperate with China on other current issue areas. The impetus to cooperate with China is a material reality. The Sino-American relationship is highly interdependent. Those who benefit from this interdependence will continue to push for cooperative rhetoric and actions toward China. But this is only part of the picture. There are numerous areas where such benefits are dependent on future Chinese cooperation. While American dependence on Chinese cooperation is unlikely to diminish any time soon, the belief that cooperation is possible could. If China came to be seen as an adversary that couldn't be trusted, the potential for cooperation would decrease rapidly. Again perceptions of China's political culture play a likely role. If Americans become disillusioned with the promise of economic liberalism, and repressive authoritarianism becomes the defining feature of China within American discourse, then 
support for the belief that China can be trusted to cooperate with the United States in a variety of issue areas will likely be diminished.

As my study demonstrates there are some important issues, which are likely to arise in the near future that have the potential to cause Americans to feel more negatively toward China. First, as reported in chapter three, by comparing American attitudinal reaction to Japan in the 1980 s with current attitudinal reactions to China, we find that the two areas of economic competition that had the largest negative impact on American attitudes in the first case are only beginning to appear in the second case. These are an increase in Chinese foreign direct investment in the United States and Chinese movement up the production ladder to more directly compete with American manufacturers in hightech industries. On the other hand, while each of these issues might be a cause for rising American hostility toward China, there is also some evidence to suggest that the American response might be tepid. The results of the psychological experiment reported in chapter four suggest that Americans attitudes are more responsive to the presence of threat when dealing with other democracies. This suggests that even if the same factors that caused Americans to feel more negatively toward Japan in the late 1980s were to become issues in the Sino-American relationship, Americans might not respond as negatively.

Second, the experiment further demonstrated that subject attitudes toward Authoritarian Others are greatly affected by perceptions that the Other's military capabilities are approximating those of the United States. Since my study also provides no evidence to suggest that Americans currently perceive Chinese military capabilities in this way, it is reasonable to assume that future increases in media preoccupation with 
Chinese military capabilities could put downward pressure on American attitudes. This latter seems even more likely to lead to shifts in American images of China than do the instances of economic threat discussed above. In a future study, it would be worthwhile to examine how Americans currently perceive China's military capabilities as well as what factors would most contribute to changes in those perceptions.

Regardless, it is clear that how Americans perceive future changes in Chinese capabilities will be greatly impacted by how Americans perceive China's political culture, both its present reality and its liberal prospects. As long as the majority of Americans continue to believe that China is moving in a liberal direction, no matter how incrementally, it is likely that the rhetoric of engagement will continue to put upward pressure on American attitudes toward China. While numerous conflicts are likely to arise between the United States and an increasingly powerful China, the belief that the United States can and should achieve its objectives through cooperating with China will also continue to put upward pressure on American attitudes. The extent to which Americans are able to believe in China's liberal prospects is closely linked with American attitudes about the wisdom of this cooperation. Therefore, it is the extent of this belief that is likely to have the biggest impact on American attitudes toward China in the future. 


\section{WORKS CITED}

Ahearn, Raymond J. 1989. Japan: Prospects for Greater Market Openness. Report to Congress, Library of Congress, Washington DC: Congressional Research Service. Acessed August 11, 2011. http://fpc.state.gov/documents/organization/155005.pdf

Al-Rodhan, Khalid R. 2007. "A Review of the China Threat Theory: A Systematic Analysis." Asian Perspective 3, no. 3: 41-66.

Archibold, Randal C. 2012. "China's Cash Buys Inroads in Caribbean." New York Times. Apr 08.

Barboza, David. 2009."People's Republic of Exports." New York Times. Oct 14.

Baum, Mathew A., and Tim M. Groeling. 2010."Reality Asserts Itself: Public Opinion on Iraq and the Elasticity of Reality." International Organization, 64: 443-479.

Berman, Dennis K., and Russell Gold. 2005."As Rancor Mounts, Cnooc Needs to Push its Offer for Unocal; Chinese Oil Company Finds Itself Put on the Defensive By AntiChina Sentiment." Wall Street Journal. July 05.

Bernstein, Richard, and Ross H. Monroe. 1997."The Coming Conflict with America." Foreign Affairs 76, no. 2: 18-32.

Bhat, T.P. 2009. "Assessing China's Compliance with WTO Commitments." India Quarterly: A Journal of International Affairs, 65, 3: 215-235.

Biden, Joseph R. Jr. 2011."China's Rise Isn't Our Demise." New York Times. Sep 08.

Bilgin, Pinar and Kivanc Cos. 2010. "Stallin's Demands: Constructions of the "Soviet Other" in Turkey's Foreign Policy, 1919-1945." Foreign Policy Analysis 6: 43-60.

Boulding, K.E. 1959. "National Images and International Systems." The Journal of Conflict Resolution 3, no. 2: 120-131.

Bradsher, Keith. 2012. "A Trade Collision Course." New York Times. Jan 31.

Breslin, Shaun. 2011."The 'China Model' and the Global Crisis: From Friedrich List to a Chinese Mode of Governance?" International Affairs 87, no. 6: 1323-1343. 
Breslin, Thomas A. 2011. The Great Anglo-Celtic Divide in the History of American Foreign Relations. Santa Barbara: Praeger.

Brewer, Marilynn B. 1999. "The Psychology of Prejudice:Ingroup Love or Outgoup Hate." Journal of Social Issues 55, no. 3: 429-444.

Brooks, Stephen G. 1997. "Dueling Realisms." International Organization 51, no. 3: 445-477.

Brownstein, Ronald. 2005. "Fair Play at Issue In Unocal Bid; CNOOC's Ties To China's Government Have Critics Claiming the Firm Has an Edge Over Chevron." Los Angeles Times. July 20.

"Brushwood and Gall: a Special Report on China's Place in the World." 2010. Economist. Dec 4.

Bueno De Mesquita, Bruce. 2002. Predicting Politics. Columbus: Ohio State University Press.

—. 2010. The Predictioneer's Game. New York: Random House.

Bumiller, Elisabeth. 2011. "U.S. and China Defense Chiefs Agree to Keep Talking." New York Times. January 11.

Campbell, David. 1992. Writing Security: United States Foreign Policy and the Politics of Identity. Minneapolis: University of Minnesota Press.

Carpenter, Ted, and James A Dorn. 2000. China's Future: Constructive Partner or Emerging Threat? Washington D.C.: Cato Institute.

Carr, Edward Hallett. 1939. The Twenty Years' Crises 1919-1939. London: Macmillian and Company limited.

Casey, Joseph, and Katherine Koleski. 2011. "Backgrounder: China's 12th Five Year Plan." U.S.-China Economic and Security Review Commission. Acessed March 8, 2012. http://www.uscc.gov/Research/backgrounder-china\%E2\%80\%99s-12th-five-year-plan

Chafetz, Glenn, Michael Spirtas, and Benjamin Frankel. 1998. "Introduction: Tracing the Influence of Identity on Foreign Policy." Security Studies 8, no. 2: 7-22. 
Chandler, Clay. 2000. "Acceptance Doesn't Mean Compliance." Washington Post. May 25.

"China in the Mind of America." 2011. Economist: 43. Jan 22.

"China's Oil Thirst." 2005. Wall Street Journal. June 24.

Chin, Gregory, and Eric Helleiner. 2008. "China as a Creditor: A Rising Financial Power?" Journal of International Affairs 62, no. 1: 87-102.

Chin, Gregory, and Ramash Thakur. 2010. "Will China Change the Rules of Global Order?" The Washington Quarterly 33, no. 4: 119-138.

Christensen, Thomas J. 2001."Posing problems without Catching up: China's Rise and Challenges for U.S. Security Policy." International Security: 4-40.

Clark, Tom, and Bob Davis. 2012. "Beijing Diversifies Away From U.S. Dollar." Wall Street Journal On-Line. March 2. Accessed February 1, 2013. http://online.wsj.com/article/SB10001424052970203753704577254794068655760.html

Copeland, Dale C. 2006. "The Constructivist Challenge to Structural Realism." In Constructivism and International Relations, edited by Stefano Guzzini and Anna Leander, 73-92. New York: Routledge.

Cottam, Martha L. 1992. "The Carter Administrations's Policy toward Nicaragua: Images, Goals, and Tactics." Political Science Quarterly 107, no. 1.

Cottam, Richard. 1977. Foreign Policy Motivation: A General Theory and a Case Study. Pittsburgh: University of Pittsburgh Press.

Copeland, Dale C. 1996. "Economic Interdependence and War: A Theory of Trade Expectations." International Security 20, no.4: 5-41.

Cox, Ronald W., and Sylvan Lee. 2012. "Transnational Capital and U.S.-China Nexus." In Corporate Power and Globalization in U.S. Foreign Policy, by Ronald W. Cox, 31-55. New York: Routledge. 
Creed, John, and Jerel Rosati. 1997. "Extending the Three-and Four-Headed Eagles: The Foreign Policy Orientations of American Elites during the 80s and 90s,." Political Psychology 18, no. 3: 583-623.

Currie, Kelley. 2009. "The Doctrine of 'Strategic Reassurance': What Does the Obama Formula for U.S.-China Relations Really Mean?" wallstreetjournal.com. Accessed July $17,2011$.

http://online.wsj.com/article/SB10001424052748704224004574488292885761628.html

Doty, Roxanne Lynn. 1993. "Foreign Policy as Social Construction: A Post-Positivist Analysis of U.S. Counterinsurgency Policy in the Philippines." International Studies Quarterly 37, no. 3: 297-320.

Douglas, Frantz, and Catherine Collins. 1989. Selling Out: How We Are Letting Japan Buy Our Land, Our Industries, Our Financial Institutions, and Our Future. Chicago: Contemporary Books.

Dower, John W. 1987. War Without Mercy: Race and Power in the Pacific War. New York: Pantheon.

Drezner, Daniel W. 2009. "Assessing China's Financial Influence in Great Power Politics." International Security 34, no. 2: 7-45.

Elwell, Craig, Marc Labonte, and Wayne M. Morrison. 2007. Is China a Threat to the U.S. Economy? CRS Report for Congress, Congressional Research Service. Accessed April 4, 2011. http://www.fas.org/sgp/crs/row/RL33604.pdf

Evans, Don. 2004. "The Great (Trade) Wall of China." Wall Street Journal. June 28. Fairclough, Norman. 2003. Analyzing Discourse. New York: Routledge.

Farnham, Barbara. 2003. "The Theory of Democratic Peace and Threat Perception." International Studies Quarterly (Blackwell Publishing) 47, no. 3: 395-415.

Fearon, James D. and David D. Latin. 2000. "Review: Violence and Social Construction of Ethnic Identity." International Organization 54, no. 4: 845-877.

"Feeding the China Frenzy." 2005. Wall Street Journal. May 20.

Ferguson, Niall. 2008. The Ascent of Money: A Financial History of the World. New York: Penguin Books. 
"Ferguson, Niall. 2009. “'Chimerica' is Headed for Divorce.” Aug 31. Newsweek 154, no.9.

Fiske, Susan T. and Shelley E. Taylor. 1984. Social Cognition. New York: Random House.

Fogel, Robert. 2010. "\$123,000,000,000,000. (Chinese economy)." Foreign Policy 177: 70-76.

Foyle, Douglas C. 1999. Counting the Public In: Presidents, Public Opinion, and Foreign Policy. New York, New York: Columbia University Press.

"Fragile Friendship: United States-Japan Relations and the Balance of Power In PostCold War Asia." 1993. Luncheon Honoring President Richard Nixon. Federal News Service. April 21.

Francis, David R. 2000. "For Free-Traders, A Siege Mentality This Month's China Trade Vote May Show If Open-Market Momentum is Truly Stalled." The Christian Science Monitor. May 04.

"Freedom in the World." n.d. Freedom House. FIW 1973-2013 (EXCEL) Country ratings and status. Accessed January 30, 2013. http://www.freedomhouse.org/reporttypes/freedom-world

Friedberg, Aaron L. 2005. "The Future of U.S.-China Relations Is Conflict Inevitable?" International Security 30, no. 2: 7-45.

Friedman, Thomas L. 1992a. "Bush Seeks Trade Benefits for China." New York Times. June 03.

-.1992b. "The Transition: The President-Elect; Clinton Says Bush Made China Gains." New York Times. Nov 20.

Garcia-Retamero, Rocio, Stephanie M. Muller, and David L. Rousseau. 2012. "The Impact of Value Similarity and Power on the Perception of Threat." Political Psychology 33, no. 2: 179-193.

Gartzke, Erik. 2007. "The Capitalist Peace." American Journal of Political Science 51, no. 1: 166-191. 
Gellman, Barton. 1998. "U.S. and China to Seek A 'Strategic Partnership." Washington Post. Apr 30.

Gertz, Bill. 2000. The China Threat: How the People's Republic Targets America. Washington D.C.: Regnery Publishing Inc.

Geva, Nehemia, and D. Christopher Hanson. 1999. "Cultural Similarity, Foreign Policy Actions, and Regime Perceptions: An Experimental Study of International Cues and Democratic Peace." Political Psychology (International Society of Political Psychology) 20, no. 4: 803-827.

Gibbon, Peter. 1989. "Westchester Opinion: Schooling in Japan Offers Some Insights." New York Times. Apr 23.

Gigot, Paul A. 2001. "Right Debate: How Hard On China?" Wall Street Journal. Apr 06. Gilpin, Robert. 1987. "American Policy in the Post-Reagan Era." Daedalus 116, no. 3: $33-67$.

Glaser, Charles. 1997. "The Security Dilemma Revisited." World Politics 50, no. 1: 171201.

—. 2011. "Will China's Rise Lead to War?: Why Realism Does Not Mean Pessimism." Foreign Affairs 90, no. 2: 1-7.

Goldstein, Avery. 2005. Rising to the Challenge. Stanford: Stanford University Press.

Goodman, Peter S., and Ben White. 2005. "Haier Withdraws Maytag Bid; Move Is Sign of Caution in China's Pursuit of Foreign Firms." Washington Post. July 20.

Greenberger, Robert S. 1992. "As Bush Is Set to Extend China's Favored Status, Broken Commitments Again May Be Response." Wall Street Journal. May 29.

—.1990. "Bush Finds It Harder to Defend China Policy as He Mulls Renewal of Favorable Trade Status." Wall Street Journal. May 17.

—.1989. "China Gets Sharp-Tongued as U.S. Awaits Its Next Move--China Relations to Improve." June 12. Wall Street Journal. 
Grieco, Joseph M. 1988. "Anarchy and the Limits of Cooperation: A Realist Critique of the Newest Liberal Institutionalism ." International Organization 42, no. 3: 485-507.

Grier, Peter. 2005. "Unocal Deal Tests U.S. Stance toward China; Some Lawmakers Believe Chinese Ownership of the Oil Firm Would Damage National Security. Others See No Harm." The Christian Science Monitor. July 18.

Gries, Peter Hays and Kaiping Peng. 2002. "Culture Clash? Apologies East and West." Journal of Contemporary China 11, no. 30: 173-178.

Gries, Peter Hays and Thomas J.Christensen. 2001. "Power and Resolve in U.S. China Policy." International Security 26, no. 2: 155-165.

Gries, Peter Hays. 2006. "Forecasting U.S.-China Relations, 2015." Asian Security 2, no. 2: $63-86$.

—.2005. "Social Psychology and the Identity Conflict Debate: Is a "China Threat" Inevitable?" European Journa of International Relations 11, no. 2: 235-265.

- 2001. "Tears of Rage: Chinese Nationalist Reactions to the Belgrade Embassy Bombing." The China Journal 46: 25-43.

Haas, Mark. 2007. "The United States and the End of the Cold War: Reactions to Shifts in Soviet Power, Policies, or Domestic Politics." International Organization 61: 145-179.

Halper, Stefan. 2010. The Beijing Consensus: Legitimizing Authoritarianism in Our Time. New York: Basic Books.

Hamburger, Tom, Carol D Leonig, and Zachary A. Goldfarb. 2012. "Obama Struggles to Make Headway on Outsourcing." Washington Post. July 10.

Hayes, Jarrod. 2009. "Identity and Securitization in the Democratic Peace: The United States and the Divergence of Response to India and Iran's Nuclear Programs." International Studies Quarterly 53: 977-999.

Herbold, Robert J. 2011. "China Vs. America: Which Is the Developing Country?" Wall Street Journal. July 09. 
Hermann, Margaret G, and Charles W. Kegley. 1995. "Rethinking Democracy and International Peace: Perspectives from Political Psychology." International Studies Quarterly 39, no. 4: 511-533.

Hermann, Richard K., and Michael P. Fischerkeller. 1995. "Beyond the Enemy Image and Spiral Model: Cognitive-Strategic Research after the Cold War." International Organization 49, no. 3: 415-450.

Herrmann, Richard K., James F. Voss, Tonya Y.E. Schooler, and Joseph Ciarrochi. 1997. "Images in International Relations: An Experimental Test of Cognitive Schemata." International Studies Quarterly 41, no. 3: 403-433.

Hewstone, Miles. 1990. "The 'Ultimate Attribution Error'? A Review of the Literature on Intergroup Causal Attribution." European Journal of Social Psychology 20: 311-335.

Hinckley, Ronald H. 1988. "Public Attitudes toward key Foreign Policy Events." The Journal of Conflict Resolution 32, no. 2: 295-318.

Hirshberg, Mathew S. 1993a. "Consistency and Change in American Perceptions of China." Political Behavior 15, no. 3: 247-263.

—. 1993b. "The Self Perpetuating National Self-Image: Cognitive Biases in Perceptions of International Interventions." Political Psychology 14, no. 1: 77-98.

Holsti, Ole. 1970. "The 'Operational Code' Approach to the Study of Political Leaders: John Foster Dulles' Philosophical and Instrumental Beliefs"." Canadian Journal of Political Science/Revue Canadienne de Science Politique 3, no. 1: 123-157.

Holsti, Ole R., and James N. Rosenau. 1983. "U.S. Leadership in a Shrinking World: the Breakdown of Consensus and the Emergence of Conflicting Belief Systems." World Politics 35, no. 3: 368-392.

Hopf, Ted. 1998. "The Promise of Constructivism in International Relations Theory." International Security 23, no. 1: 171-200.

—. 2002. The Social Construction of International Politics: Identities and Foreign Policies, Moscow, 1955 and 1999. Cornell: Cornell University Press. 
Howle, Roy C. 2001. "An Evitable War: Engaged Containment and the U.S.-China Balance." Parameters 31, no. 3: 92-104.

Ikenberry, John G. 1989. "Rethinking the Origins of American Hegemony." Political Science Quarterly 104, no. 3: 375-400.

- 2011. "The Future of the Liberal World Order: Internationalism After America." Foreign Affairs 90, no. 1: 56-63.

International Monetary Fund. n.d. "World Economic Outlook." World Economic Outlook Databases. Acessed March 7, 2012. http://www.imf.org/external/ns/cs.aspx?id=28

—. 2011. "World Economic Outlook." World Economic Outlook Databases. Accessed September 7, 2011. http://www.imf.org/external/ns/cs.aspx?id=28

Iritani, Evelyn. 2005. "China Showing Bigger Interest in U.S.; An Offer For Maytag and a Possible Bid for Unocal Could Lead to Increased Scrutiny in Washington." Los Angeles Times. June 22.

Isaacs, Harold R. 1958/1980. Scratches on our Minds. New York: M.E. Sharpe, Inc.

Jentleson, Bruce W. 1992. "The Pretty Prudent Public: Post-Vietnam American Opinion on the Use of Military Force." International Studies Quarterly 36, no. 1: 49-73.

Jervis, Robert. 1978. "Cooperation Under the Security Dilemma." World Politics 30, no. 2: $167-214$.

—. 1976. Perception and Misperception in International Politics. New Jersey : Princeton University Press.

Johnston, Alastair Iain. 2003. "Is China a Status Quo Power?" International Security 27, no. 4: 5-56.

Kagan, Robert. 2005. "The Illusion of "Managing" China." washingtonpost.com. April 15. Accessed April 6, 2011. http://www.washingtonpost.com/wp-dyn/articles/A590492005May14.html

Kahl, Colin H. 1998. "Constructing a Separate Peace: Constructivism, Collective Liberal Identity, and Democratic Peace." Security Studies 8, no.2: 94-144. 
Kanabayashi, Masayosh, and Urban C. Lehner. 1983. "Japanese Adopt Another Package to Open Market: But the Plan, Aimed at Aiding Nakasone's Trip to U.S., Doesn't Cover Beef, Citris." Wall Street Journal. Jan 14.

Kang, David C. 2003."Getting Asia Wrong: The Need for New Analytical Frameworks." International Security 27, no. 4: 57-85.

Kaplan, Fred. 2004."China Expands. Europe Rises. And the United States..." New York Times. Dec 26.

Kaplan, Robert D. 2005. "How We Would Fight China." Atlantic Magazine . Accessed July 14, 2011. http://www.theatlantic.com/magazine/archive/2005/06/how-we-wouldfight-china/3959/

Kaplowitz, Noel. 1990. "National Self Images, Perception of Enemies, and Conflict Strategies Psychopolitical Dimensions of International Relations." Political Psychology 11, no.1: 39-82.

Katzenstein, Peter J. and Nobuo Okawara. 2001-2002. "Japan, Asian-Pacific Security, and the Case for Analytical Eclecticism." International Security 26, no. 3: 153-185.

Katzenstein, Peter, Robert O. Keohane, and Stephen D. Krasner. 1998. "International Organization and the Study of World Politics." International Organization 52, no. 4: 645685.

Kennedy, Paul. 1987. The Rise and Fall of the Great Powers. New York: Random House,

Keohane, Robert O. 1984. After Hegemony: Cooperation and Discord in the World Political Economy. New Jersey: Princeton University Press.

Keohane, Robert O. 1993. "Institutional Theory and the Realist Challenge after the Cold War." In Neorealism and Neoliberalism: The Contemporary Debate, by David A. Baldwin. New York: Columbia University Press.

Keohane, Robert O., and Joseph S. Nye. 1977. Power and Interdependence: World Politics in Transition. Boston: Little Brown. 
Keohane, Robert O., and Lisa L. Martin. 1995. "The Promise of Institutionalist Theory." International Security 20, no. 1:39-51.

Kesper, Jeffrey A. June 08, 1988. "Arts Aide Reflects On A Tour of China." New York Times.

Kissinger, Henry A. 2011. "Avoiding a U.S.-China Cold War." The Washington Post. Jan 14.

Krasner, Stephen D. 1983. International Regimes. Ithaca: Cornell University Press.

Kratochwil, Friedrich. 2006. "Constructing a New Orthodoxy? Wendt's Social Theory of International Politics and the constructivist challenge." In Constructivism and

International Relations: Alexander Wendt and his critics, by Stefano Guzzini and Anna Leander, 21-47. London: Routledge.

Krippendorf, Klaus. 2004 Content Analysis: an Introduction to its Methodology. London: Sage Publications.

Kristof, Nicholas D. 1993. "The Rise of China." Foreign Affairs 72, no. 5: 59-59.

Krugman, Paul. 1994. "The Myth of Asia's Miracle." Foreign Affairs 73, no. 6: 62-78. -.2011. "Holding China To Account." New York Times. Oct 03.

Laffey, Mark, and Jutta Weldes. 2008. "Decolonizing the Cuban Missile Crisis." International Studies Quarterly 52: 555-577.

Laffy, Mark. 1999. "Adding an Asian Strand: Neoliberalism and the Politics of Culture in New Zealand 1984-1987." In Cultures of Insecurity: States Communities, and the Production of Danger, by Jutta Weldes et al., 233-260. Minneapolis: University of Minnesota Press.

Lampton, David M. 2007. "The Faces of Chinese Power." Foreign Affairs 86, no. 1: 115127.

Landler, Mark. 2011. "Clinton, Stressing a Regional Policy, Says Distrust Lingers in U.S.-China Relations." New York Times. Jan 15. 
Lapid, Yosef. 2001. "Rethinking the 'International': IBO Clues for Post-Westphalian Mazes." In Identities, Borders, Order: Rethinking International Relations Theory, by David Jacobson, and Yosef Lapid Albert Mathias, 1-20. Minneapolis: University of Minnesota Press.

Lardy, Nicholas R. 2003. The Economic Rise of China: Threat or Opportunity. August 1, Federal Reserve Bank of Cleveland. Accessed April 4, 2011. http://www.clevelandfed.org/research/commentary/2003/0801.pdf

Larson, Deborah Welch, and Alexei Shevchenko. 2010. "Status, Identity, and Rising Powers." Prepared for CIPSS/CEPSI Workshop on International Security and Political Economy. Montreal: Center for International Peace and Security Studies, McGill University. Accessed January 20, 2012. http://cepsicipss.ca/docs/publications/Larson_Shevchenko_Working\%20Paper.pdf

Lasater, Martin L. 1988. "Asia: America Inches Toward China." Wall Street Journal. Feb 01 .

Layne, Christopher. 2008. "China's Challenge to U.S. Hegemony." Current History. 107, no. 705: 13-18.

Levinson, Jerome I. 2000. "... Or Big Business?" Washington Post. May 22.

Levy, Jack S. 1988. "Domestic Politics and War." Journal of Interdisciplinary History 18, no. 4: 653-673.

Lippman, Thomas W. 1999."The Tables Turn as a Bush Criticizes Clinton's Policy Toward China." The Washington Post. Aug 20.

Mann, James.2000. About Face: A History of Ameroca's Curious Relationship with China from Nixon to Clinton. New York: Vintage Books (A Division of Random House).

Mansfield, Edward D., and Brian M. Pollins. 2001. "The Study of Interdependence and Conflict: Recent Advances, Open Questions, and Directions for Future Research." The Journal of Conflict Resolution 45, no. 6: 834-859.

Marshall, Monty G., and Keith Jaggers. N.d."Political Regime Characteristics and Transitions 1800-2010." Accessed Jauary 30, 2013. Polity IV Project.

http://www.systemicpeace.org/polity/polity4.htm 
Mattern, Janice Bially. 2005. Ordering International Politics: Identity, Crises and Representational Force. New York: Routledge.

Mearsheimer, John J. 2010. "The Gathering Storm: China's Challenge to U.S. Power in Asia." The Chinese Journal of International Politics: 381-396.

—. 2001. The Tragedy of Great Power Politics. New York: W. W. Norton. Michel, Serge, and Michel Beuret. 2009. China Safari: On the Trail of Beijing's Expansion In Africa. New York: Nation Books.

Mintz, Alex, and Nehemia Geva. 1993. "Why Don't Democracies Fight Each Other? An Experimental Study." The Journal of Conflict Resolution 37, no.3: 484-503.

Monroe, Alan D. 1979. "Consistency between Public Preferences and National Policy Decisions." American Politics Research 7, no.3: 3-19.

Montgomery, Evan Braden. 2006."Breaking Out of the Security Dilemma Realism, Reassurance, and the Problem of Uncertainty." International Security 31, no.2: 151-185.

Moore, Gregory J. 2010. "Not Very Material but Hardly Immaterial: China's Bombed Embassy and Sino-American Relations." Foreign Policy Analysis: 23-41.

Moravcsik, Andrew. 1997. "Taking Preferences Seriously: A Liberal Theory of International Politices." International Organization 51, no.4: 513-553.

Morgenthau, Hans J. 1973. Politics Among Nations: The Struggle for Power and Peace. 5th. New York: Knopf.

Morrison, Wayne M. 2011. “China-U.S. Trade Issues. Federal Publications. CRS Report for Congress, Paper 862. Congressional Research Service. Accessed March 29, 2012. http://digitalcommons.ilr.cornell.edu/key_workplace/862

Mosher, Steven. 2002. Hegemon: China's Plan to Dominate Asia and the World. San Francisco: Encounter Books.

Muppidi, Himadeep. 1999. "Postcoloniality and the production of International Insecurity: the Persistent Puzzle of U.S.- Indian Relations." In Cultures of Insecurity: 
States Communities, and the Production of Danger, by Jutta Weldes et al, 119-146. Minneapolis: University of Minnesota Press.

Nakamura, David. 2011. "Broader U.S. Role in Asia is Outlined by Obama." the Washington Post. Nov 13.

Nanto, Dick K. 1982. "Japan-U.S. Trade Relations." Issue Brief Number IB81011, Congressional Research Service Major Issues System, The Library of Congress, Washington DC. Accessed February 13, 2012.

http://digital.library.unt.edu/ark:/67531/metacrs8612/m1/1/high_res_d/IB81011_1982De c28.pdf

"National Press Club Luncheon Debate With: Senator Max Baucus (D-MT) Representative Nancy Pelosi (D-CA) Topic: U.S.-China Trade Relations Moderator: Gil Klein.” 1994. Federal News Service. April 19.

Neumann, Iver. 1999. Uses of the Other: 'The East' in European Identity Formation. Minneapolis: University of Minnesota Press.

"New Bout of Japan-Bashing." 1990 New Straits Times. March 3.

"New Wind For the Panting Giant: Tasks for America: Compete, Save, Stimulate, Persist." 1989. New York Times. Jan 10.

Nye, Joseph S. Jr. 2002. "The Dependent Colossus." Foreign Policy, no. 129: 74-76. Obama, Barack. 2008. "U.S.-China Policy Under an Obama Administration." American Chamber of Commerce People's Republic of China. Accessed August 82011. http://www.amchamchina.org/upload/wysiwyg/ObamaENArticle.pdf

Odysseos, Louiza. 2007. The Subject of Coexitence: Otherness in International Relations. Minneaapolis: University of Minnesota.

Okimoto, Daniel. 2009. "The Financial Crisis and America's Capital Dependence on Japan and China." Asia-Pacific Review 16, no. 1: 37-55.

O'Neil, Jim, and Anna Supnytska. 2009. The Long-Term Outlook for the BRICs and N-11 Post Crises. Global Economic Paper No: 192, Commodities and Strategy Research, Goldman Sachs Global Economics. Accessed January 18, 2011. 
http://www.goldmansachs.com/our-thinking/topics/brics/brics-reports-pdfs/long-termoutlook.pdf

Overholt, William H. 2011. "The China Model." Fudan Journal of the Humanities and Social Sciences 4, no. 2: 1-44.

Owen, John M. 1994."How Liberalism Produces Democratic Peace." International Security 19, no. 2: 87-125.

Page, Benjamin I., and Tao Xie. 2010. Living With the Dragon: How the American Public Views the Rise of China. New York: Columbia University Press.

Pan, Chengxin. 2004. "The "China Threat" in American Self-Imagination: the Discurisve Construction of Other as Power Politics." Alternatives 29: 305-331.

Panda, Rajaram. 2009. "Changing Perceptions of U.S. Policy towards China Under Obama." Mainstream. December 12.

Papayoanou, Paul A. 1997. "Economic Interdependence and the Balance of Power." International Studies Quarterly 41, no.1: 113-140.

Xxx dePhillips, Michael M., and Charles Hutzler. 2001."U.S. Advice For China: Tread Lightly--Zoellick Urges Beijing To Avoid Provocations During Trade Review." Wall Street Journal. 08 June.

Pine, Art, and Urban C Lehner. 1983. "Trade Winds: Protectionist Feelings Against Japan Increase In the U.S. and Europe: Prime Ministerto Take Plan to Reagan to Ease Curbs but Effect Appears Small: The Parable of The Ant and The Elephant." Wall Street Journal. Jan 14.

Pollack, Andrew. 1988. "Chip Pact Falls Short of Goals." New York Times. Aug 2. Porter, Eduardo. 2005. "OK Japan Isn't Taking Over the World, But China." New York Times. July 03.

Powell, Robert. 1994. "Review: Anarchy in International Relations Theory: The Neorealist-Neoliberal Debate." International Organization 48, no. 2: 313-344.

"Press Conference with President Bill Clinton and Chinese President Jiang Zemin Following Their Meetings." 1997. Federal News Service. Oct 29. 
Prestowitz, Clyde V. Jr. 1988. Trading Places: How We Allowed Japan to Take the Lead. New York: Basic Books Inc.

Ray, James Lee. 1997. "The Democratic Path to Peace." Journal of Democracy 8, no.2: 49-64.

Rice, Condoleezza. 2000. "Promoting the National Interest." Foreign Affairs 79, no.1: 45-62.

Richter, Paul. 2005. "Beijing Backs Out." More U.S.-China Battles Are Likely; Despite CNOOC's Failed Bid For Unocal, It is Highy Probably that Chinese Businesses Will Continue to Try to Buy American Companies. Los Angeles Times. Aug 03.

Romney, Mitt. 2011. "How I'd Deal With China's Cheating." Washington Post. Oct 14, Rosenthal, A. M. 1989. "On My Mind; The Absent Americans." New York Times. May 19.

—.1991a. "Bush Backs China Trade Status, Reopening Conflict Over Rights." New York Times. May 16.

—.1991b. "Bush Renewing Trade Privileges For China, But Adds Missile Curbs." New York Times. May 28.

—.1992. “On My Mind; Toys or Torture.” New York Times. Dec. 18.

Ross, Robert S. 2005."Assessing the China Threat." National Interest 81: 81-87.

Rousseau, David. 2002. "Motivations for Choice: The Salience of Relative Gains in International Politics." The Journal of Conflict Resolution 46, no.3: 394-426.

Rousseau, David, Christopher Gelpi, Dan Reiter, and Paul K. Huth. 1996. "Assessing the Dyadic Nature of the Democratic Peace, 1918-88." The American Political Science Review 90, no.3: 512-533.

Rowen, Henry S. 2007. "When will the Chinese People be Free?" Journal of Democracy 18: $38-42$.

Rummel, R. J. 1983. "Libertarianism and International Violence." The Journal of conflict Resolution 27, no. 1: 27-71. 
Russett, Bruce. 1993. Grasping the Democratic Peace: Principles for a Post-Cold War World. Princeton: Princeton University Press.

Safire, William. 1990. Essay; Our 'Open Doormat'." New York Times. Apr 06. Samuelson, Robert J. 2009. "Obama's Tire Tariff: Bad Policy, Right Message." Washington Post. Sep 21,

Sanger, David E. 1988. "Japan Surprised as Trade Surplus Soars." New York Times. Dec 13.

Schafer, Mark and Michael d. Young. 1998."Is There Method in Our Madness? Ways of Assessing cognition in International Relations." Mershon International Studies Review 42, no.1: 63-96.

Schafer, Mark. 1997. "Images and Policy Preferences." Political Psychology 18, no.4: 813-829.

Schonberg, Karl K. 2009. Constructing 21st Centruy U.S. Foreign Policy: Identity, Ideology, and America's World Role in a New Era. New York: Palgrave Macmillan.

Schoolland, Kenli. 2012. "The China Model Is it a Golden Formula?" Economic Affairs 32: $88-90$.

Setser, Brad W. 2008. "Sovereign Wealth and Sovereign Power: The Strategic Consequences of American Indebtedness." CSR No. 37, Center for Geoeconomic Studies, Council on Foreign Relations. Accessed May 232011. www.cfr.org/content/publications/.../Debt and_PowerCSR37.pdf

Shambaugh, David. 2011. "Coping with a Conflicted China." The Washington Quarterly 34, no. 1: 7-27.

Shapiro, Robert Y., and Benjamin I. Page. 1988. "Foreign Policy and the Rational Public." Journal of Conflict Resolution 32, no. 2: 211-247.

Snyder, Glenn Herald. 2002. "Mearsheimer's World--Offensive Realism and the Struggle for Security a Review Essay." International Security 27, no. 1: 149-173.

Sobel, Richard. 2001. The Impact of Public Opinion on U.S. foreign Policy Since Vietnam. New York: Oxford University Press. 
Solomon, Jay, and Greg Hitt. 2005."For U.S., Engaging China Is Delicate Dance; Mindful of Congress, yet Needing Beijing on North Korea, White House Picks Fights Carefully." Wall Street Journal. May 18.

Sommer, Jeff. 2011. "Chasing the China Bandwagon." New York Times. Jan 23.

Sterba, James P., Adi Ignatius, and Robert S. Greenberger. 1989. "Class Struggle: China's Harsh Actions Threaten to Set Back 10-Year Reform Drive--Suspicions of Westernization Are Ascendant, and Army Has a Political Role Again--A Movement Unlikely to Die." Wall Street Journal. June 05.

Stern, Andy. 2011. "China's Superior Economic Model." Wall Street Journal. Dec 01.

Sumiya, Mikio. 1991. "Japan: Model Society of the Future?" Annals of the American Academy of Political and Social Science: 513: 139-150.

Taira, Koji. 1991. "Japan, an Imminent Hegemon?" Annals of the American Academy of Political and Social Science 513: 151-163.

Tan, Cheryl Lu-Lien. 2005."The New Asian Import: Your Oven; Interest in Maytag by Chinese Firm is Next Step in Takeover of Kitchens By Foreign Appliance Makers." Wall Street Journal. June 22.

Thompson, Helen. 2007. "Debt and Power: The United States' Debt in Historical Perspective." International Relations 21, no. 3: 305-323.

Uchitelle, Louis. 1988. "When the World Lacks a Leader." New York Times. Jan 31. U.S. Census Bureau. N.d. "Top Trading Partners--Total Trade, Exports, Imports." Foreign Trade Statistics. Accessed August 16, 2011. http://www.census.gov/foreigntrade/statistics/highlights/top/top0512.html

U.S. Congress. 1994 Senate Foreign Relations Committee East Asian and Pacific Affairs Subcommittee Hearings on U.S. Policy toward China. May 4.

- 2011a. U.S.-China Economic and Security Review Commission. Hearing on The Implications of China's Military and Civil Space. May 11.

- 2011b. U.S.-China Economic and Security Review Commission. 2011. Hearing on China's Foreign Policy: Challenges and Players. $112^{\text {th }}$ Cong., $1^{\text {st }}$ Sess., April 13. 
U.S. Congress. House. 1990. Committee on Foreign Affairs. Subcommittee on Human Rights and International Organizations and Subcommittee on International Economic Policy and Trade of the House Committee on Foreign Affairs. Most-Favored Nation Status of China. Federal News Service. May 16.

-.1995. Committee on International Relations, Subcommittee on Asia and the Pacific. Prepared Testimony of Robert A. Kapp, President, United States-China Business Council. Federal News Service March 2.

- 1996a. Committee on International Relations, Subcommittees on Asia and the Pacific and International Economic Policy and Trade. Prepared Statement by Maurice R. Greenberg Chairman and Chief Executive Officer American International Group INC. May 16. xxx

—. 1996b. Committee on International Relations, Subcommittee on International Operations and Human Rights China MFN: Human Rights Consequences. Prepared Testimony by Dr. William F. Schulz Executive Director Amnesty Intermational U.S.A. Federal News Service. June 18.

- 1989. Joint House Subcommittee Hearing of the Subcommittee on Human Rights and International Organizations the Subcommittee on International Economic Policy and Trade the Subcommittee on Asian and Pacific Affairs of the House Foreign Affairs committee. U.S.-China Relations. Federal News Service. July 13.

U.S. Department of Defense. 2010. "2010 Quadrennial Defense Review Report." United States Department of Defense. Accessed June 15, 2011.

http://www.defense.gov/qdr/qdr\%20as\%20of\%2029jan10\%201600.PDF

U.S. International Trade Commission. N.d. Interactive Tariff and Trade DataWeb. Accessed August 8, 2011. http://dataweb.usitc.gov/

U.S. State Department. 1995. Special State Department Briefing Briefer: Winston Lord, Assistant Secretary of State For East Asian and Pacific Affairs. Federal News Service. June 2.

-.1989. Q and A With Secretary of State James Baker Following Meeting Wich Chinese National People's Congress Chairman Wan Li State Department. Federal News Service. May 22. 
U.S. Trade Representative. 2003. "China's WTO Compliance." Report to Congress, United States Trade Representative, Executive Office of the President of the United States, Washington D.C. Accessed Sept 10, 2012. http://www.ustr.gov/archive/assets

- 2011. "China's WTO Compliance." Report to Congress, United States Trade Representative, Executive Office of the President of the United States, Washington D.C. Accessed Sept 10, 2012. http://www.ustr.gov/webfm send/3189

U.S. Treasury Department. 2011a. "International Economic and Exchange Rate Policies." Report to Congress, Office of International Affairs, Washington DC, 2011. Accessed June 1, 2011. http://www.treasury.gov/resource-center/international/exchange-ratepolicies/Pages/index.aspx

U.S. Treasury Department. 2011b. Foreign Exchange Report. Accessed October 1, 2011. http://www.treasury.gov/resource-center/international/exchange-rate-policies

U.S. White House. 1997. "Joint U.S.-China Statement." October 29. Accessed May 1, 2011. http://www.state.gov/www/regions/eap/971029_usc_jtstmt.html

-.1994. President Clinton Announces Decision on Most Favored Nation Trading Status for China. Federal News Service. May 26.

Van Ness, Peter. 1993. "China as a Third World State: Foreign Policy and Official National Identity." In China's Quest for National Identity, by Lowell Dittmer and Samuel S. Kim, 194-214. Ithaca: Cornell University Press.

Vogel, Ezra F. 1979. Japan as Number One. Cambridge: Harvard University Press.

Walker, R.B.J. 1992. Inside/Outside: International Relations as Political Theory. Cambridge: Cambridge University Press.

Walker, Stephen G. 1990. "The Evolution of Operational Code Analysis." Political Psychology: 403-418.

Waltz, Kenneth. 1979. Theory of International Politics. New York: McGraw-Hill.

Wang, Jianwei. 2000. Limited Adversaries: Post-Cold War Sino-American Mutual Images. Oxford, New York: Oxford University Press. 
Wedeen, Lisa. 2002. "Conceptualizing Culture: Possibilities for Political Science." The American Political Science Review 96, no.4: 713-728.

Weldes, Jutta. 1999. "Cultural Production of Crisis." In Cultures of Insecurity: States, Communities, and the Production of Danger, by Jutta Weldes, 35-62. Minneapolis: University of Minnesota Press.

Wines, Michael, and Elisabeth Bumiller. 2011. "Test Unrelated to Gates Visit, China Says." New York Times. January 13.

"Widening U.S. Trade Deficit Worries the World Bankers." 1977 The Miami News. Sept 28.

Zakaria, Fareed. 1996."China: Appease...Or Contain?; Speak Softly, Carry a Veiled Threat." The New York Times Magazine. 18 February. 
APPENDICES 


\section{APPENDIX A:}

\section{Polls and Surveys used to determine America attitudes toward China}

1. ABC News Poll: U.S.-Japan Relations [March, 1990]

2. Gallup Poll [March, 1991]

3. Gallup/CNN/USA Today Poll [November, 1993]

4. Gallup/CNN/USA Today Poll [February, 1994]

5. Gallup/CNN/USA Today Poll [March, 1996]

6. Gallup/CNN/USA Today Poll [June, 1997]

7. Z Zogby's Real America Poll [May, 1998]

8. $\quad$ CBS News Poll [May, 1998]

9. CBS News Poll [May, 1998]

10. ABC News Poll [June, 1998]

11. CBS News/New York Times Poll [June, 1998]

12. Gallup Poll [June, 1998]

13. Gallup/CNN/USA Today Poll [July, 1998]

14. Pew News Interest Index Poll [July, 1998]

15. Gallup Poll [February, 1999]

16. Gallup/CNN/USA Today Poll [March, 1999]

17. Gallup Poll [May, 1999]

18. CBS News Poll [May, 1999]

19. Time/CNN/Yankelovich Partners Poll [May, 1999]

20. Gallup Poll [January, 2000]

21. Gallup Poll [March, 2000]

22. Gallup Poll [March, 2000]

23. Gallup Poll [November, 2000]

24. Harris Poll [November, 2000]

25. Gallup Poll [February, 2001]

26. CBS News Poll [April, 2001]

27. Gallup Poll [February, 2002]

28. AJC American Jewish Opinion Survey [December, 2002]

29. Gallup Poll [February, 2003]

30. Worldview 2003 American On The Eve Of War Survey [March, 2003]

31. Gallup Poll [February, 2004]

32. Attitudes Toward China Survey [December, 2004]

33. Gallup Poll [February, 2005]

34. Pew Global Attitudes Project Poll [May, 2005]

35. Gallup Poll [February, 2006]

36. Pew Global Attitudes Project Poll [May, 2006]

37. Gallup Poll [February, 2007]

38. Pew Global Attitudes Project Poll [April, 2007]

39. Hope \& Fear: American and Chinese Attitudes Toward Each Other Survey [August, 2007] 
40. US Opinions on Asia Pacific Countries and Taiwanese Membership in the UN Survey [September, 2007]

41. US Opinions on Asia Pacific Countries and Taiwanese Membership in the UN Survey [September, 2007]

42. Gallup/USA Today Poll [February, 2008]

43. Pew Global Attitudes Project Poll [April, 2008]

44. Gallup Poll [February, 2009]

45. CNN/Opinion Research Corporation Poll [April, 2009]

46. Pew Global Attitudes Project Poll [May, 2009]

47. Gallup Poll [February, 2010]

48. Pew Global Attitudes Project Poll [April, 2010]

49. Transatlantic Trends 2010 Survey [June, 2010] 


\section{APPENDIX B:}

\section{Polls and Surveys used to determine American attitudes toward Japan}

1. General Social Survey [February, 1977]

2. Gallup Poll (AIPO) [March, 1978]

3. Japan And Korea [April, 1978]

4. Gallup/CCFR Survey of American Public Opinion and U.S. [Nov, 1978]

5. Attitudes Toward Korea [September, 1979]

6. General Social Survey 1982 [February, 1982]

7. General Social Survey 1983 [February, 1983]

8. General Social Survey 1985 [February, 1985]

9. General Social Survey 1986 [February, 1986]

10. Gallup/CCFR Survey of American Public Opinion and U.S. Foreign Policy 1986 [October, 1986]

11. Roper/U.S. News \& World Report Poll [January, 1987]

12. People, The Press \& Politics Poll [April, 1987]

13. CBS News/New York Times Poll [May, 1987]

14. Attitudes Toward U.S.-European Relations [November, 1987]

15. General Social Survey 1988 [February, 1988]

16. General Social Survey 1989 [February, 1989]

17. ABC News/Washington Post Poll [February, 1989]

18. Gallup Poll [February, 1989]

19. Cambridge Reports National Omnibus Survey [July, 1989]

20. Gallup Poll [August, 1989]

21. ABC News Poll: US-Japan Relations [March, 1990]

22. People, The Press \& Politics Poll 1990 [May, 1990]

23. People, The Press \& Politics Poll 1990 [August, 1990]

24. Gallup Poll [January, 1991]

25. General Social Survey 1991 [February, 1991]

26. Gallup Poll [March, 1991]

27. New World Order--What The Peace Should Be [March, 1991]

28. Americans Talk Issues \#16 [June, 1991]

29. ABC News Poll [July, 1991]

30. ABC News Poll [November, 1991]

31. Gallup Poll [November, 1991]

32. Gallup Poll [February, 1992]

33. General Social Survey 1993 [February, 1993]

34. ABC News Poll [June, 1993]

35. Gallup/CNN/USA Today Poll [June, 1993]

36. General Social Survey 1994 [January, 1994]

37. Gallup/CNN/USA Today Poll [February, 1994]

38. Gallup/USA Today/Sankei Shimbun Poll [February, 1994]

39. ABC News/Washington Post Poll [February, 1994]

40. Gallup/CNN/USA Today Poll [February, 1994] 
41. Gallup/CNN/USA Today Poll [June, 1994]

42. Gallup/USA Today/Sankei Shimbun Poll [June, 1994]

43. Gallup/CCFR Survey of American Public Opinion and U.S. Foreign Policy 1995 [October, 1994]

44. Gallup/CNN/USA Today Poll [November, 1995] 


\section{APPENDIX C}

SCENARIO \#1 Economic Relations between the U.S. and Country X [ECONOMIC RELATIONSHIP \#1-OPPORTUNITY] "Country X is a very rich country and has a lot of power in the global economy. Trade between $\mathrm{X}$ and the United States has been very beneficial for both states. In the United States, this economic relationship has led to consumer benefits such as the greater quality and lower prices of many imported products. The benefits for X have included economic growth and wage increases."

[ECONOMIC RELATIONSHIP \#2-THREAT] "Country $\mathrm{X}$ is a very rich country and has a lot of power in the global economy. The United States has grown increasingly dependent on $\mathrm{X}$ as American consumers buy more and more exports from $\mathrm{X}$. $\mathrm{X}$ also holds a very large portion of America's debt, which some people worry gives $\mathrm{X}$ additional economic leverage over the United States. Others blame $\mathrm{X}$ for the weak American economy and especially for the loss of American manufacturing jobs"

[POLITICAL CULTURE \#1-DEMOCRACY] Country $\mathrm{X}$ is a democratic country whose people enjoy free and fair elections as well as basic human rights such as free speech and right of assembly.

[POLITICAL CULTURE \#2-AUTHORITARIAN] Country $\mathrm{X}$ is led by an authoritarian government that is frequently being accused of human rights abuses. The news media in $\mathrm{X}$ is subject to strict government controls and citizens are often imprisoned, or worse, for speaking out against the government. Many Americans believe that the United States should stop trading with X until it improves its human rights record. 


\section{SCENARIO \#2 Security Relations between the U.S. and Country Y [SECURITY RELATIONSHIP \#1—OPPORTUNITY/COOPERATION]}

"Country $\mathrm{Y}$ is a militarily powerful country that has proven a valuable supporter of American efforts to reign in rogue regimes. Y supported American sanctions against North Korea last year and is expected to support sanctions against Iran, which have been proposed by the United States and are currently being discussed at the United Nations." [SECURITY RELATIONSHIP \#2 -THREAT/CONFLICT] "Country Y is a militarily powerful country that has recently demonstrated an unwillingness to cooperate with the United States. Y refused to support American sanctions against North Korea last year and it seems that it is now refusing to support the sanctions against Iran, which have been proposed by the United States and are currently being discussed at the United Nations."

[POLITICAL CULTURE \#1-DEMOCRACY] Country $\mathrm{X}$ is a democratic country whose people enjoy free and fair elections as well as basic human rights such as free speech and right of assembly.

[POLITICAL CULTURE \#2-AUTHORITARIAN] Country X is led by an authoritarian government that is frequently being accused of human rights abuses. The news media in $\mathrm{X}$ is subject to strict government controls and citizens are often imprisoned, or worse, for speaking out against the government. Many Americans believe that the United States should stop trading with X until it improves its human rights record. 


\section{APPENDIX D: Code Book}

The following is a description of the rules used to code articles gathered from the New York Times for the purpose of determining trends in American media representation of China over a twenty-six year period. The articles were first divided into short passages (See Appendix E) and then coded as positive, negative, neutral or non-applicable according to the following rules. These rules were followed by four coders, when coding a subset of the data population in order to demonstrate inter-coder reliability. A Pearson's Correlation test demonstrated a mean correlation among all coders of .84

Form Variable Constructs (code without reading the article first)

\section{General Information:}

Title-Record the complete title of the article. Issue Date--Record the month and year of publication issue.

Page Number-Record the page number on which the article appears. Source-Record the source in which the article appears. Passages ${ }^{58}$ - Record the number of passages in the article. Codes - Record the code for each passage.

Each passage is coded as one of the following categories:

\section{Positive (+):}

This category includes favorable or optimistic depictions of the Sino-American relationship, ${ }^{59}$ as well as favorable or optimistic attitudes toward China ${ }^{60}$ either as expressed by the author of the article, attributed to Americans in general or attributed to specific American groups or individuals. This category also includes favorable or optimistic attitudes toward the United States ${ }^{61}$ attributed to China, the Chinese people, or specific Chinese groups or individuals. This category further includes descriptions of actions taken by either country that clearly indicate cooperation, compromise, or efforts

\footnotetext{
${ }^{58}$ In this study the term "passage" refers to a 140-180 word segment of an article. Instructions on creating passages are included in appendix A.

${ }^{59}$ In this study the term "Sino-American" indicates the relationship between mainland China (AKA The People's Republic of China) and the United States.

${ }^{60}$ In this study the term "China" is used to refer to mainland China (AKA the People's Republic of China). Here the term is used to refer to China as a political body and therefore refers both to the nation in general and to government bodies and leaders.

${ }^{61}$ Here the term "United States" is used to refer to the US as a political body and therefore refers both to the nation in general and to government bodies and leaders.
} 
toward improving relations. Lastly, this category includes actions taken by one country that provide explicitly stated benefits for the other country.

\section{Negative (-):}

This category includes negative or pessimistic depictions of the Sino-American relationship, as well as unfavorable or pessimistic attitudes toward China either as expressed by the author of the article, attributed to Americans in general or attributed to specific American groups or individuals. This category also includes unfavorable or pessimistic attitudes toward the United States attributed to China, the Chinese people, or specific Chinese groups or individuals. This category further includes descriptions of actions taken by either country that clearly indicate a lack of cooperation, an inability to compromise, or any other threat to the relationship as well as descriptions of actions that are viewed as illegal or unfair. Lastly, this category includes actions taken by one country that lead to explicitly stated costs to the other country.

\section{Neutral (N):}

This category includes any of the following that are not clearly and explicitly discussed in favorable, optimistic, unfavorable, or pessimistic terms: the Sino-American relationship, debates about the Sino-American relationship within China or the United States, issues either directly or indirectly related to the Sino-American relationship, actions taken by either country that impact the Sino-American relationship, relations with a third country that impact the Sino-American relationship. This category further includes descriptions of actions taken by either country that do not clearly indicate conflict or cooperation and have no clear and explicitly stated impact on the current relationship.

\section{Not Applicable (N/A):}

This category should be applied only in cases where (1) the passage does not refer to either China or the United States in any way. Note that the passage must refer to both countries to be considered applicable but need not explicitly mention them both, (2) the passage refers solely to relations between China and a third country and the United States interest's or impact on this bilateral relationship is not clear in the text, (3) the passage refers solely to relations between the United States and a third country and China's interests or impact on this bilateral relationship is not clear in the text, (4) the passages reference to either China or the United States is solely in geographical terms, or (5) the passages reference to China or the United States deals solely with sports (including games) or art and there is no inclusion of anything that can be coded as negative or positive according to the above rules.

Basic Instructions: The following is a list of guidelines given to ensure that all coders follow the same basic techniques when coding the texts 
1. Code each passage as a separate entity.

2. Code every passage with only one of the following four codes: $(+,-, \mathrm{N}, \mathrm{NA})$

3. Be sure to code only according to the context of the article.

a. When in doubt ask yourself how someone with no knowledge of SinoAmerican relations would code the passage.

4. Many passages include both positive and negative elements. To effectively code the passage do the following:

a. Underline any adjectives or other phrases that indicate positivity or negativity.

b. Look at your underlines to decide on the code for the passage (if more positive phrases are underlined then code the passage positive. If more negative phrases are underlined then code the passage negative).

c. Usually a passage is overwhelmingly either positive or negative but you will occasionally need to use your judgment. For example: it may be obvious that one heavily negative phrase outweighs one slightly positive phrase.

d. If a passage has an equal balance of positive and negative code it as neutral.

5. Don't spend too much time on a single passage - you may want to code with a question mark and come back to the passage.

a. Always code according to the rules in the code book. You may want to reread the code book prior to choosing the code for a particularly difficult passages

6. WHEN IN DOUBT CODE NEUTRAL.

a. If a passage does not clearly fit the rules for coding positive, negative, or not applicable then it should be coded as neutral. 


\section{APPENDIX E: Framing Passages}

Prior to coding texts from the New York Times it was necessary to ensure that articles were first broken up into manageable passages. To ensure that all coders are coding the exact same passages the following instructions were followed by all.

Each passage should consist of every complete sentence included within nine lines of text (135-165 words). There are two methods that can be used to frame passages:

Method one:

1. Place an open bracket in front of the first word of text.

2. Count nine full lines of text.

3. Place a closed bracket at the last piece of end punctuation (period, exclamation point, or question mark) that appears within those nine lines

a. This could appear anywhere in the passage and won't necessarily be on the ninth line.

4. You now have your first passage.

5. Place an open bracket in front of the first word following the closed bracket.

6. Count nine lines including the line in which this open bracket is placed.

7. Place a closed bracket after the last piece of end punctuation that appears within those nine lines.

8. You now have your second passage.

9. Repeat the process throughout the article.

Method two:

1. Print a PDF copy of any article

2. Choose the first 9 Lines in the article and cut them out, creating a window.

3. Use this window on subsequent articles to choose passages.

4. Place the first word in the article in the upper left hand corner of the window

5. Place a closed bracket after the final piece of end punctuation that appears within the window

6. Bring the window down so that the first line in the window includes the first word following this bracket.

7. Repeat this process throughout the article.

8. Note: If the window is difficult to use because one passage begins on one page and continues onto the second page then 9 lines can be counted. 
Additional Information:

- It is fairly rare for a complete page of text to have more or less than five complete passages. If this occurs double check your marks.

- If four lines remain at the end of the article include them in the previous passage. If five or more lines remain they treat them as an additional passage (even if the fifth line only includes a single word).

- Some articles repeat the first sentence twice. Ignore this anomaly and count as usual. In other words both iterations of this sentence are to be included in this passage.

- The nine lines of text should be complete lines of text. If a line includes only a few words try to adjust for the anomaly (i.e. move your bracket to include a few words in the tenth line of text.

- Two or more sentences separated by a semi colon should not be separated into different passages (in other words semi colons should not be considered end punctuation). 
VITA

Shelley D. Wick

Born, Lynwood Washington

1995-2002

B.A., East Asian Languages and Literature

B.A. with honors, International Relations

University of Colorado

Boulder, Colorado

2005-2009

M.A., International Relations

Florida International University

Miami Florida

2005-2012

Teaching Assistant

Florida International University

Miami Florida

$2012-2013$

Dissertation Year Fellowship

Florida International University

Miami Florida

$2009-2013$

Doctoral Candidate

Florida International University

Miami Florida

\section{PUBLICATIONS AND PRESENTATIONS}

Wick, Shelley D., (2013) Economic Threat: Are Americans Responding to China's Current Economic Rise the Same Way They Responded toward Japan's Rise in the 1980s and 1990s? Work in Progress to be submitted to Asian Survey May 2013.

Wick, Shelley D., (2012). Capabilities, Cooperation, and Culture: Mapping American Ambivalence toward China. Accepted for publication by Foreign Policy Analysis.

Wick, Shelley D., (April 2012). Constructing Threat: A Comparison of Attitudinal Responses to Economic Threat Emanating From Japan in the 1980s and From China in the New Millennium. Paper presented at the annual meeting of the International Studies Association, San Diego CA.

Wick, Shelley D., (October 2011). Economic Threat: How do Americans Respond to a Rising China? Paper presented at the annual meeting of the Southern International Studies Association, Elon, NC. 
Wick, Shelley D., (April 2011), Lessons Learned: Interdisciplinary Views of Writing and Writing Pedagogy. Paper presented as part of a panel: "Blurring Disciplinary Boundaries and Identities: Expanding Local Writing Relations through an Interdisciplinary Writing TA Program, at the Annual Conference on College Composition and Communication, Atlanta, GA.

Wick, Shelley D., (March 2011) What Matters Most: An Experimental Test of Attitude Determinants in International Relations. Paper presented at the annual meeting of International Studies Association, Montreal, Canada.

Wick, Shelley D., (September 2010). Capabilities, Cooperation, and Culture: What Matters Most in Shaping American Attitudes towards China. Paper presented at the annual meeting of the Western International Studies Association, Los Angeles, CA.

Wick, Shelley D., (October 2007). Competitor and Partner: A Look at China's Impact on Latin American Economies. Paper presented at the annual meeting of the Southern International Studies Association, Savannah, Georgia.

Wick, Shelley D., (March 2007). China's Economic Engagement with Latin America. Paper presented at The Ruth K. and Shepard Broad Educational Series Mini Conference: "Image Politics: China 's Engagement with the Global South" Florida International University, Miami, Fl. 